\title{
Solid-State NMR Characterization of Mowry Formation Shales
}

\author{
Topical Report
}

Francis P. Miknis

April 1992

Work Performed Under Contract No.: DE-FC21-86MC11076

For

U.S. Department of Energy

Office of Fossil Energy

Morgantown Energy Technology Center

Morgantown, West Virginia

By

University of Wyoming Western Research Institute Laramie, Wyoming 


\section{DISCLAIMER}

This report was prepared as an account of work sponsored by an agency of the United States Government. Neither the United States Government nor any agency thereof, nor any of their employees makes any warranty, express or implied, or assumes any legal liability or responsibility for the accuracy, completeness or usefulness of any information, apparatus, product, or process disclosed, or represents that its use would not infringe privately owned rights. Reference herein to any specific commercial product, process, or service by trade name, trademark, manufacturer, or otherwise, does not necessarily constitute or imply its endorsement, recommendation, or favoring by the United States Government or any agency thereof. The views and opinions of authors expressed herein do not necessarily state or reflect those of the United States Govemment or any agency thereof.

This report has been reproduced directly from the best available copy.

Available to DOE and DOE contractors from the Office of Scientific and Technical Information, P.O. Box 62, Oak Ridge, TN 37831; prices available from (615)576-8401, FTS 626-8401.

Available to the public from the National Technical Information Service, U.S. Department of Commerce, 5285 Port Royal Rd., Springfield, VA 22161. 


\title{
Solid-State NMR Characterization of Mowry Formation Shales
}

\author{
Topical Report
}

Francis P. Miknis

Work Performed Under Contract No.: DE-FC21-86MC11076

\author{
For \\ U.S. Department of Energy \\ Office of Fossil Energy \\ Morgantown Energy Technology Center \\ P.O. Box 880 \\ Morgantown, West Virginia 26507-0880 \\ By \\ University of Wyoming \\ Western Research Institute \\ P.O. Box 3395 \\ University Station \\ Laramie, Wyoming 82071
}

April 1992 


\section{TABLE OF CONTENTS}

Page

LIST OF TABLES....................................................................................................

LIST OF FIGURES........................................................................................... iv

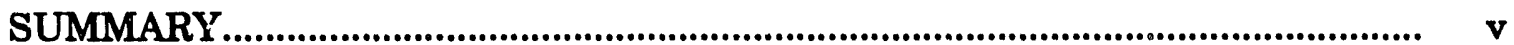

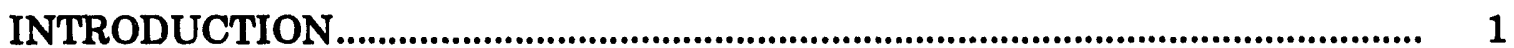

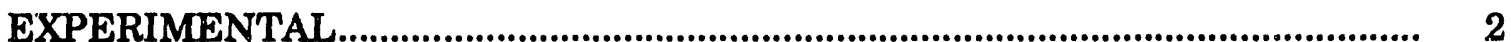

Sample Description.......................................................................................... 2

NMR Measurements............................................................................ 2

RESULTS AND DISCUSSION ..........................................................................

Organic Geochemistry of Mowry Formation Samples ..................................... 6

Relationship Between Hydrogen Index and Loss of Kerogen Mass................ 13

Observed and Predicted Aromaticity Values........................................................ 16

Determination of Hydrogen Generated............................................................. 17

Hydrogen Requirements.................................................................................. 19

${ }^{29}$ Si NMR Measurements....................................................................... 20

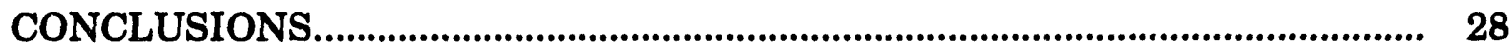

ACKNOWLEDGEMENTS.................................................................................... 29

DISCLAIMER.......................................................................................................... 29

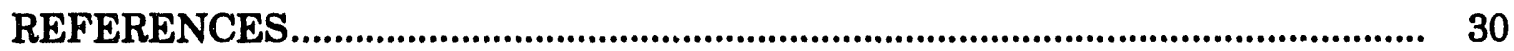

APPENDIX A: Solid-State ${ }^{13}$ C NMR Spectra of Acid-Washed and Unwashed Mowry Shales...................................................................... 33

APPENDIX B: Solid-State ${ }^{29}$ Si NMR Spectra of Acid-Washed and

Unwashed Mowry Shales. 


\section{IIST OF TABLES}

Table

Page

1. Well Descriptions for Mowry Formation Samples....................................... 4

2. Carbon Aromaticities and Geochemical Analysis of Mowry

Source Rocks............................................................................................................... 4

3. Summary of Hydrogen Budget Calculations for Mowry Source Rocks........................................................................................................... 15

4. NMR Estimate of ${ }^{29} \mathrm{Si}$ in Quartz and Clay Minerals in Mowry Source Rocks. 


\section{LIST OF FIGURES}

Figure

1. Map of Location of Wells for Mowry Formation Samples

2. Example of Signal-to-Noise Improvement from Acid Washing of Mowry Sample, State \#1: (a) Raw Shale and (b) Acid-Washed

Shale.

3. CP/MAS ${ }^{13} \mathrm{C}$ NMR Spectra of Mowry Formation Source Rocks Versus Depth of Burial.

4. Van Krevelen Diagram Showing Types of Kerogens and Products Generated During Thermal Maturation

5. Plot of Fraction of Carbon Converted to Oil Carbon Versus

Fraction of Aliphatic Carbon in Oil Shales and Coals.

6. Plot of Carbon Aromaticity Versus Depth of Burial of Mowry

Source Rocks.

7. Plot of Vitrinite Reflectance Versus Depth of Burial of Mowry

Source Rocks.

8. Plot of Carbon Aromaticities Versus Hydrogen Index of Mowry

Source Rocks.

9. Plot of Hydrogen Index Versus Depth of Burial of Mowry

Source Rocks

10. Examples of Improvement in Signal-to-Noise Ratio of ${ }^{29} \mathrm{Si}$ NMR

Spectra of Mowry Source Rocks.

11. ${ }^{29} \mathrm{Si}$ NMR Spectra of Mowry Source Rock from Kawulok \#1 Well Using: (a) 120 s Pulse Delay and (b) 10 s Pulse Delay.

12. X-ray Diffraction Traces of Clay Fraction Versus Depth of Burial of Mowry Source Rocks.

13. Percentage of Illite in Mixed-Layer Clays Versus Depth of Burial of Mowry Source Rocks.

14. ${ }^{29} \mathrm{Si}$ NMR Spectra of Mowry Source Rocks: (a) Sample from $7,765 \mathrm{ft}$ and (b) Sample from $9,695 \mathrm{ft}$. 


\section{SUMMARY}

Solid-state ${ }^{13} \mathrm{C}$ and ${ }^{29} \mathrm{Si}$ NMR measurements were carried out on a series of petroleum source rocks from the Mowry Formation of the Powder River Basin in Wyoming. The objectives of this study were to use CP/MAS ${ }^{13} \mathrm{C}$ NMR measurements to monitor changes in the carbon structure of the kerogen that result from depth of burial, and to examine the feasibility of ${ }^{29} \mathrm{Si}$ NMR for studying the thermal alteration of clay minerals during diagenesis. Carbon and silicon NMR measurements were made on a suite of samples covering a present-day depth interval of 3,000 to $11,500 \mathrm{ft}$. Because total organic carbon values were mainly in the range of 1 to $2 \mathrm{wt} \%$, a large-volume sample spinner was used for the ${ }^{13} \mathrm{C}$ measurements. Washing the samples with $\mathrm{HCl}$ was found to improve the spectral quality of both the ${ }^{13} \mathrm{C}$ and ${ }^{29} \mathrm{Si}$ spectra. In general, the NMR results endorsed other geochemical analyses that were performed on the source rocks as part of another study to examine pressure compartmentalization in the Mowry Formation. The carbon aromaticity of the kerogen increased with depth of burial, and at depths greater that approximately $10,000 \mathrm{ft}$ the kerogen showed little capacity to generate additional oil because of the small fraction of residual aliphatic carbon. By combining NMR and Rock-Eval measurements, an estimate of the hydrogen budget was obtained. The calculations indicated that approximately $20 \%$ of the kerogen was converted to hydrocarbons, and that sufficient hydrogen was liberated from aromatization and condensation reactions to stabilize the generated products. The ${ }^{29} \mathrm{Si}$ NMR spectra were characterized by a relatively sharp quartz resonance and a broad resonance from the clay minerals. With increasing depth of burial, the clay resonance became broader and shifted slightly downfield. These changes qualitatively support $\mathrm{X}$-ray analysis that shows progressive alteration of illite to smectite with depth of burial. 


\section{INTRODUCTION}

Increasing costs and diminishing returns from oil and gas exploration threaten the nation's long-term energy security and international competitiveness. New approaches and supporting technology are needed to reverse these negative trends which presently characterize the domestic oil and gas industry. The discovery of subsurface fluid or pressure chambers has the potential to delineate a new class of hydrocarbon traps, thereby revitalizing interest in domestic exploration. To derive the benefits from pressure compartmentalization in petroleum exploration, the mechanisms for chamber formation must be understood.

The University of Wyoming (UW), through funding by the Gas Research Institute, has initiated a multidisciplinary research program that is aimed at the development of a conceptual model of the formation, distribution, and destruction of pressure chambers and seals in sedimentary basins characterized by dynamic burial and erosional histories. This research is focused on the Powder River Basin (Wyoming and Montana), because this basin is known to have numerous and diverse types of pressure chambers. Moreover, log, core, outcrop, pressure, and seismic data are readily available for input into geochemical models. Any models developed for pressure chamber formation or destruction in the Powder River Basin will have wide applicability in other basins around the world, particularly for other Cretaceous sections characterized by prograding deltaic and offshore bar sandstones in close proximity to transgressive organic-rich shales.

The main goal of the research program is to document the presence of pressure chambers and seals, and to determine and model the mechanisms responsible for their formation, distribution, and destruction. A second goal is to use the information to design and interpret seismic experiments for detecting pressure chambers.

A major task of the UW research program is to evaluate the petrographic, diagenetic, and other geochemical aspects of pressure chamber genesis. This task involves, inter alia, development of kinetic models that can be used to reconstruct the diagenetic and maturational history of pressure chambers. A key to understanding the diagenetic and maturational behavior is knowledge of the organic carbon structure of the kerogen in the petroleum source rocks at various stages of maturation.

Solid-state ${ }^{13} \mathrm{C}$ NMR techniques of cross polarization (CP) with magic-angle spinning (MAS) and high-power decoupling are rapidly becoming the method of choice for determining kerogen structure and structural changes that accompany diagenesis and maturation. These techniques have been applied to a suite of samples from the Mowry Formation of the Powder River Basin to augment and support the UW research program. The objectives of the NMR study are to measure changes in the kerogen structure of petroleum source rocks due to thermal 
maturation. These data, in conjunction with other analyses, and kinetic measurements will be used to construct a model for reconstructing the diagenetic and maturational history of pressure chambers. Ultimately, this information will become a framework for seismic detection of these pressure chambers. The results of the NMR analyses are discussed in this report.

\section{EXPERIMENTAL}

\section{Sample Description}

Samples of Mowry Formation source rocks were obtained from drill cuttings that span a present-day depth interval of 3,000 - 11,500 ft. Locations of the sample wells in the Powder River Basin are shown in Figure 1. Descriptions of the wells from which the cuttings were obtained are given in Table 1. Total organic carbon (TOC) values ranged from $1.2-4.2 \mathrm{wt} \%$. TOC values are reported in Table 2, along with the NMR carbon aromaticities, Rock-Eval parameters, and parameters derived from the Rock-Eval measurements (Tissot and Welte 1984).

Prior to making the NMR measurements, the Mowry shale samples were washed with a $6 \mathrm{~N} \mathrm{HCl}$ solution to remove metal oxides, hydroxides, and carbonates which are or can contain paramagnetic impurities (Dereppe and Moreaux 1987). This procedure has been shown to provide NMR spectra of improved signal-to-noise $(\mathrm{S} / \mathrm{N})$ ratios and resolution, particularly for samples containing low levels of carbon such as the levels found in typical source rocks. However, it is not easy to predict, a priori, whether improved spectra will be obtained by acid washing. Consequently, all spectra were obtained on acid-washed samples. An example on the $\mathrm{S} / \mathrm{N}$ improvement is shown in Figure 2 for drill cuttings obtained at a depth of $8,370-8,385 \mathrm{ft}$ from State \#1 Well.

\section{NMR Measurements}

Solid-state NMR measurements were made on a Chemagnetics CMX 100/200 solids spectrometer, which consists of two superconducting magnets and an operating console. Carbon aromaticity measurements were made at a ${ }^{13} \mathrm{C}$ frequency of $25 \mathrm{MHz}$ using the technique of cross polarization (CP) with magicangle spinning (MAS) and high-power decoupling. A large-volume (2.5 $\mathrm{mL})$ sample spinner was used. Spinning rates were between 3.5 and $4.0 \mathrm{kHz}$. Other NMR parameters were a $90^{\circ}$ pulse width of $6.4 \mu \mathrm{s}$, a contact time of $1 \mathrm{~ms}$, a pulse delay of $1 \mathrm{~s}$, and a sweep width of $16 \mathrm{kHz}$. These instrumental parameters are typical for acquiring CP/MAS ${ }^{13} \mathrm{C}$ NMR spectra of petroleum source rocks (Miknis et al. $1982 \mathrm{a}, \mathrm{b}$ ). Generally, 64,800 transients were recorded for each spectrum because of the low levels of TOC in the source rocks. A $50 \mathrm{~Hz}$ exponential multiplier was applied to the free induction decay of each ${ }^{13} \mathrm{C}$ spectrum before integration. 


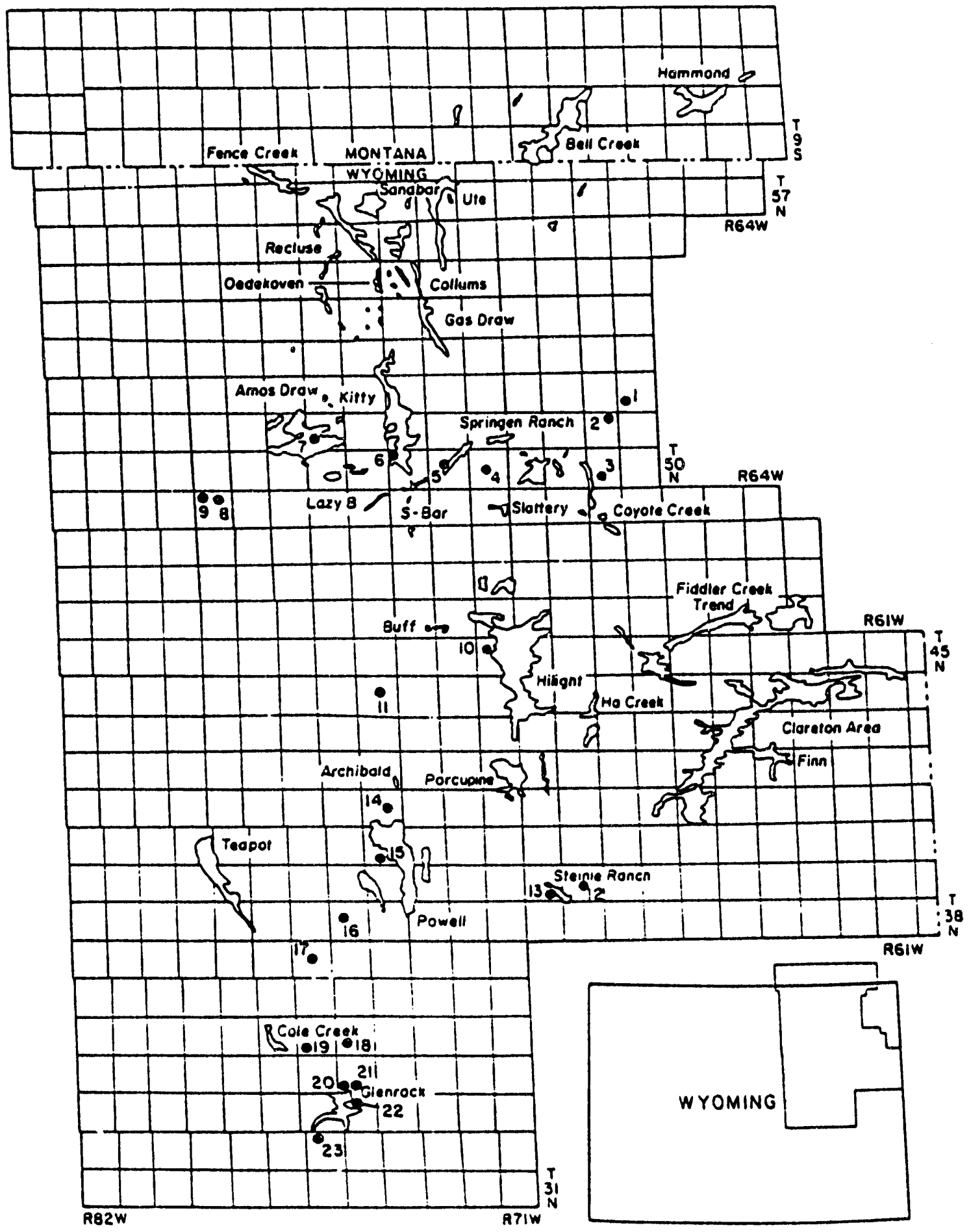

Figure 1. Map of Location of Wells for Mowry Formation Samples 

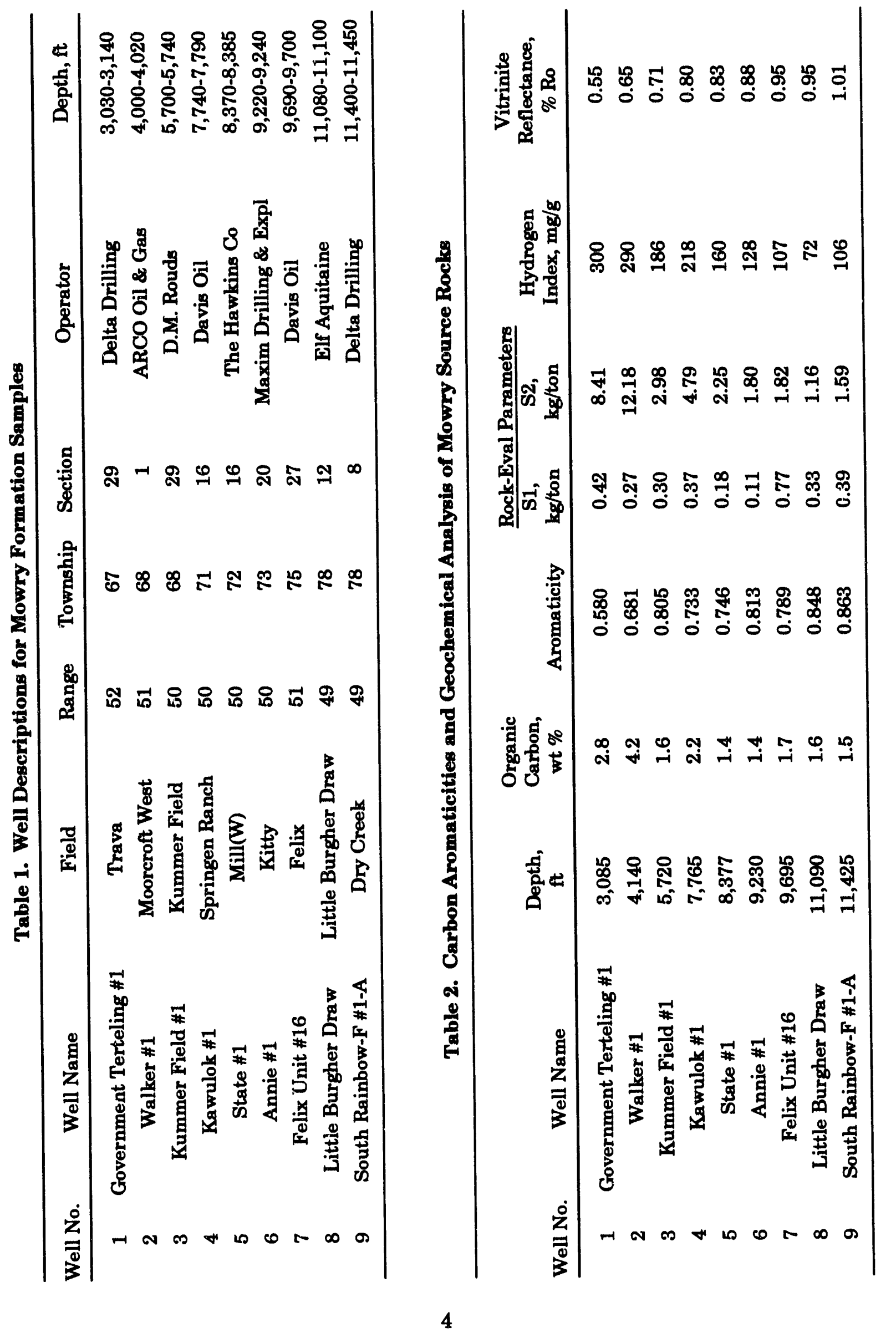

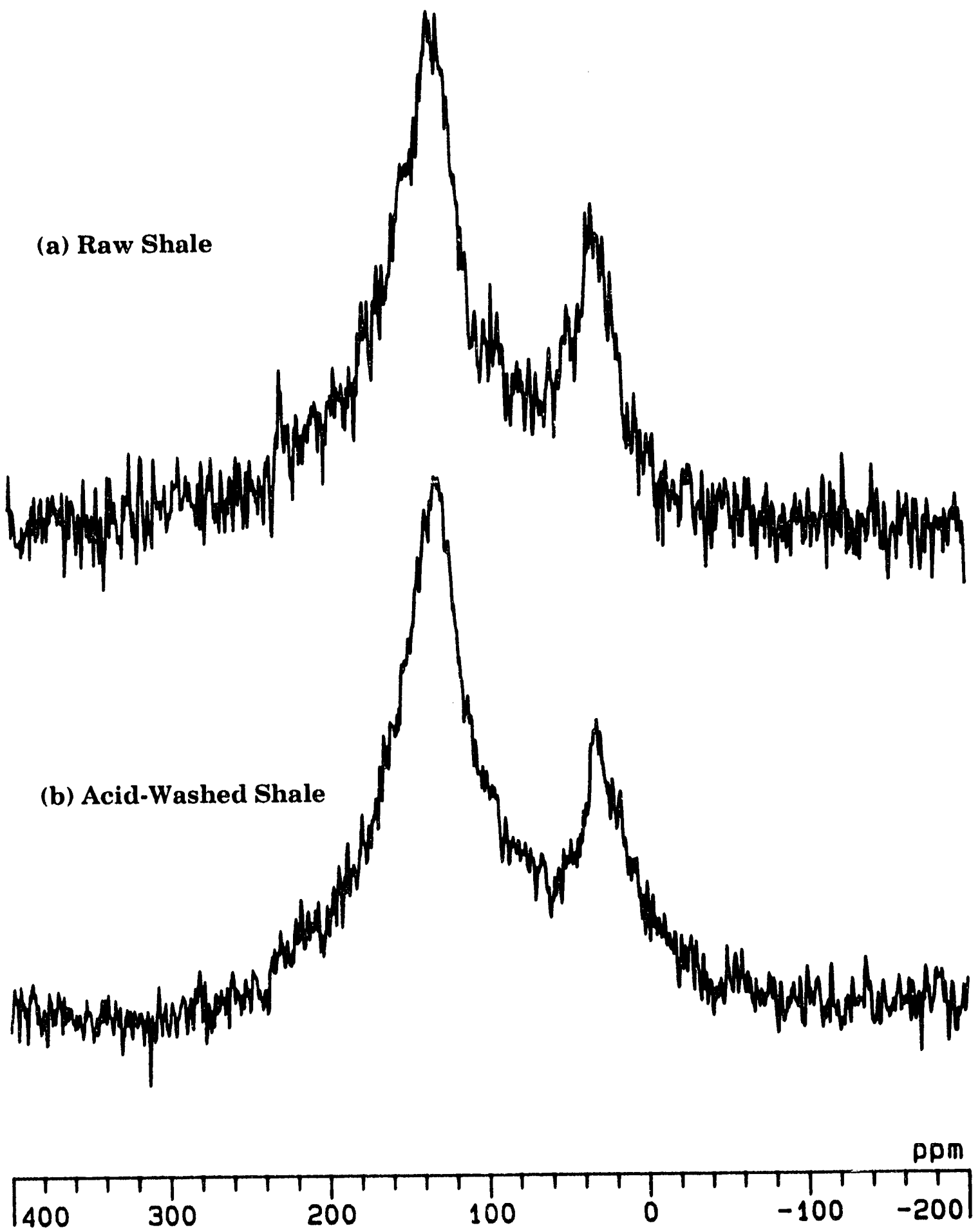

Figure 2. Example of Signal-to-Noise Improvement from Acid Washing of Mowry Sample, State \#1: (a) Raw Shale and (b) Acid-Washed Shale 
CP/MAS ${ }^{13} \mathrm{C}$ NMR spectra of the Mowry samples are included in Appendix A. The first spectrum in Appendix $A$ lists the NMR parameters that were used to acquire the ${ }^{13} \mathrm{C}$ spectra. All ${ }^{13} \mathrm{C}$ spectra were externally referenced to liquid tetramethylsilane (TMS) based on the solid-state spectrum of hexamethylbenzene (HMB) as the secondary reference and assigning $17.21 \mathrm{ppm}$ to the aliphatic carbon chemical shift of HMB relative to liquid TMS (Hayashi and Hayamizu 1991).

Some exploratory ${ }^{29} \mathrm{Si}$ NMR measurements were also made on the Mowry Formation source rocks to determine what information ${ }^{29} \mathrm{Si}$ NMR measurements might provide on the clay minerals in support of other geochemical analyses. These measurements were made using single-pulses with high-power decoupling at a frequency of $39.6 \mathrm{MHz}$. Spinning rates were between 3.6 and $4.0 \mathrm{kHz}$. Spectra of all the samples were recorded using a pulse delay of $10 \mathrm{~s}$. However, some spectra were recorded at delays of 2 to $300 \mathrm{~s}$ to obtain an estimate of the spin lattice relaxation times of ${ }^{29} \mathrm{Si}$ in some samples. ${ }^{29} \mathrm{Si} \mathrm{NMR}$ were recorded on both the raw and acid-washed samples. The ${ }^{29} \mathrm{Si}$ spectra were artificially broadened using a 15 $\mathrm{Hz}$ exponential multiplier. The ${ }^{29} \mathrm{Si}$ NMR spectra are shown in Appendix B. The first spectrum in Appendix B lists the NMR parameters that were used to acquire the ${ }^{29} \mathrm{Si}$ spectra. All ${ }^{29} \mathrm{Si}$ spectra were externally referenced tu liquid TMS based on the solid-state spectrum of sodium-3-(trimethylsilyl)-propane-1-sulfonate (DSS) as the secondary reference and assigning $1.46 \mathrm{ppm}$ to the ${ }^{29} \mathrm{SI}$ chemical shift in DSS relative to liquid TMS (Hayashi and Hayamizu 1991).

All NMR spectra were phased manually and integrated using the instrument's software. For the CP/MAS ${ }^{13} \mathrm{C}$ aromaticity measurements, the integrations covered the range from -160 to $360 \mathrm{ppm}$. This large range was required to include any contributions from spinning sidebands to the aromatic carbon integrals. For all samples, the region between 90 and $360 \mathrm{ppm}$ was considered the aromatic carbon region. This region included possible small contributions from carbonyl carbons in the region 165 to $210 \mathrm{ppm}$, and aromatic sidebands at approximately $300 \mathrm{ppm}$. The region between -20 and 90 ppm was considered the aliphatic carbon region, and the integrated sideband intensity between -20 and $-80 \mathrm{ppm}$ was added to the aromatic carbon integral. The ${ }^{29} \mathrm{Si}$ spectra were integrated between the region -50 to $-120 \mathrm{ppm}$.

\section{RESULTS AND DISCUSSION}

\section{Orranic Geochemistry of Mowry Formation Samples}

Figure 3 shows a montage of CP/MAS ${ }^{13} \mathrm{C}$ NMR spectra for Mowry samples from depths of about 3,000 to $11,500 \mathrm{ft}$. The major band on the right portion of the spectra $(0-\sim 60 \mathrm{ppm})$ represent carbons in aliphatic carbon structures. The major band on the left portion of the spectra $(100-200 \mathrm{ppm})$ represents carbons in aromatic structures and in any carbonyl and carboxylate structures, if present. 


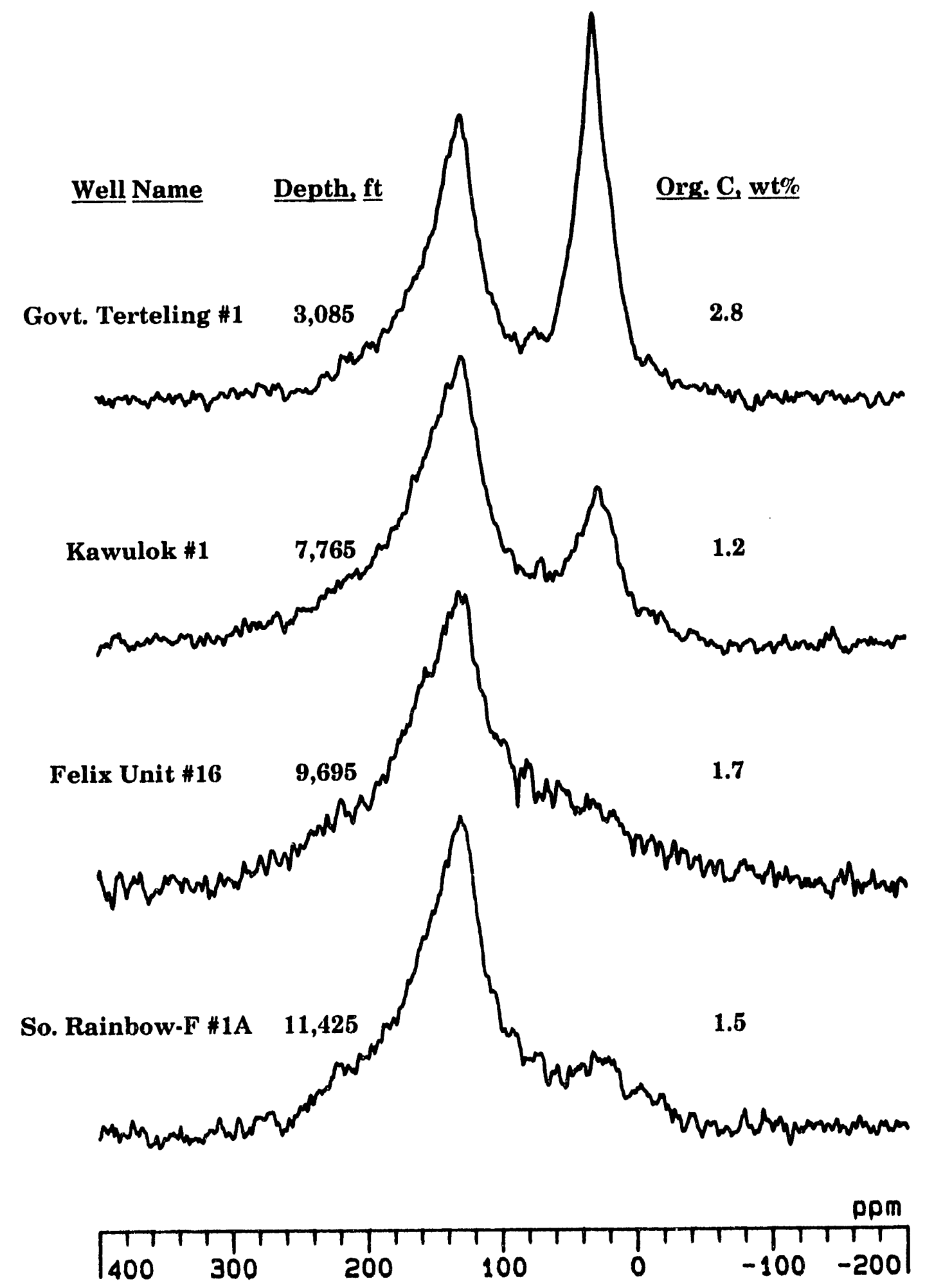

Figure 3. CP/MAS ${ }^{13} \mathrm{C}$ NMR Spectra of Mowry Formation Source Rocks Versus Depth of Burial 
Despite the low amounts of organic carbon in the samples, the use of the largevolume sample spinner enabled observation of signals from the kerogen in the source rocks without the need for time-consuming preparation of kerogen concentrates.

The NMR spectra provide a clear picture of maturational changes in the carbon structure of the kerogen caused by increasing temperature due to depth of burial. There is a noticeable loss of aliphatic carbon structures with depth. These carbons are hydrogen rich and are largely responsible for any oil that is generated. At some depth between 8,000 and $9,000 \mathrm{ft}$, the fraction of aliphatic carbons in the kerogen is not sufficient to generate oil. Instead, these carbons would likely decompose into gaseous products with increasing depth and temperature. The NMR spectrum of the South Rainbow-F \#1-A Well shows almost exclusively aromatic carbon residue. The organic matter at this depth has little additional capacity for oil and gas generation. On a van Krevelen diagram (Figure 4) such maturational changes are typified by the substantial decrease in the hydrogen per carbon atom $(\mathrm{H} / \mathrm{C})$ ratio during evolution. The direction of the arrows depicts increasing depth of burial.

Miknis and Smith (1984) have suggested that NMR can be used to determine the minimum aliphatic carbon fraction necessary for generating oil by pyrolysis using data acquired from artificial maturation of petroleum source rocks in a Fischer assay retort. For a series of United States oil shales, this fraction was 0.30, based on extrapolation of the data to zero oil yield as determined by Fischer assay. However, when coals of varying rank up through low volatile bituminous are included (Miknis unpublished data), the minimum aliphatic carbon fraction for producing oil is about 0.18 , which corresponds to a carbon aromaticity of 0.82 (Figure 5). If both oil and gas are included in the correlation, the minimum aliphatic carbon fraction becomes 0.08 , which corresponds to a carbon aromaticity of 0.92 (Miknis et al. 1982a). These data are based on artificial pyrolysis. However, it is noteworthy that the most deeply buried Mowry samples, and those which are representative of natural maturation, have values that lie between the two values, (i.e., $0.82<f_{a}=0.86<0.92$ ). Recently, Lo (1991) correlated maximum Fischer assay oil yields with the $\mathrm{H} / \mathrm{C}$ ratio of the starting material, which included Type I, II, and III kerogens, to determine whether artificial pyrolysis could simulate natural maturation. Interestingly, extrapolation of that correlation to zero oil yield gives a minimum $\mathrm{H} / \mathrm{C}$ ratio of approximately 0.71 for oil generation, which can be considered as an endorsement for the NMR determination of the minimum aliphatic carbon fraction needed to generate oil.

Plots of the variation of carbon aromaticity and vitrinite reflectance versus depth are shown in Figures 6 and 7, respectively. Vitrinite reflectance, which is a measure of the thermal maturity of the organic matter, ranges from about $0.55 \%$ at approximately $3,000 \mathrm{ft}$ to $1.01 \%$ at $11,500 \mathrm{ft}$. According to Tissot and Welte (1984) the oil generation window is about 0.5 to $0.7 \%$ and 1.1 to $1.3 \%$ reflectance. 


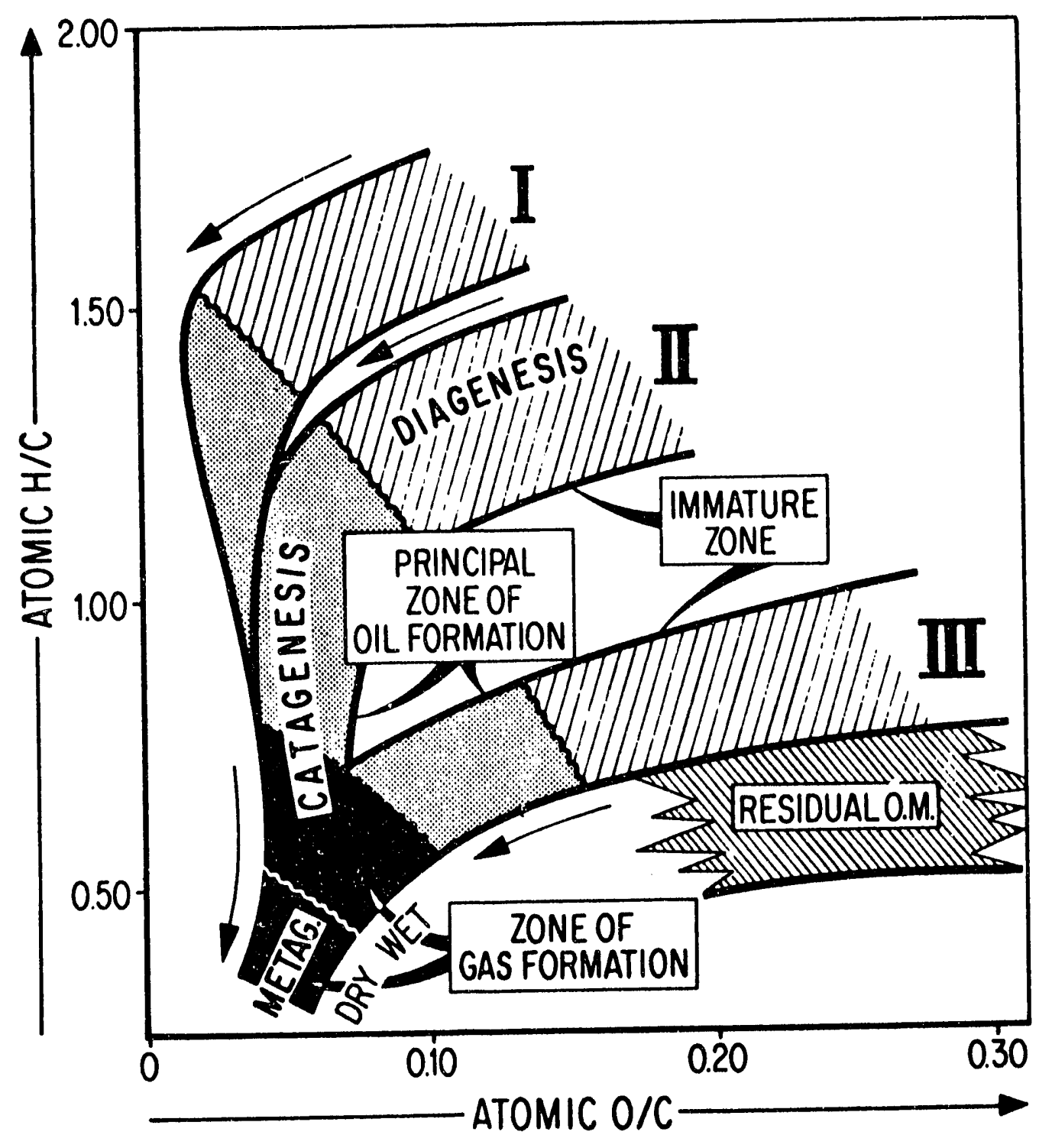

PRINCIPAL PRODUCTS OF KEROGEN EVOLUTION

$\mathrm{CO}_{2}, \mathrm{H}_{2} \mathrm{O}$
$\mathrm{OlL}_{\mathrm{GAS}}$

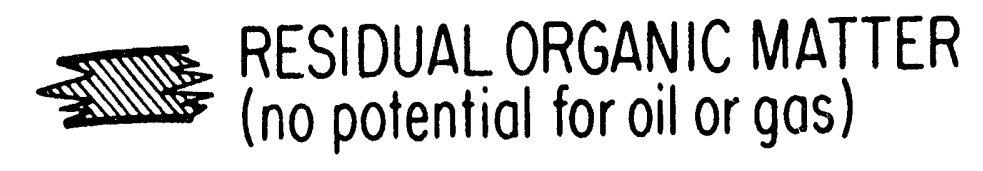

Figure 4. Van Krevelen Diagram Showing Types of Kerogens and Products Generated During Thermal Maturation (from Tissot 1984) 


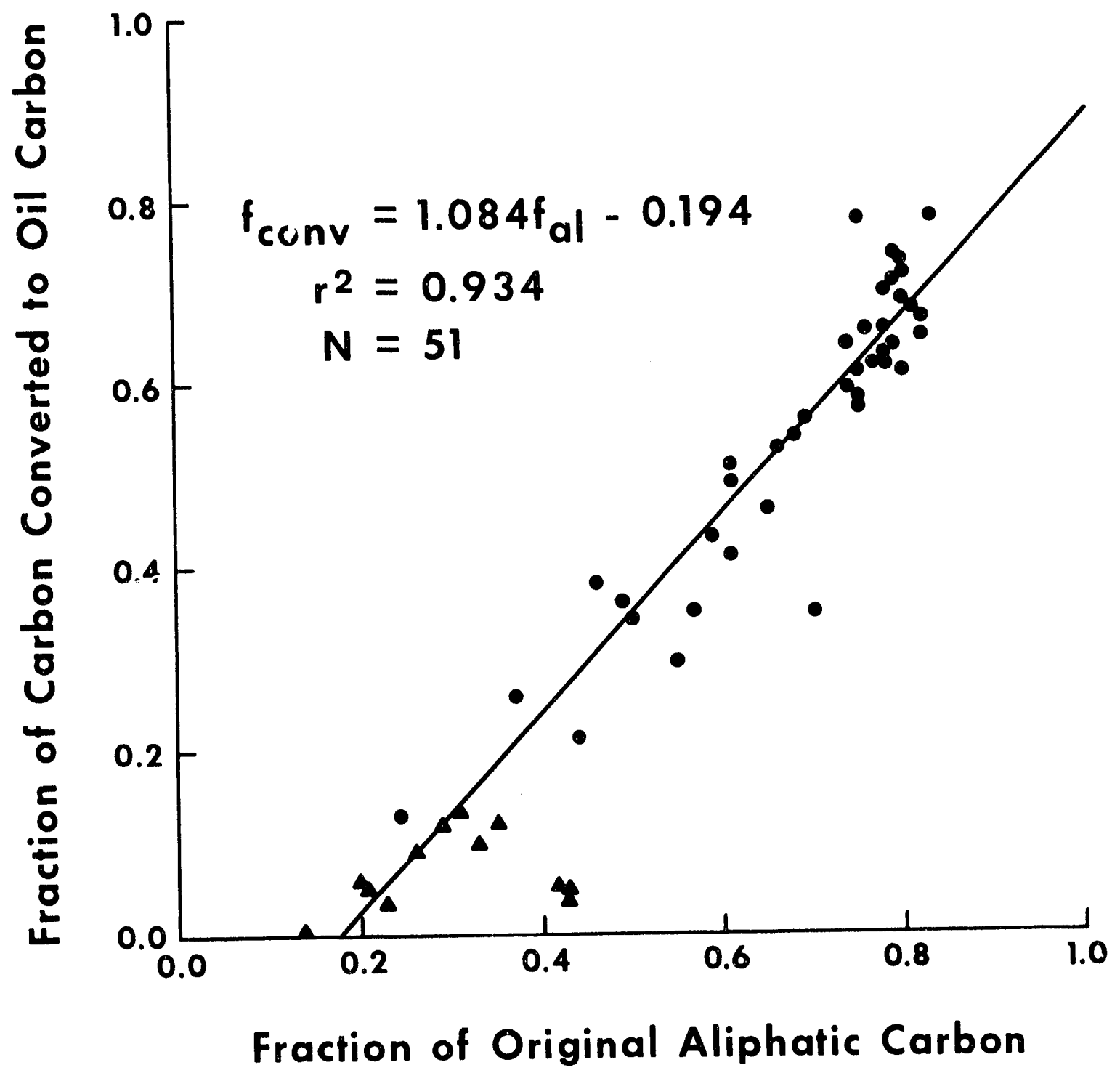

Figure 5. Plot of Fraction of Carbon Converted to Oil Carbon Versus Fraction of Aliphatic Carbon in Oil Shales and Coals 


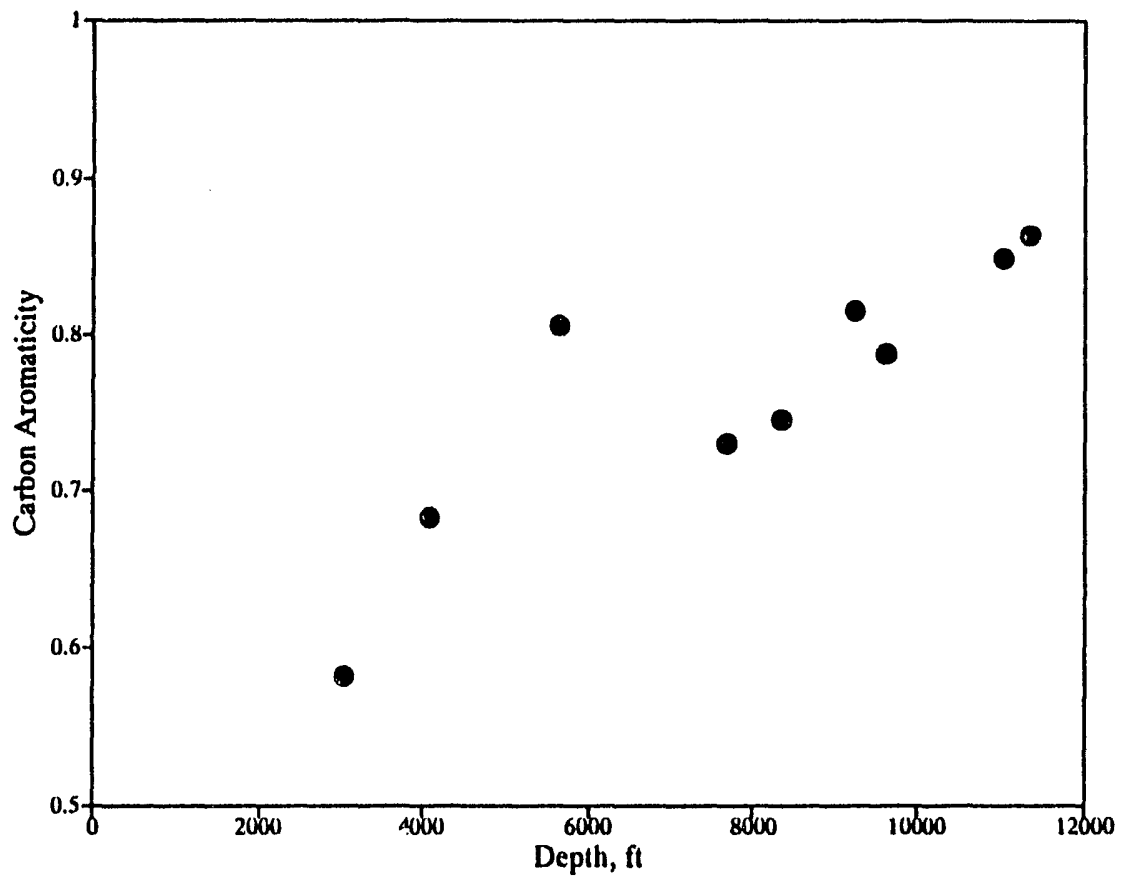

Figure 6. Plot of Carbon Aromaticity Versus Depth of Burial of Mowry Source Rocks

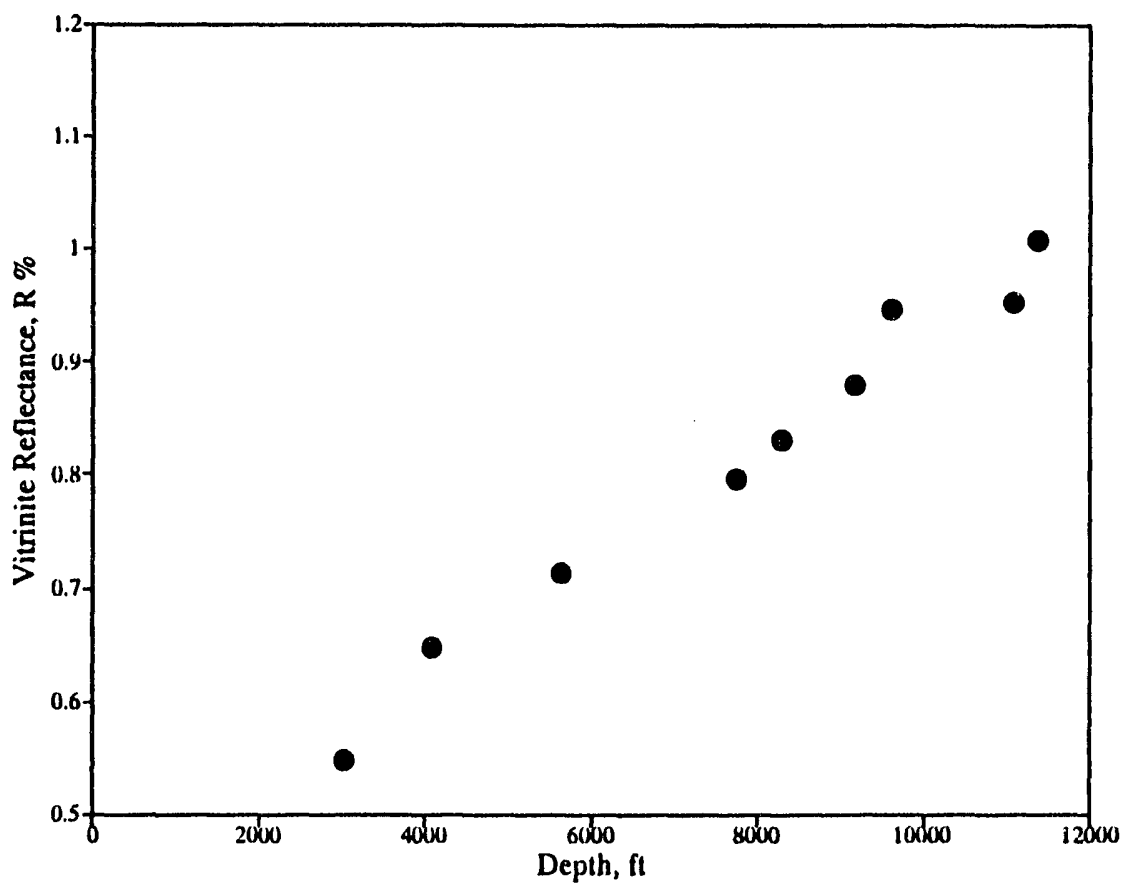

Figure 7. Plot of Vitrinite Reflectance Versus Depth of Burial of Mowry Source Rocks 
Above $1.3 \%$ reflectance, oil is thermally cracked to wet gas. The NMR carbon aromaticities are in agreement with these observations in that the aromaticities of the samples at about $11,000 \mathrm{ft}$ still have enough of an aliphatic carbon fraction to generate gas. Vitrinite reflectance measurements on a much larger suite of Mowry shales show a gradual increase to about $9,000 \mathrm{ft}$, then a more rapid increase in the thermal maturity below $9,000 \mathrm{ft}$. This ohservation has been interpreted to indicate that an accelerated geothermal gradient must have existed for geologically significant periods of time. Consequently, higher formation pressures would have been expected as well (MacGowan et al. submitted).

The spectra in Figure 3 are not normalized for any mass loss of kerogen that occurs during maturation and generation of hydrocarbons. Therefore, the actual amounts of aliphatic and aromatic carbons relative to the actual amounts in the starting material cannot be obtained from the data. However, Patience et al. (1992) have recently derived a method to monitor the hydrogen budget during maturation by combining NMR data with data obtained from Rock-Eval and other geochemical measurements. This method allows one to determine the extent of aromatization reactions during maturation, and to determine whether sufficient hydrogen is liberated for capping free radicals and for forming new bonds during petroleum generation. Patience et al. developed their procedure using kerogens isolated from source rocks, primarily to obtain higher quality ${ }^{13} \mathrm{C}$ NMR spectra so that greater discrimination of carbon functionalities could be obtained using dipolar dephasing and spectral deconvolution techniques (Mann et al. 1991). In the present study, NMR measurements were made directly on the source rocks, without first isolating the kerogen, using a large-volume sample spinner. These measurements provided spectra of sufficient quality such that reliable carbon aromaticities were obtained. In the subsequent discussion, the calculational procedure and interpretations of Patience et al. have been closely followed.

The hydrogen budget calculations are based on three key assumptions:

1) During diagenesis, the mass loss of kerogen that forms petroleum can be calculated from the change in the hydrogen index (HI) of the immature and mature states of the kerogen. These values are readily obtained from Rock-Eval measurements.

2) The percentage loss of kerogen mass can be used to calculate a theoretical increase in the carbon aromaticity that is due to a concentration effect only.

3) The difference between the theoretical value and the actual determined value of the carbon aromaticity can be used to calculate the net increase in aromatic carbon that results from aromatization reactions of the aliphatic and alicyclic moieties. 
Other assumptions about how much hydrogen is liberated per aromatization reaction, and how much is required to cap radicals are made in order to perform the calculations.

\section{Relationship Between Hydrogen Index and Loss of Kerogen Mass}

There is a strong correlation between the potential oil yields of oil shale determined by Fischer assay and the amount of aliphatic carbon in the kerogen (Maciel et al. 1978; 1979; Miknis et al. 1982a; Hagaman et al. 1984; Miknis and Maciel 1984; Miknis 1992). Similarly, there is a strong correlation between residual carbon in a spent shale and the aromatic carbon in the original kerogen (Miknis et al. 1982c; Miknis and Conn 1986). There is also a very good correlation between the HI determined from Rock-Eval and Fischer assay oil yields (Hunt 1979). Thus, there should be some correlation between NMR determined aromaticities and the HI determined from pyrolysis (Patience et al. 1992). For the Mowry shales this correlation is shown in Figure 8. The correlation is reasonably good, considering the low levels of TOC in the samples on which the NMR measurements were made. The low TOC levels also affect the accuracy and precision of the elemental analyses and $\mathrm{HI}$ values.

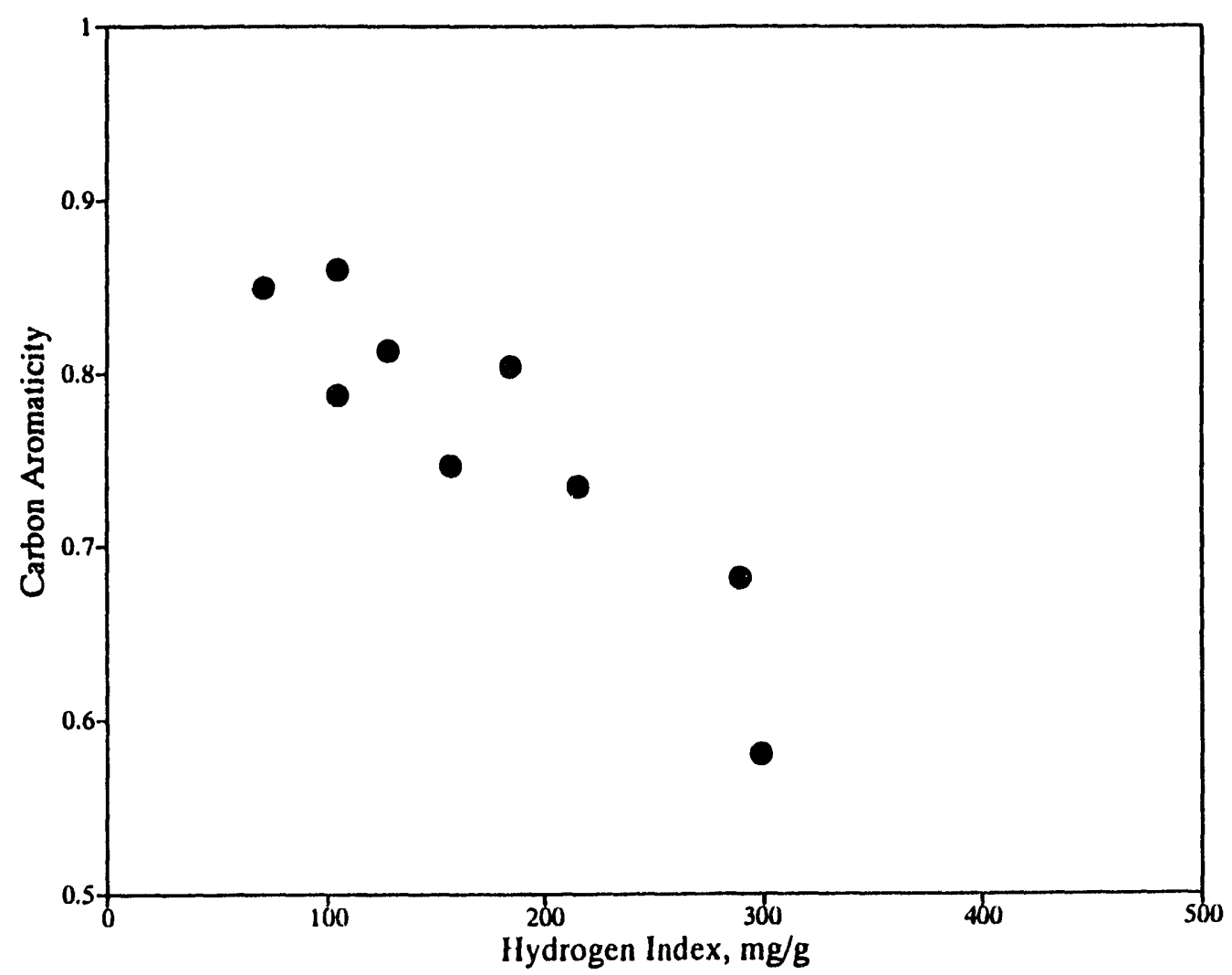

Figure 8. Plot of Carbon Aromaticities Versus Hydrogen Index of Mowry Source Rocks 
An important consideration in the increase in carbon aromaticity $\left(f_{a}\right)$ with decreasing HI (increasing maturation, Figure 8 ) is whether the increase in $f_{a}$ is due to selective concentration of aromatic carbon as alkyl groups are lost to form petroleum, or due to the formation of new species of aromatic carbons. To determine this, an expected $f_{a}$ is calculated for a given $H I$, assuming concentration only, and compared with the observed or measured value of $f_{a}$. In order to do this, the fraction of initial organic matter in an immature sediment that is lost during thermal alteration to cause a change in HI must be known. Patience et al. (1992) describe a procedure whereby this calculation can be made from pyrolysis data. The entire derivation of Patience et al. will not be repeated here; only the salient features are described.

The assumption is made that the initial total organic matter (TOM) consists of two components: $X$, which is the fraction of TOM that can generate oil, and can be measured by pyrolysis (HI); and 1-X, which is an inert fraction that does not generate oil. After a period of oil generation, the $\mathrm{HI}$ declines to a new value. At this stage, the fraction of original TOM that can still be generated is $Y$, and $X-Y$ represents the fraction of original TOM that has generated petroleum up to this stage.

From pyrolysis measurements, the $\mathrm{HI}$ is given by,

$$
\mathrm{HI}=\left(\mathrm{S}_{2} / \mathrm{TOC}\right) \times 100
$$

where $\mathrm{S}_{2}$ is the high temperature peak in Rock-Eval that is due to hydrocarbon generation.

The assumptions are made that the theoretical value of $\mathrm{HI}$ is ca. 1200 when $X=1$, and that the TOC represents about $85 \%$ of the TOM. Therefore, for any other initial value of $\mathrm{HI}$,

$$
\mathrm{X}=\mathrm{HI}_{\mathrm{i}} / 1200
$$

For any final value of $\mathrm{HI}$,

$$
\mathrm{HI}_{\mathrm{f}} / 1200=\mathrm{Y} /(1-\mathrm{X}+\mathrm{Y})
$$

After some algebraic manipulation

$$
X-Y=\left(H I_{i}-H_{f}\right) /\left(1200-H_{f}\right)
$$

Equation 4 can be used to obtain the fractional mass loss of organic matter from a knowledge of the hydrogen indices obtained from pyrolysis data. 
T- avelop the discussion further, the $\mathrm{HI}_{\mathrm{i}}$ and $\mathrm{HI}_{\mathrm{f}}$ for the Mowry source rocks are assu, ed to be 300 (3,085 ft sample) and 72 (11,090 ft sample), respectively. These ve.lues are comparable to the HI values for the North Sea Kimmeridge Clay Formation (Table 3). Equation 4 predicts that an estimated 20\% of the original TOM has been lost during thermal maturation of the Mowry Formation. Patience et al. calculated TOM conversion values of $27 \%$ for the Kimmeridge Clay Formation and $38 \%$ for the Monterey Formation. The results of the hydrogen budget calculations are summarized in Table 3. A plot of the HI values versus depth is shown in Figure 9.

Table 3. Summary of Hydrogen Budget Calculations for Mowry Source Rocks

\begin{tabular}{|c|c|c|c|}
\hline Parameters & $\begin{array}{c}\text { Mowry } \\
\text { Formation }\end{array}$ & $\begin{array}{l}\text { Monterey } \\
\text { Formation }\end{array}$ & $\begin{array}{c}\text { Kimmeridge Clay } \\
\text { Formation }\end{array}$ \\
\hline \multicolumn{4}{|l|}{ Hydrogen Index, $\mathrm{mg} / \mathrm{g}$} \\
\hline Initial & 300 & 550 & 375 \\
\hline Final & 72 & 150 & 65 \\
\hline \multicolumn{4}{|l|}{$\%$ of total organic } \\
\hline generated, $\mathbf{X}$ & 25.0 & 45.8 & 31.2 \\
\hline \multicolumn{4}{|l|}{$\begin{array}{l}\% \text { of total organic } \\
\text { matter that can still }\end{array}$} \\
\hline generate, $\mathbf{Y}$ & 4.8 & 7.8 & 4.2 \\
\hline \multicolumn{4}{|l|}{$\%$ of total organic } \\
\hline generated, X-Y & 20.2 & 38.0 & 27.0 \\
\hline \multicolumn{4}{|c|}{ Carbon Aromaticities, $f_{a}$} \\
\hline Initial & 0.580 & 0.240 & 0.318 \\
\hline Final & 0.863 & 0.602 & 0.760 \\
\hline \multicolumn{3}{|l|}{$\%$ Increase in } & Aromatic Carbon, $\mathrm{f}_{\mathrm{o}}$ \\
\hline Minimum & 10 & 13 & 24 \\
\hline Maximum & 22 & 22 & 32 \\
\hline $\begin{array}{l}\text { Range of Available } \\
\text { New H per C }\end{array}$ & $\begin{array}{l}10 / 20 \\
22 / 20\end{array}$ & $\begin{array}{l}13 / 38- \\
22 / 38\end{array}$ & $\begin{array}{l}24 / 27- \\
32 / 27\end{array}$ \\
\hline
\end{tabular}

a Data from Patience et al. 1992 


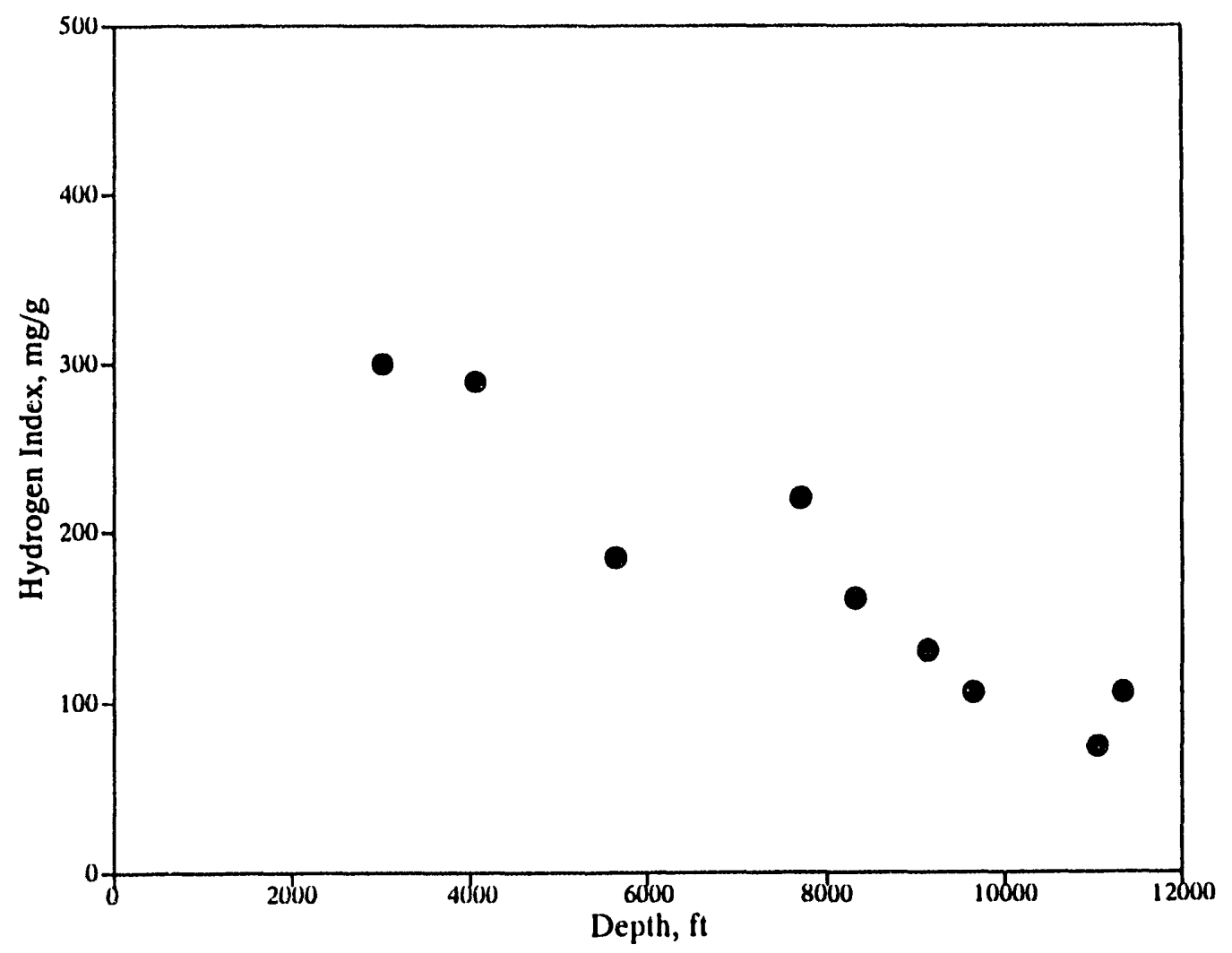

Figure 9. Plot of Hydrogen Index Versus Depth of Burial of Mowry Source Rocks

\section{Observed and Predicted Aromaticity Values}

After establishing the amount of conversion of the source rocks from the pyrolysis data, the next step in the procedure is to determine the effect that the kerogen mass loss has on its carbon aromaticity, $f_{a}$. This effect depends on two factors: 1) the aromaticity (and composition) of the petroleum generated, and 2) whether the increase in carbon aromaticity is due to formation of additional aromatic carbons, or selective preservation (concentration) of aromatic carbon in the residual kerogen. The first step is to consider the effect of petroleum composition.

In principle, the carbon aromaticity of the generated petroleum can vary from zero (exclusively aliphatic) to the aromaticity of the original source material. The latter assumes that the petroleum will not have an aromaticity greater than the parent kerogen. If the sample at a depth of $3,085 \mathrm{ft}$ (Government Terteling \#1 Well, Table 1) is considered as representative of the original source material, then the carbon aromaticity is $58 \%$. If the petroleum generated over the $\mathrm{HI}$ interval $(\sim 3,000-11,500 \mathrm{ft})$ has a $f_{a}$ equal to the initial kerogen (i.e., $\left.58 \%\right)$ then the final kerogen $f_{a}$ will be the same as the initial $f_{a}$, assuming no additional formation of 
aromatic carbon in the residual kerogen. On the other hand, if the petroleum has no aromatic carbon $\left(f_{a}=0\right)$, then the final kerogen aromaticity will be:

$$
\begin{aligned}
\mathbf{f}_{\mathbf{a}}(\text { final }) & =58 /(1-(\mathrm{X}-\mathrm{Y})) \\
& =58 /(1-0.20) \\
& =72.5 \%
\end{aligned}
$$

However, petroleum compositional data generally indicate aromatic contents closer to the initial kerogen value rather than the zero \% value (Barwise et al. 1984; Miknis 1992).

For an initial hydrogen index $\left(\mathrm{HI}_{\mathrm{i}}\right)$ of 300 at $3,085 \mathrm{ft}$ and a final hydrogen index $\left(\mathrm{HI}_{\mathrm{f}}\right)$ of 72 at $11,500 \mathrm{ft}$, the results are:

$$
\begin{aligned}
\text { predicted } f_{a}(\text { final }) & =58.0 \%, \text { if the petroleum } f_{a}=58 \% \\
\text { predicted } \left.f_{a} \text { (final }\right) & =72.5 \%, \text { if the petroleum } f_{a}=0 \% \\
\text { observed } \left.f_{a} \text { (final }\right) & =85.0 \%
\end{aligned}
$$

The observed or final $f_{a}$ value is between 13 and $27 \%$ greater for the Mowry Formation kerogen than the value that would be predicted under the assumption that aromatic carbons are concentrated and not formed during petroleum generation. Therefore, aromatization and condensation reactions, both of which liberate hydrogen for capping radicals and forming new bonds, are taking place during petroleum generation.

\section{Determination of Hydrogen Generated}

The next step is to calculate the amount of hydrogen that is liberated as a result of aromatization and condensation reactions. The assumption is made that aromatization reactions occur at the expense of aliphatic and alicyclic carbon moieties which produce aromatic carbon either by dehydrogenation of hydroaromatic structures (e.g., tetralin-like structures) or by ring closure of alkyl sidechains followed by dehydrogenation. The hydrogen released is then used to cap radicals and reduce the molecular weight of the produced material. This also increases the $\mathrm{H} / \mathrm{C}$ ratio of the product relative to the original kerogen. Schematically, this can be illustrated as:

$$
\text { R-C-X-Kerogen + 2H }
$$

where $R$ is an alkyl carbon structure and $X$ is an unspecified atom $(C, N, O, S)$.

The extent of aromatization determines whether the hydrogen released by aromatization is sufficient to complete the above reaction, or whether there is even an excess of hydrogen. This calculation is dependent on an assumption of the 
a romatic carbon lost to the petroleum generated. The percentage of original aliphatic carbon that is converted to aromatic carbon can be calculated from:

$$
f_{o}=\text { aromatic } \mathbf{C} \text { in final kerogen }+ \text { aromatic } \mathbf{C} \text { in petroleum - initial aromatic } \mathbf{C}
$$

For the Mowry Formation samples, this value is,

$$
f_{0}=(85 \times 0.8)+0.2 \times f_{a}(\text { oil })-58
$$

Assuming that $f_{a}$ (oil) can range from 0 to $58 \%$,

$$
f_{o}=10 \text { to } 21.6 \% \text { for } f_{a}(o i l)=0 \text { to } 58 \%
$$

In the study of Patience et al. (1992) these calculations gave values of

$$
f_{o}=13 \text { to } 22 \% \text { for } f_{o}(\text { oil })=0 \text { to } 24 \%
$$

for the Monterey Formation kerogens, and

$$
f_{o}=24 \text { to } 32 \% \text { for } f_{o}(o i l)=0 \text { to } 31.8 \%
$$

for the Kimmeridge Clay Formation kerogens (Table 3).

If one assumes that upon aromatization, one "aromatized" carbon atom liberates one hydrogen atom for radical capping, that is,

$$
-\mathrm{CH}_{2}-\mathrm{CH}_{2}-\ldots \ldots \ldots . . . \mathrm{CH}=\mathrm{CH}-+2 \mathrm{H}
$$

then the number of hydrngen atoms liberated during generation can be calculated. For the Mowry samples, 10 to 22 carbon atoms per 100 carbon atoms are aromatized; therefore, 10 to 22 hydrogen atoms are liberated. From the mass balance, 20 carbon atoms per 100 carbon atoms generate petroleum, assuming that there is no substantial change in the carbon content between the petroleum and kerogen, when expressed as a percentage of the TOM. This assumption is probably reasonable, given the other assumptions made in the calculation procedure.

The new hydrogen per carbon atom $(\mathrm{H} / \mathrm{C})$ available for radical capping is in the range of $10 / 20$ to $22 / 20$, or 0.50 to 1.10 , which is the number of hydrogens liberated per carbon atom generated. These results are about in the same range as those for the Kimmeridge Clay Formation (Table 3). 


\section{Hydrogen Requirements}

The amount of hydrogen liberated from aromatization reactions needs to be compared with the amount of hydrogen required to cap the $C-X(X=C, N, S, O)$ bonds that are cleaved during generation. Some additional assumptions are needed to make this comparison. The basic assumption here is that each molecule in the petroleum originally was attached to the kerogen by an alkyl group, and cleavage of this bond requires one hydrogen atom to cap the cleaved end of the molecule. However, the type of product formed, long chain waxy oils versus shorter chain volatile oils, will have an influence on the amount of hydrogen required per carbon atom. Thus, generation of methane requires one $\mathrm{H}$ per carbon, ethane requires one $\mathrm{H}$ per two carbons, propane requires one $\mathrm{H}$ per three carbons, etc. Therefore, the carbon number distribution needs to be known because the overall $\mathrm{H}$ required per carbon atom $(\mathrm{H} / \mathrm{C})$ depends on the carbon number distribution.

Patience et al. used compositional data from "typical" marine petroleums from the North Sea, the Gulf of Suez, and a lacustrine sourced oil from Thailand to obtain an estimate of the hydrogen required for capping radicals during generation. Their analysis showed that the required $\mathrm{H} / \mathrm{C}$ ratios were in the range: 0.14 to 0.15 for the North Sea oil; 0.23 to 0.25 for the Suez oil; and 0.05 to 0.06 for the Thai oil. Because the hydrogen generated during kerogen breakdown (H/C ratios) for the Monterey and Kimmeridge Formation had ranges greater than any of these ranges ( 0.34 to 0.58 and 0.89 to 1.19 , Monterey and Kimmeridge, respectively), they concluded that there is much more hydrogen liberated during generation than is needed to satisfy the hydrogen demands of the products. The calculated hydrogen liberated per carbon atom generated for the Mowry Formation is in the range, 0.5 to 1.1. Using the same arguments of Patience et al., we conclude that sufficient hydrogen is generated during breakdown of the Mowry kerogen to satisfy the demands of the products.

The preceding arguments only consider hydrogen involved in capping radicals on the fragments that end up as petroleum. Some consideration must be given to the unpaired electron on the kerogen fragment that remains as kerogen. If each of these fragments were capped with hydrogen, then the $\mathrm{H} / \mathrm{C}$ ratios would be twice the value calculated above. However, electron spin resonance (ESR) measurements indicate that the number of unpaired electrons increases with increasing maturity (Marchand and Conard 1980). Therefore, not all of the radicals of the kerogen are capped, but no attempts have been made to estimate what this fraction might be. Thus, the $\mathrm{H} / \mathrm{C}$ ratios calculated in the preceding section represent lower bounds for the hydrogen budget. 


\section{${ }^{90}$ Si NMIR Measurements}

NMR measurements on ${ }^{29} \mathrm{Si}$ are the most common for the inorganic elements because of the large number of minerals and clays that contain silicon. Generally, clay minerals are difficult to analyze by ${ }^{29} \mathrm{Si}$ NMR because it is difficult to find pure monomineralic clay samples for chemical shift references, and because clay composition can vary considerably over short distances. Nevertheless, NMR can provide useful information about clay minerals when such minerals are first characterized by other means such as X-ray analysis. Reviews on the applications of ${ }^{29} \mathrm{Si}$ NMR to the study of minerals have been written (Stone 1982; Kirkpatrick et al. 1985; Kirkpatrick 1988). An advantage of ${ }^{29} \mathrm{Si}$ NMR measurements is that the chemical shift of the ${ }^{29} \mathrm{Si}$ is related to the number of nearest neighbors attached to the ${ }^{29} \mathrm{Si}$ nucleus. In this sense NMR measurements complement X-ray measurements which measure longer range order in minerals. Some of the most useful correlations are for the tetrahedral coordination of ${ }^{29} \mathrm{Si}$ with ${ }^{27} \mathrm{Al}$ through the oxygen bond (Si-O-X, X=Si or Al) in aluminosilicates (Lippmaa et al. 1980), and a nomenclature has been developed to describe these silicon sites.

The nomenclature classifies the different silicon sites as to the number of bridging oxygen atoms per Si tetrahedron, and are denoted, $Q^{0}-Q^{4}$. In the case of zeolitic aluminosilicates, the number of next-nearest neighbor aluminum atoms attached to the silicon tetrahedron through oxygen are identified as $Q^{4}(0 \mathrm{Al}), Q^{4}(1$ $\mathrm{Al}), \mathrm{Q}^{4}(2 \mathrm{Al})$, etc. The chemical shift of $\mathrm{Q}^{4}{ }^{29} \mathrm{Si}$ ranges from about $-80\left(\mathrm{Q}^{4}(4 \mathrm{Al})\right)$ to $-120 \mathrm{ppm}\left(\mathrm{Q}^{4}(0 \mathrm{Al})\right)$. Therefore, the Al/Si ratio can be obtained for these materials. The 2:1 clay minerals correspond to the $Q^{3}$ Type and have chemical shift ranges, -92 to $-95 \mathrm{ppm}$ for $\mathrm{Q}^{3}(0 \mathrm{Al}),-86$ to-89 $\mathrm{ppm}$ for $\mathrm{Q}^{3}(1 \mathrm{Al})$, and -82 to $-86 \mathrm{ppm}$ for $\mathrm{Q}^{3}(2$ Al) (Lindgreen et al. 1991). These chemical shifts enable some clay minerals to be identified. For example, montmorillonite has a chemical shift at $-93 \mathrm{ppm}$ and kaolinite at $-91.5 \mathrm{ppm}$. Chemical shifts of ${ }^{29} \mathrm{Si}$ in silicate minerals have been tabulated (Goberdhan 1988).

${ }^{29}$ Si NMR spectra were acquired using single pulses. NMR spectra acquired on the acid-washed samples were also found to give spectra of improved $S / N$ and resolution, as illustrated in Figure 10 . For the most part the ${ }^{29} \mathrm{Si}$ NMR spectra of the Mowry source rocks consist of two bands, one sharp band assigned to low quartz $\left(\mathrm{Q}^{4}(0 \mathrm{Al})\right)$ centered at approximately $-107 \mathrm{ppm}$, and a broad band covering the range of -80 to $-105 \mathrm{ppm}$, due to ${ }^{29} \mathrm{Si}$ in $\mathrm{Q}^{3}$ structures of varying $\mathrm{Al}$ contents of the clay minerals. The effect of acid washing is to enhance the quartz signal over that of the clay minerals. This is probably due to the removal of some paramagnetic ions $\left(\mathrm{Fe}^{+3}, \mathrm{Mn}^{+2}\right)$ that are present in the interlayers. However, a detailed investigation of why acid washing improves the NMR signals was not conducted.

One disadvantage of ${ }^{29} \mathrm{Si}$ NMR for quantitative measurements is that the spin-lattice relaxation times are long, particularly in quartz (Barnee et al. 1986). 


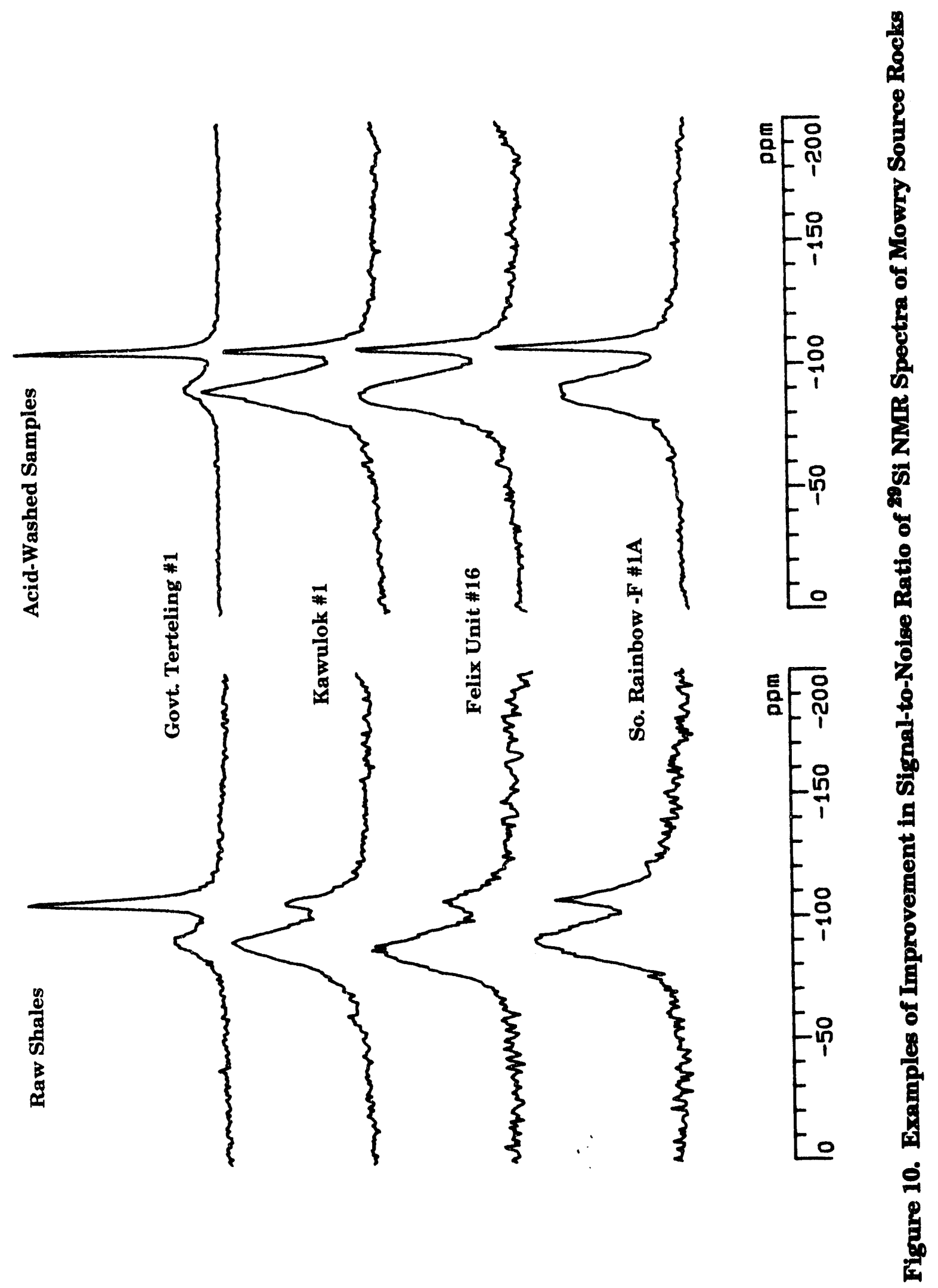


An example is shown in Figure 11 for the Mowry sample from the Kawulok \#1 Well. There is a noticeable increase in the quartz signal at a pulse delay of $120 \mathrm{~s}$ compared to that at $10 \mathrm{~s}$. Because of this direct integration of the spectra acquired at a pulse delay of $10 \mathrm{~s}$ can not be used to obtain the amount of silicon in quartz versus clay minerals. However it was possible to correct the quartz component by extrapolating to the situation where full spin relaxation occurs using the expression:

$$
M(t)=M_{0}\left(1-\exp \left(-t / T_{1}\right)\right)
$$

where $T_{1}$ is the spin-lattice relaxation time of ${ }^{29} \mathrm{Si}$ in quartz, and $\mathrm{M}_{0}$ is the quartz signal intensity at long pulse delays. A fit of the quartz ${ }^{29} \mathrm{Si}$ signal intensities for pulse delays of 2 to $300 \mathrm{~s}$ gave a $\mathrm{T}_{1}$ of 69 seconds. This means that at a pulse repetition rate of $10 \mathrm{~s}$, the quartz signals represent only $13.5 \%$ of the true signal. Accordingly, the integrals for the ${ }^{29} \mathrm{Si}$ in quartz were extrapolated to the true values using equation 5 , and renormalizing the integrals. The results are presented in Table 4. For the clays the $10 \mathrm{~s}$ pulse was adequate (Thompson 1984). Although the spectra of the acid-washed samples had somewhat better resolution and $S / N$ ratios, the calculated amounts of silicon in quartz and clays were in good agreement for the two sets of samples.

Tabie 4. NMR Estimate of ${ }^{29} \mathrm{Si}$ in Quartz and Clay Minerals in Mowry Source Rocks

\begin{tabular}{|c|c|c|c|c|c|}
\hline \multirow[b]{2}{*}{ Well Name } & \multirow[b]{2}{*}{ Depth, ft } & \multicolumn{2}{|c|}{ Raw Samples } & \multicolumn{2}{|c|}{ Acid-Washed } \\
\hline & & Quartz & $\overline{\text { Clays }}$ & Quartz & Clays \\
\hline Government Terteling \#1 & 3,085 & 0.927 & 0.073 & 0.912 & 0.088 \\
\hline Walker \#1 & 4,140 & 0.916 & 0.084 & 0.907 & 0.093 \\
\hline Kummer Field \#1 & 5,720 & 0.841 & 0.159 & 0.855 & 0.145 \\
\hline Kawulok \#1 & 7,765 & 0.723 & 0.277 & 0.719 & 0.281 \\
\hline State \#1 & 8,377 & 0.664 & 0.336 & 0.697 & 0.303 \\
\hline Annie \#1 & 9,230 & 0.626 & 0.374 & 0.702 & 0.298 \\
\hline Felix Unit \#16 & 9,695 & 0.675 & 0.325 & 0.707 & 0.293 \\
\hline Little Burgher Draw & 11,090 & 0.675 & 0.325 & 0.709 & 0.291 \\
\hline South Rainbow-F \#1-A & 11,425 & 0.776 & 0.224 & 0.772 & 0.228 \\
\hline
\end{tabular}



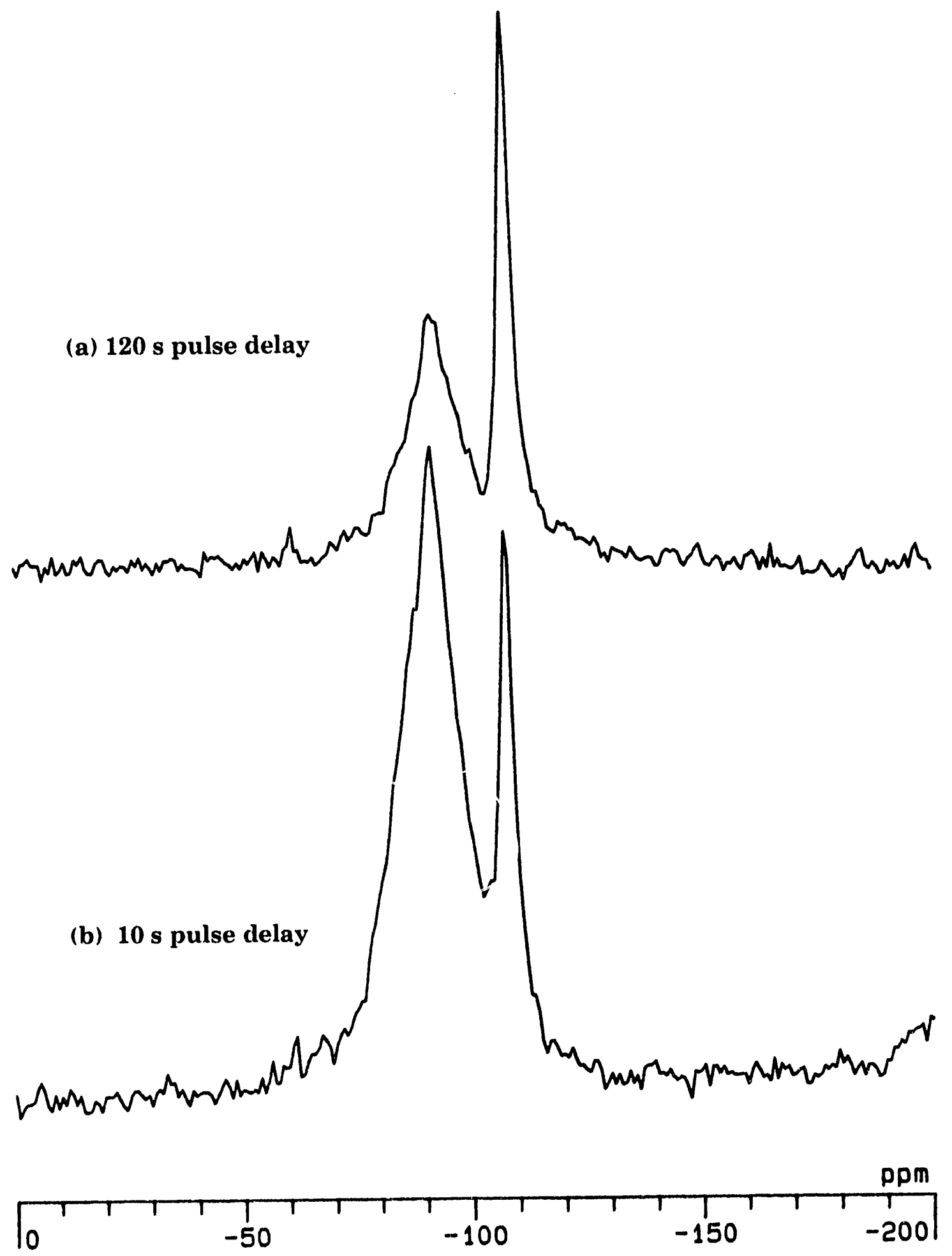

Figure 11. ${ }^{29}$ Si NMR Spectra of Mowry Source Rock from Kawulok \#1 Well Using: (a) 120 s Pulse Delay and (b) 10 s Pulse Delay

23 
The principal clay minerals in marine sediments are smectite and illite, although kaolinite is dominant in some (Hunt 1979). Upon heating, smectite releases bound water and is altered to illite. The importance of this clay dehydration step is that the additional water released can provide additional pore water for the primary migration of the generated hydrocarbons. However, clay mineral dehydration is not a prerequisite for the accumulation of oil. Nevertheless, the changes in clay mineralogy with depth of burial can provide information about thermal maturation in the sediment.

X-ray diffraction analyses of the clay-sized fraction of the Mowry Formation sandstones indicate that the cuttings are dominated by kaolinite, mixed-layer smectite/illite, chlorite, quartz, and some feldspars (MacGowan, submitted). Figure 12 shows the X-ray diffractograms of the clay-sized fraction of the Mowry shale between 3,000 and 11,500 ft. The percentage of illite in the illite/smectite mixedlayer clays is shown in Figure 13. The X-ray data show that the alteration of smectite to illite begins to become important at about $8,000 \mathrm{ft}$ and continues to about $10,000 \mathrm{ft}$ where the mixed-layer clay contains about $85 \%$ illite. This range is also the same range of depths where the changes in the carbon aromaticities were the greatest.

Although it would be difficult to identify specific clay minerals using ${ }^{29} \mathrm{Si}$ NMR, some of the spectral features provide qualitative support for some of the other measurements made on the samples, particularly the transformations of clay minerals. For example, the ${ }^{29} \mathrm{Si}$ NMR signals in the clay minerals from samples less than approximately $8,000 \mathrm{ft}$ have maximum values at a chemical shift of -91 to -92 ppm (Figure 14), which can be interpreted as arising from kaolinite, and possibly contributions from smectite in the mixed-layer clays. ${ }^{29} \mathrm{Si}$ in montmorillonite, for example, has a chemical shift of approximately $-93 \mathrm{ppm}$ (Barnes et al. 1986). At depths approaching 10,000 ft and greater, the silicon NMR signal from the clays becomes broader and the chemical shift is about -89 ppm for the maximum in the clay peak. This corresponds to a $Q^{3}(1 \mathrm{Al}) \mathrm{Type}$, but the broadness is indicative that there is little short range ordering of the silicon chemical environments. Illites generally give a broad resonance between -80 and -105 ppm (Thompson 1984). Thus, the ${ }^{29} \mathrm{Si}$ NMR results are consistent with progressive alteration of illite in the Mowry samples at the greater depths of burial. Qualitatively, these observations from ${ }^{29} \mathrm{Si}$ NMR support those obtained by X-ray analysis. 


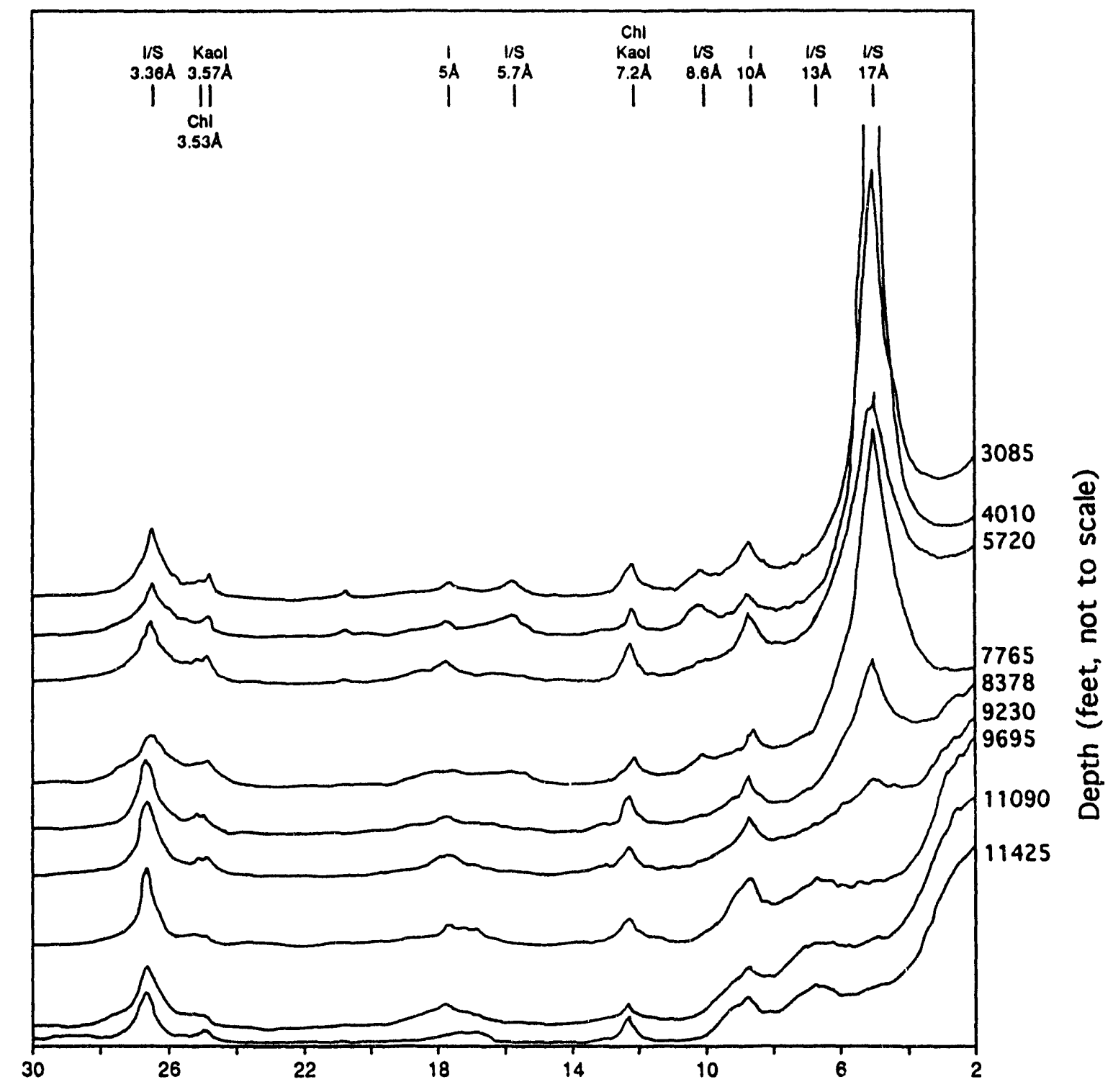

Figure 12. X-ray Diffraction Traces of Clay Fraction Versus Depth of Burial of Mowry Source Rocks 


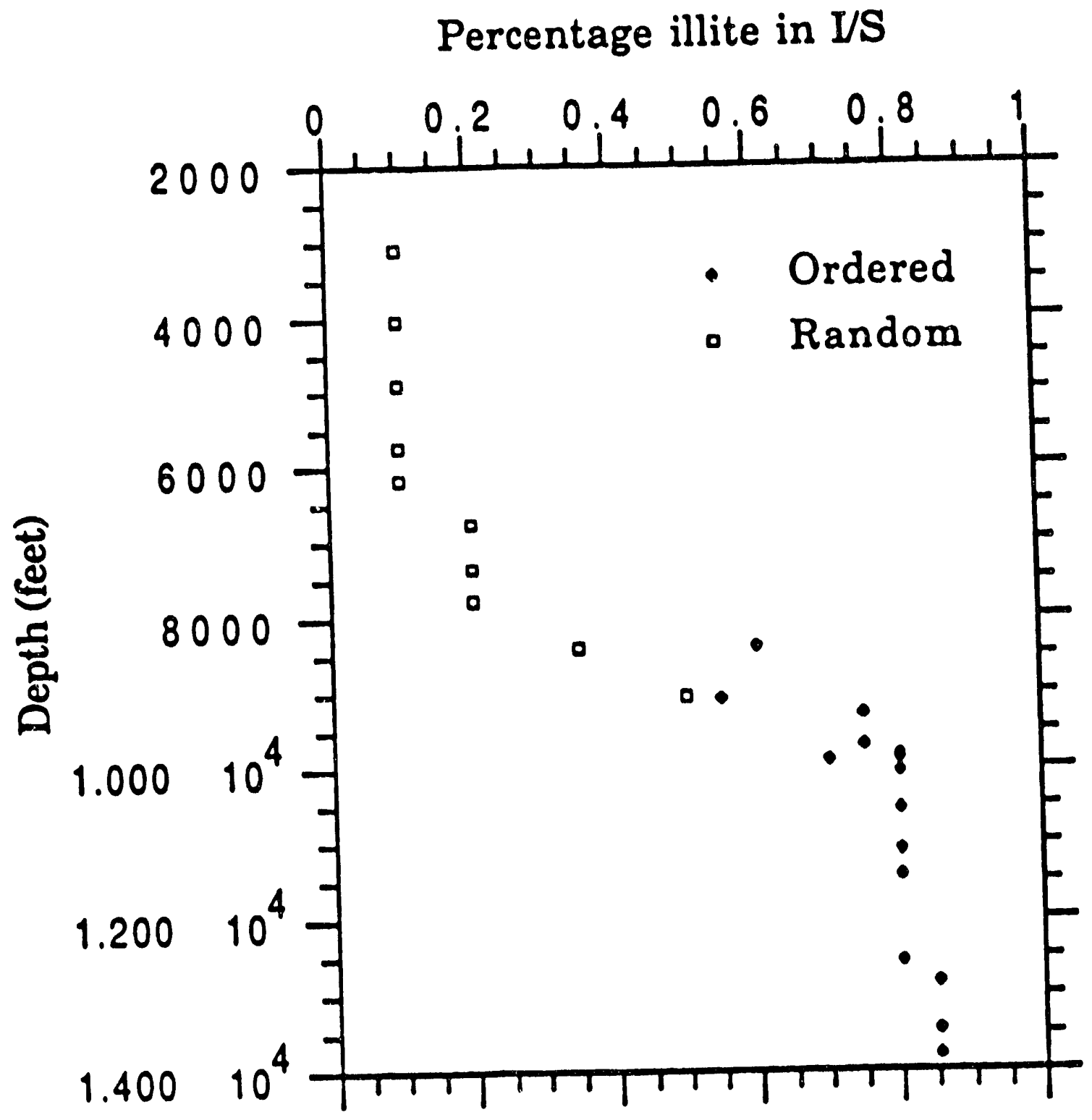

Figure 13. Percentage of Illite in Mixed-Layer Clays Versus Depth of Burial of Mowry Source Rocks 


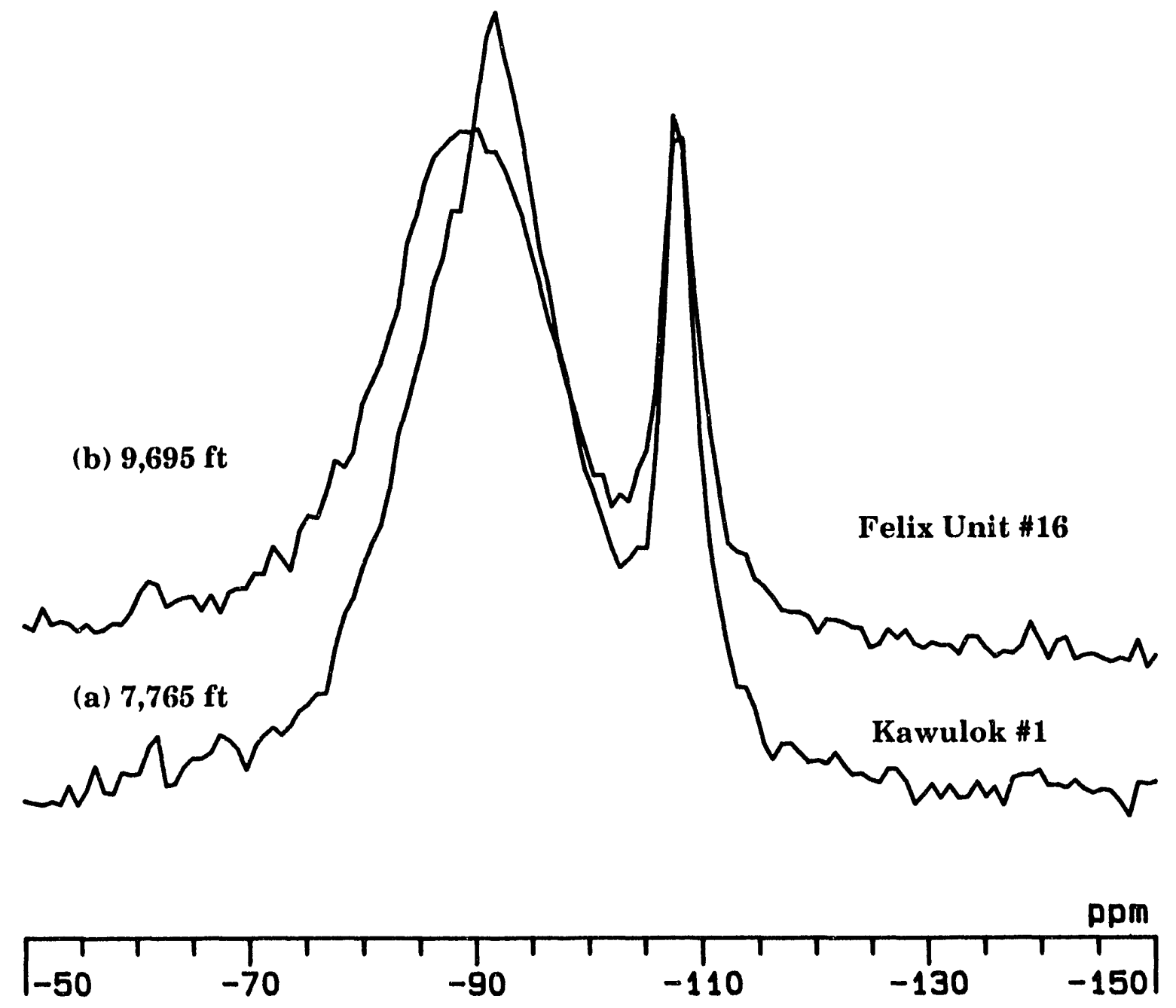

Figure 14. ${ }^{29}$ Si NMR Spectra of Mowry Source Rocks: (a) Sample from $7,765 \mathrm{ft}$ and (b) Sample from 8,695 ft 


\section{CONCLUSIONS}

In summary, the NMR measurements largely support other geochemical analyses that show evidence of a fundamental change in the rock-fluid system of the Muddy and Mowry Formations of the Powder River Basin between a current depth of burial of 8,000 to $10,000 \mathrm{ft}$. These changes are related to changes in the organic geochemistry of the source rock as indicated by vitrinite reflectance measurements of thermal maturation, Rock-Eval determination of production indices, and solid-state NMR measurements of changes in carbon aromaticities. In addition, X-ray analysis of the clay minerals indicated alteration of smectite to illite occurs over the same depth of burial interval. These observations were supported qualitatively by ${ }^{29} \mathrm{Si}$ NMR measurements. These observations suggest that pressure compartmentalization resulted from maturation of the organic matter, and subsequent generation and expulsion of hydrocarbons at these burial depths.

The ${ }^{13} \mathrm{C}$ NMR measurements were combined with Rock-Eval measurements to obtain an assessment of the hydrogen budget during maturation following a procedure derived by Patience et al. (1992). These calculations suggested that about $20 \%$ of the original TOM in the Mowry Formation source rocks was lost during thermal maturation, and that beyond a depth of approximately $11,000 \mathrm{ft}$, the kerogen had little capacity to generate additional oil, but had some potential for gas generation. Additional calculations showed that sufficient hydrogen was generated from aromatization and condensation reactions during maturation to form stable hydrocarbon liquids and gases.

${ }^{29} \mathrm{Si}$ NMR spectra of the Mowry source rocks consisted largely of a relatively narrow band associated with quartz, and a broad band associated with the various clay minerals. The increase in the amount of clay minerals with depth was evident from the decreasing quartz resonance with depth. Furthermore, there appeared to be a subtle change in the ${ }^{29} \mathrm{Si}$ NMR spectra of the clay minerals over the interval, 8,000 to $10,000 \mathrm{ft}$. At less than $8,000 \mathrm{ft}$, the maximum in the broad ${ }^{29} \mathrm{Si}$ clay resonance was centered at approximately -91 to $-92 \mathrm{ppm}$, whereas at greater than $10,000 \mathrm{ft}$, the clay resonances were centered at approximately $\mathbf{- 8 8} \mathbf{p p m}$ and were even broader. This was interpreted as support of the alteration of illite to smectite in the same depth interval. 


\section{ACKNOWLEDGEMENTS}

We express appreciation to the U.S. Department of Energy for funding of this work under Cooperative Agreement No. DE-FC21-86MC11076. The solid-state NMR analyses were provided, in part, by a DOE University Research Instrumentation grant No. DE-FG05-89ER75506. Such support does not, however, constitute endorsement by DOE of the views expressed in this paper. Technical support from Professor R. Surdam's research group at the Department of Geology and Geophysics, University of Wyoming was also appreciated. Portions of the research were conducted under Gas Research Institute Contract No. 5089-2601894.

\section{DISCLAIMER}

Mention of specific brand names or models of equipment is for information only and does not imply endorsement of any particular brand. 


\section{REFERENCES}

Barnes, J.R., A.D. Clague, N.J. Clayden, C.M. Dobsen, and R.B. Jones, 1986, The Application of ${ }^{29} \mathrm{Si}$ and ${ }^{27} \mathrm{Al}$ Solid-State NMR Spectroscopy to Characterizing Minerals in Coals. Fuel, 65: 437-441.

Barwise, A.J.G., A.L. Mann, G. Eglington, A.P. Gowar, A.M.K. Wardroper, and C.S. Gutteridge, 1984, Kerogen Characterization by Carbon-13 NMR Spectroscopy and Pyrolysis-Mass Spectrometry. Org. Geochem., 6: 343-349.

Dereppe, J.-M., and C. Moreaux, 1987, A Limitation of ${ }^{13}$ C CP-MAS NMR Spectroscopy for the Study of Treated Coals. Fuel, 66: 1008-1009.

Goberdhan, D.G., 1988, Solid-State NMR Studies of Silicates, Minerals, and Clays. The British Library, West Yorkshire, United Kingdom.

Hagaman, E.W., F.M. Schell, and D.C. Cronauer, 1984, Oil Shale Analys is by CP/MAS Carbon-13 NMR Spectroscopy. Fuel, 63: 915-919.

Hayashi, S., and K. Hayamizu, 1991, Chemical Shift Standards in High Resolution Solid-State NMR (1) ${ }^{13} \mathrm{C},{ }^{29} \mathrm{SI}$, and ${ }^{1} \mathrm{H}$ Nuclei. Bull. Chem. Soc. Jpn., 64: 685687.

Hunt, J.M., 1979. Petroleum Geochemistry and Geology, W.H. Freeman and Co., San Francisco, p. 461.

Kirkpatrick, R.J., 1988, MAS NMR Spectroscopy of Minerals and Glasses. Reviews in Mineralogy, 18: 341-403.

Kirkpatrick, R.J., K.A. Smith, S. Schramm, G. Turner, and W.-H. Yong, 1985, Solid-State Nuclear Magnetic Resonance Spectroscopy of Minerals. Ann. Rev. Earth Planet. Sci., 13: 29-47.

Lindgreen, H., H. Jacobsen, and H.J. Jakobsen, 1991, Diagenetic Structural Transformations in North Sea Jurassic Illite/Smectite. Clays and Clay Minerals, 39: 54-69.

Lippmaa, E., M. Mägi, A. Samoson, G. Engelhardt, and A.R. Grimmer, 1980, Structural Studies of Silicates by Solid-State High-Resolution ${ }^{29} \mathrm{Si}$ NMR Spectroscopy. J. Am. Chem. Soc., 102: 4889-4893.

Lo, H.B., 1991, How Well Can Artificial Coalification Simulate the Naturational Maturation Trend? Org. Geochem., 17: 415-420. 
MacGowan, D.B., Z.S. Jiao, R.C. Surdam, and F.P. Miknis, submitted, Formation Water Chemistry of the Muddy Sandstone and Organic Geochemistry of the Mowry Shale, Powder River Basin, Wyoming: Evidence For Mechanism of Pressure Compartment Formation. In AAPG Memoir, "Pressure Compartmentalization in Sedimentary Basins," P.J. Ortoleva and Z.Al-Shaeib, eds.

Maciel, G.E., V.J. Bartuska, and F.P. Miknis, 1978, A Correlation Between Oil Yields of Oil Shales and ${ }^{13} \mathrm{C}$ Nuclear Magnetic Resonance Spectra. Fuel, 57: 505.

Maciel, G.E., V.J. Bartuska, and F.P. Miknis, 1979, Improvement in Correlation Between Oil Yields of Oil Shales and ${ }^{13} \mathrm{C}$ NMR Spectra. Fuel, 58: 155.

Mann, A.L., R.L. Patience, and I.J.F. Poplett, 1991, Quantitative Determination of Molecular Structure of Kerogens Using ${ }^{13}$ C-NMR Spectroscopy: I. Effects of Variation in Kerogen Type. Geochim. Cosmochim. Acta, 55: 2259-68.

Marchand, A., and J. Conard, 1980, Electron Paramagnetic Resonance in Kerogen Studies. In Kerogen, B. Durand, ed., Editions Technip, Paris, pp 243-270.

Miknis, F.P., D.A. Netzel, J.W. Smith, M.A. Mast, and G.E. Maciel, $1982 a,{ }^{13}$ C NMR Measurements of the Genetic Potentials of Oil Shale. Geochim. Cosmochim. Acta, 46: 977-984.

Miknis, F.P., J.W. Smith, E.K. Maughan, and G.E. Maciel, 1982b, Nuclear Magnetic Resonance: A Technique for Direct Nondestructive Evaluation of Source Rock Potential. AAPG Bulletin 66, 1396-1401.

Miknis, F.P., N.M. Szeverenyi, and G.E. Maciel, 1982c, Characterization of the Residual Carbon in Retorted Oil Shales by Solid-State ${ }^{13} \mathrm{C}$ NMR. Fuel, 61: 341-345.

Miknis, F.P., and J.W. Smith, 1984, An NMR Survey of United States Oil Shales. Org. Geochem., I.A. Breger Memorial Issue, 5: 193-201.

Miknis, F.P., and G.E. Maciel, 1984, Some Examples of ${ }^{13} \mathrm{C}$ NMR Applications to Oil Shales, in Petrakis, L., and J.P. Fraissard, eds., Magnetic Resonance Introduction, Advanced Topics and Applications to Fossil Energy, NATO ASI Series C. D. Reidel Publishing, Boston, MA, 124: 545-555.

Miknis, F.P. and P.J. Conn, 1986, A Common Relation for Correlating Pyrolysis Yields of Coals and Oil Shales. Fuel, 65: 248 - 250. 
Miknis, F.P., 1992, Combined NMR and Fischer Assay Study of Oil Shale Conversion, Fuel, in press.

Patience, R.L., A.L. Mann, and I.J.F. Poplett, 1992, Quantitative Determination of Molecular Structure of Kerogens using ${ }^{13} \mathrm{C}$ NMR Spectroscopy II: The Effects of Thermal Maturation on Kerogens From Marine Sediments. Geochem. et Cosmochem. Acta, in press.

Stone, W.E.E., 1982, The Use of NMR in the Study of Clay Minerals. In J.J. Fripiat, ed, Advanced Techniques for Clay Mineral Analysis, Elsevier, Amsterdam, 77-112.

Thompson, J.G., 1984, ${ }^{29} \mathrm{Si}$ and ${ }^{27} \mathrm{Al}$ Nuclear Magnetic Resonance Spectroscopy of 2:1 Clay Minerals. Clay Minerals, 19: 229-236.

Tissot, B.P., 1984, Recent Advances in Petroleum Geochemistry Applied to Hydrocarbon Exploration, AAPG Bulletin, 68, 545-563.

Tissot, B.P. and D.H. Welte, 1984. Petroleum Formation and Occurrence, 2nd Edition, Springer-Verlag, Berlin. 


\title{
APPENDDX A
}

\author{
Solid-State ${ }^{13} \mathrm{C}$ NMR Spectra of \\ Acid-Washed and Unwashed Mowry Shales
}




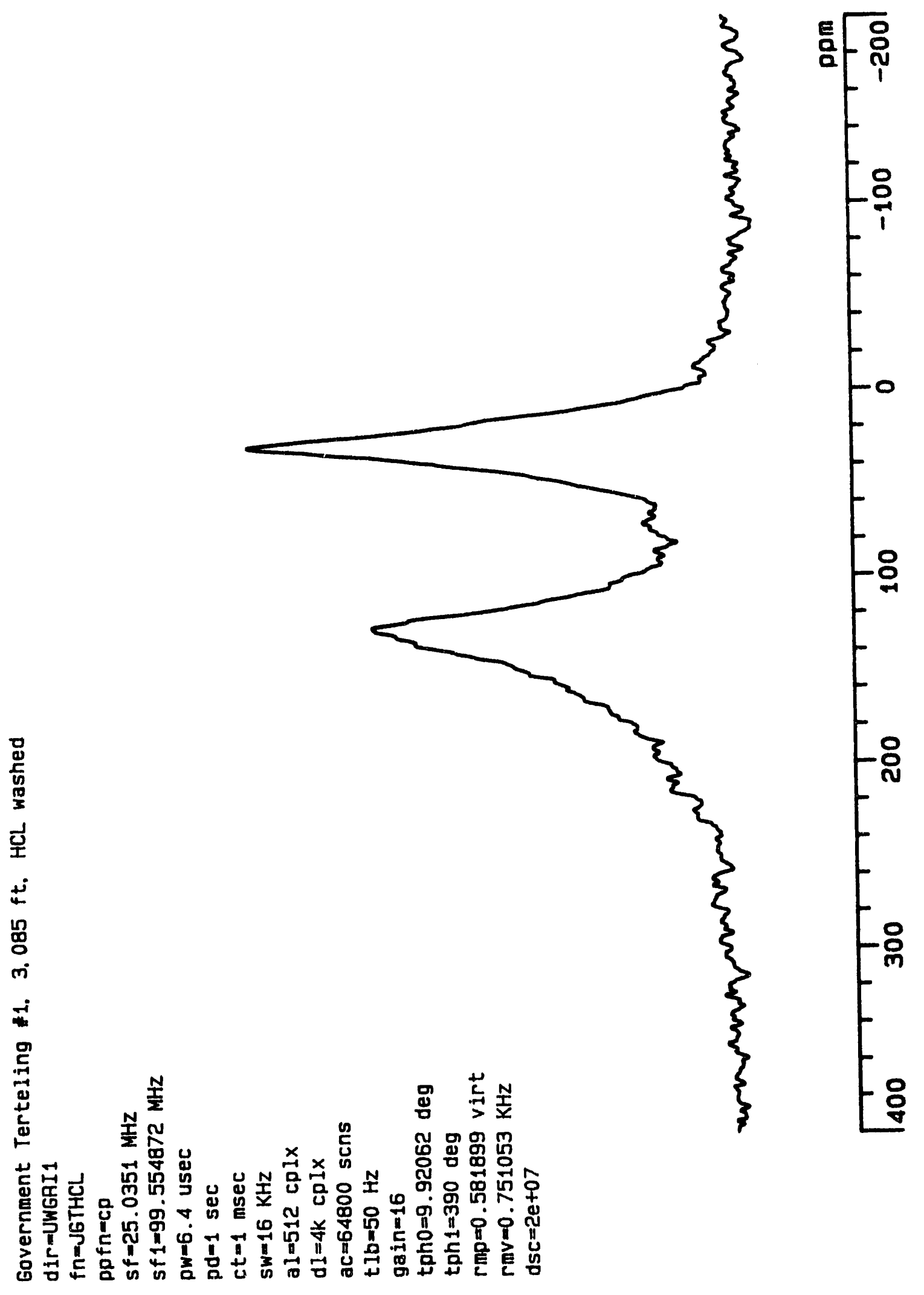




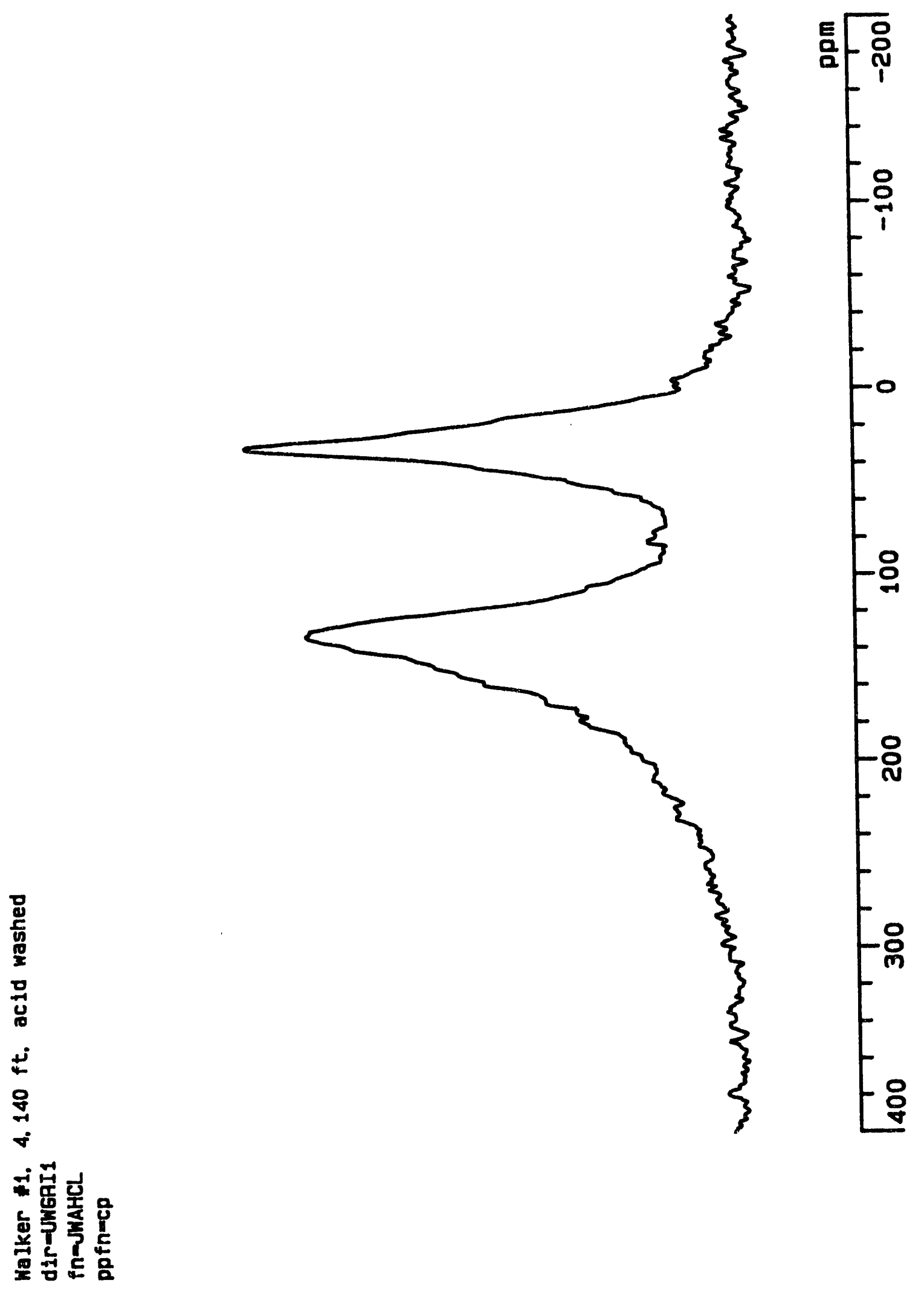




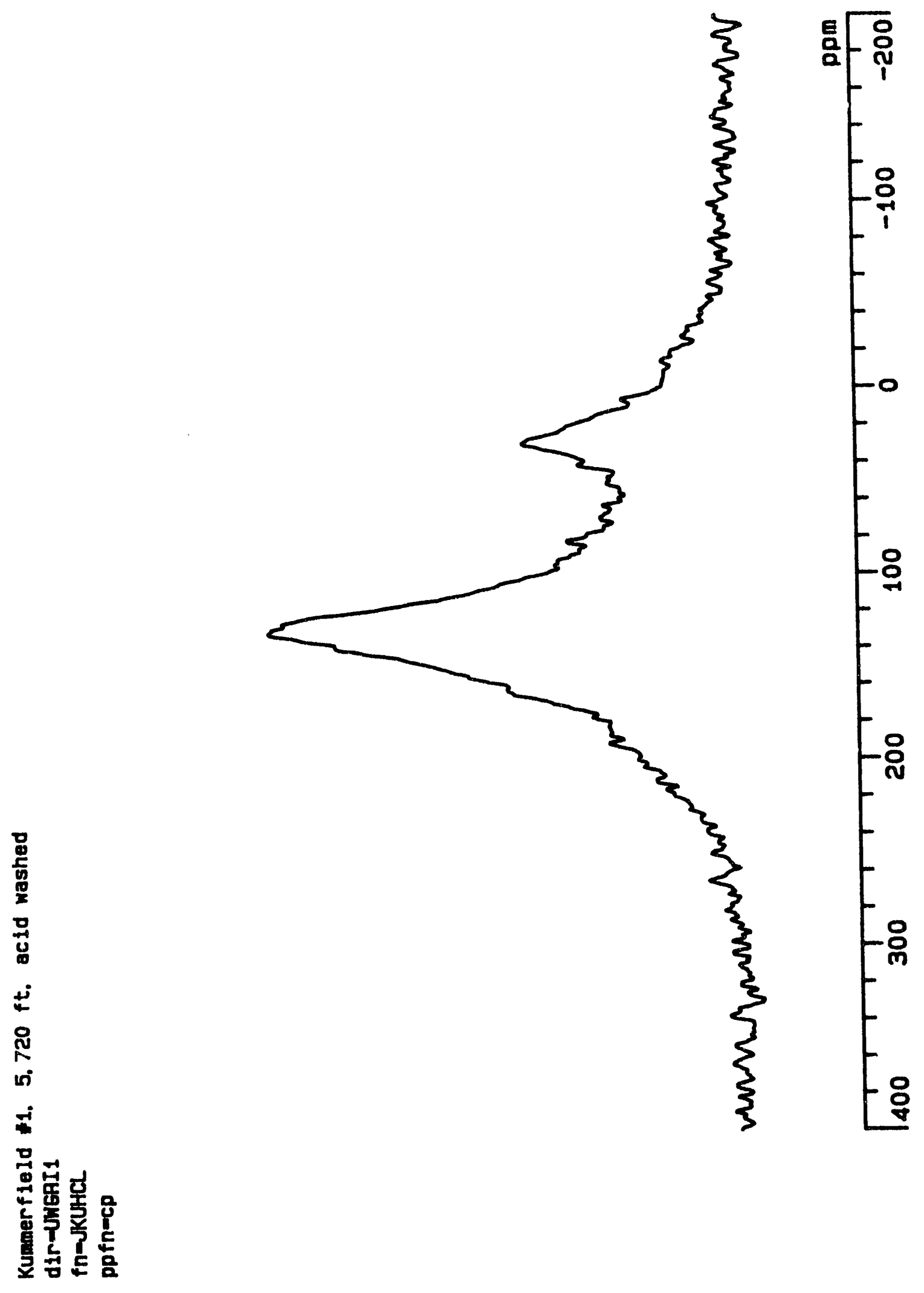




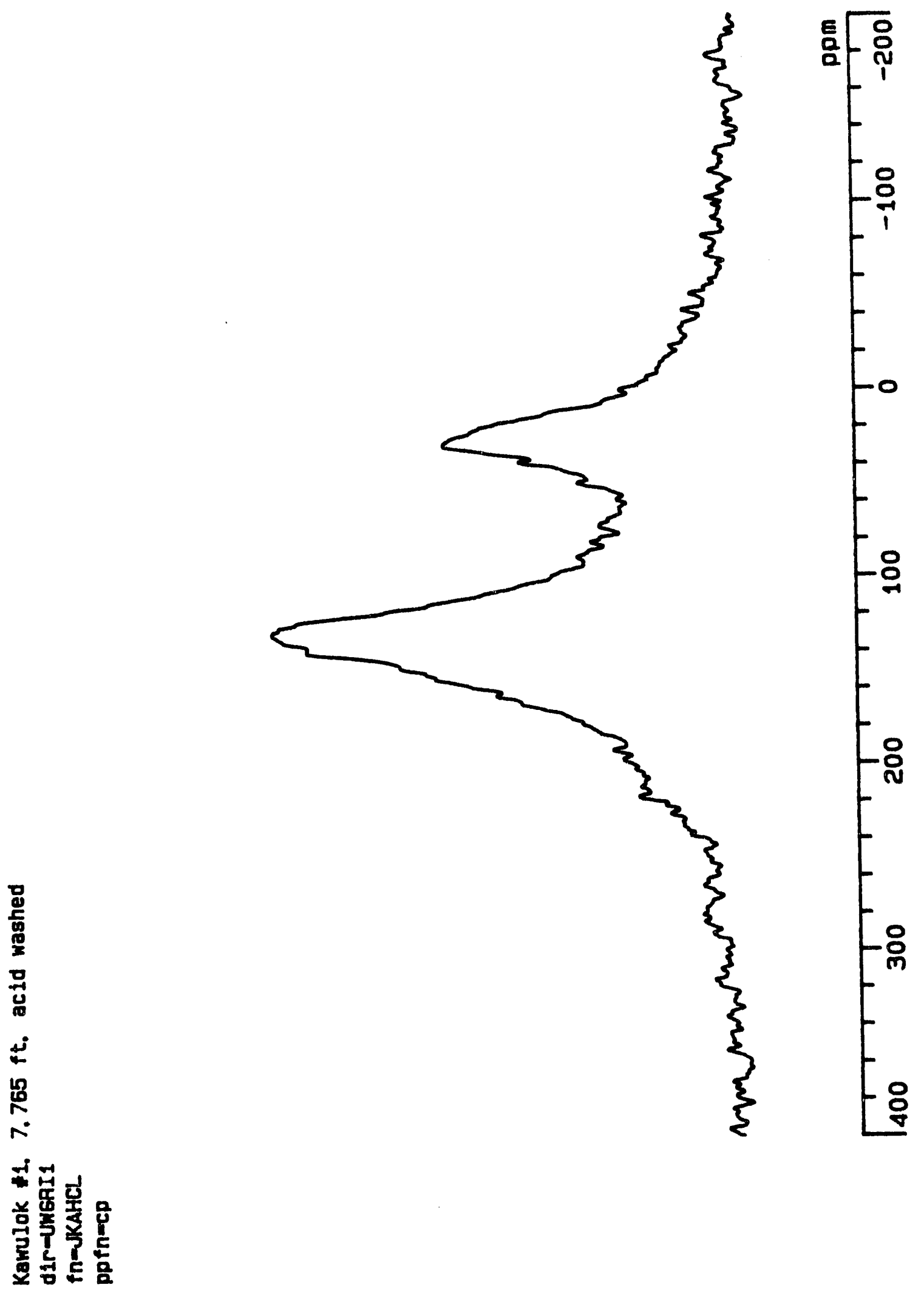




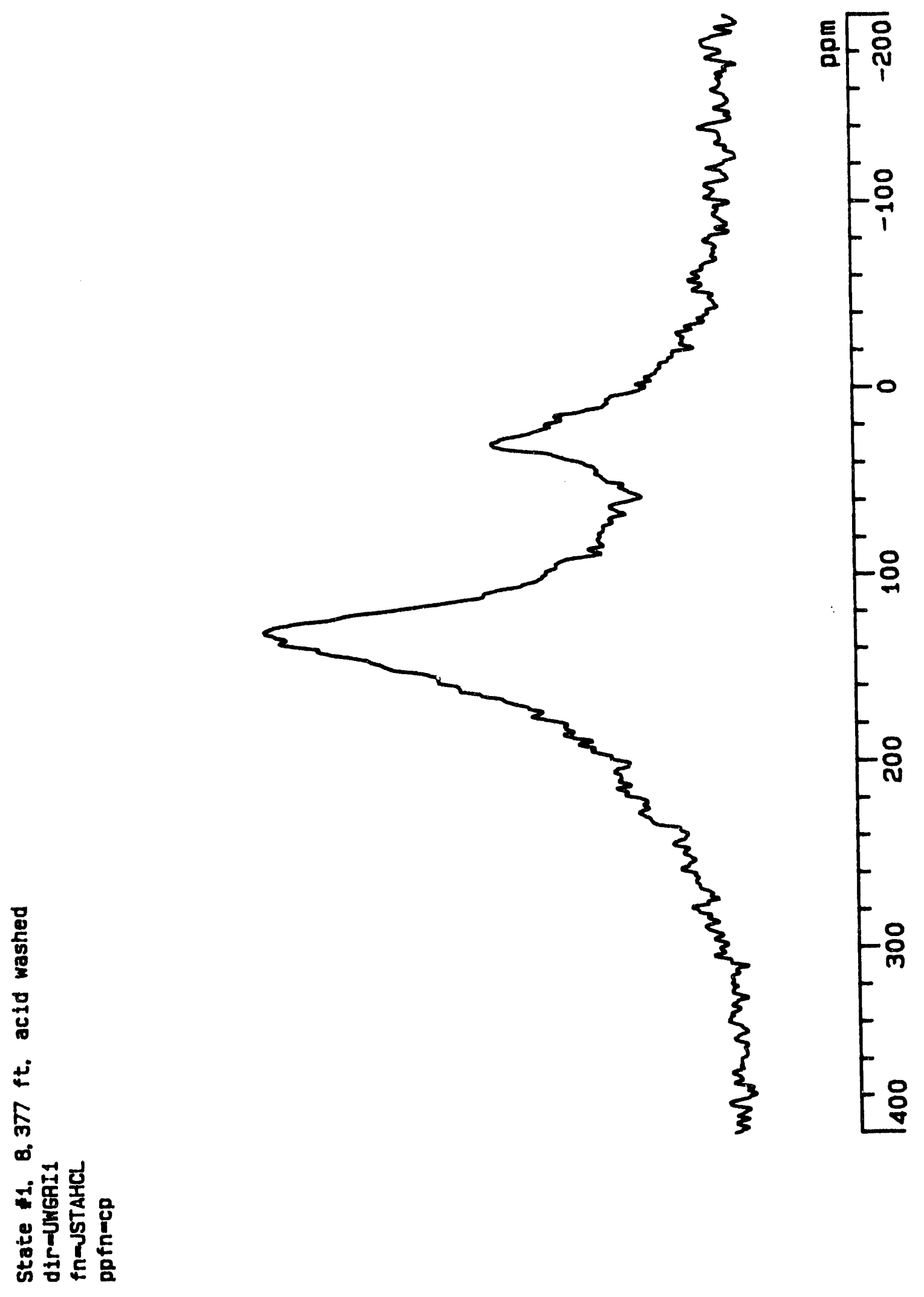




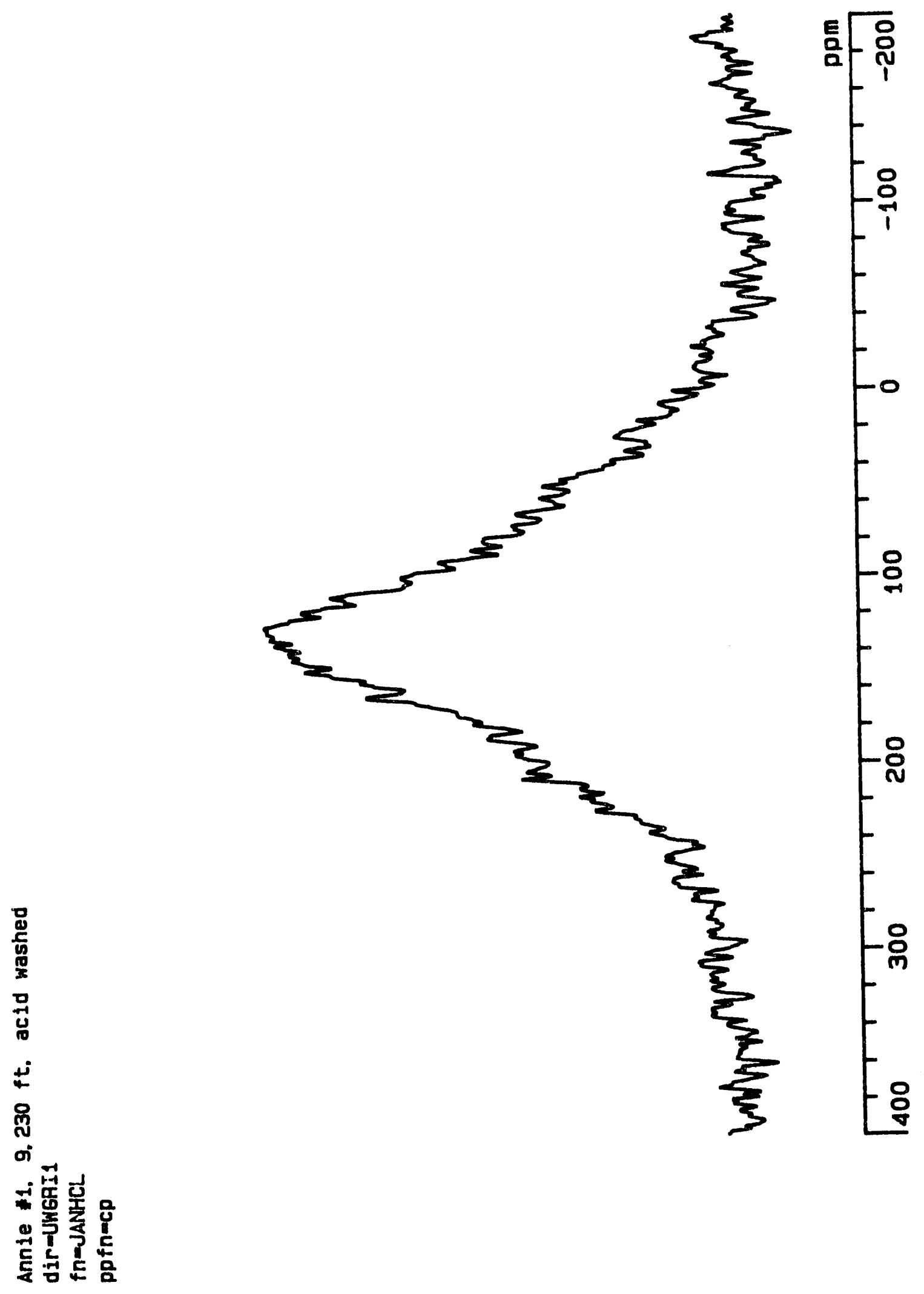




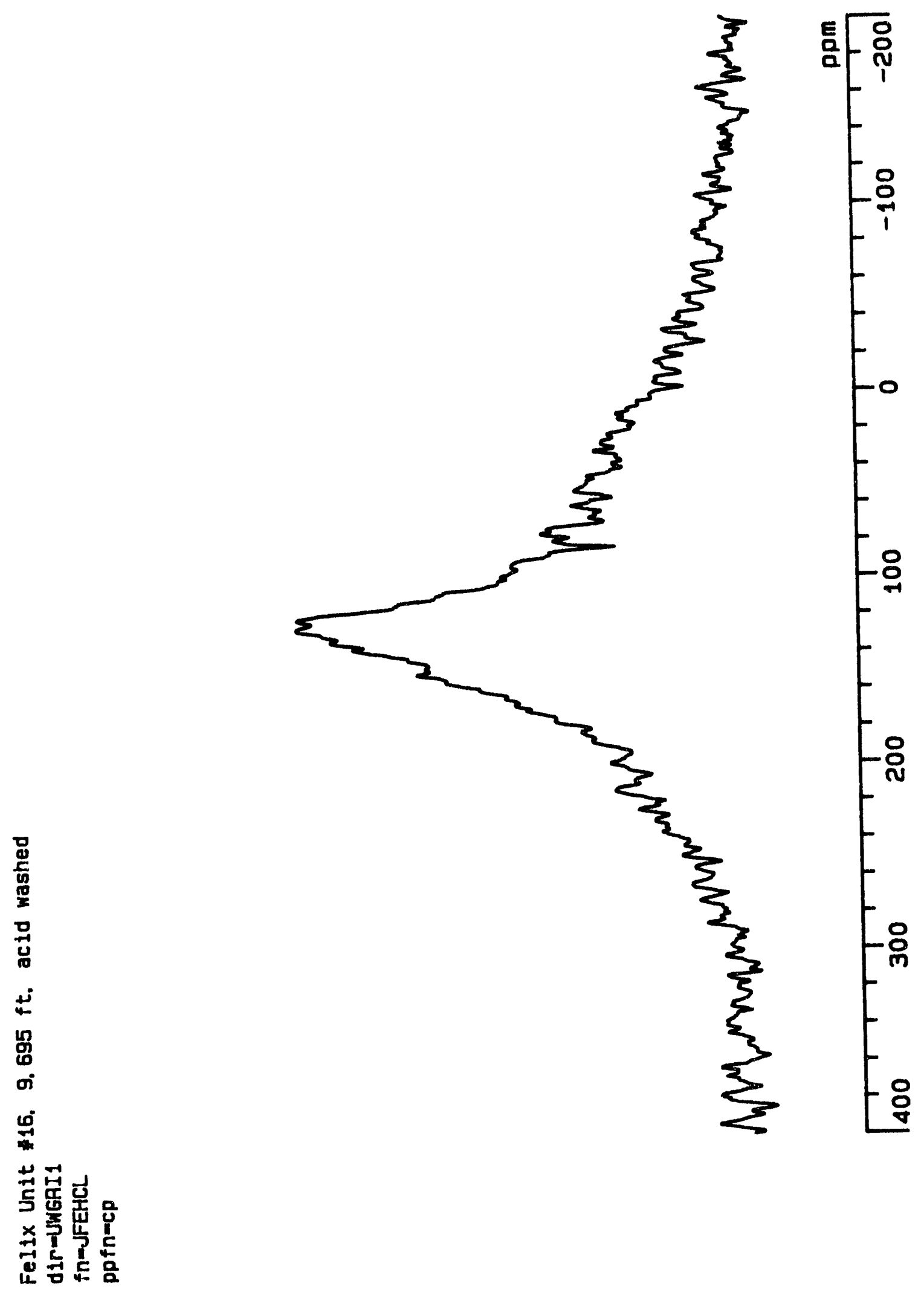



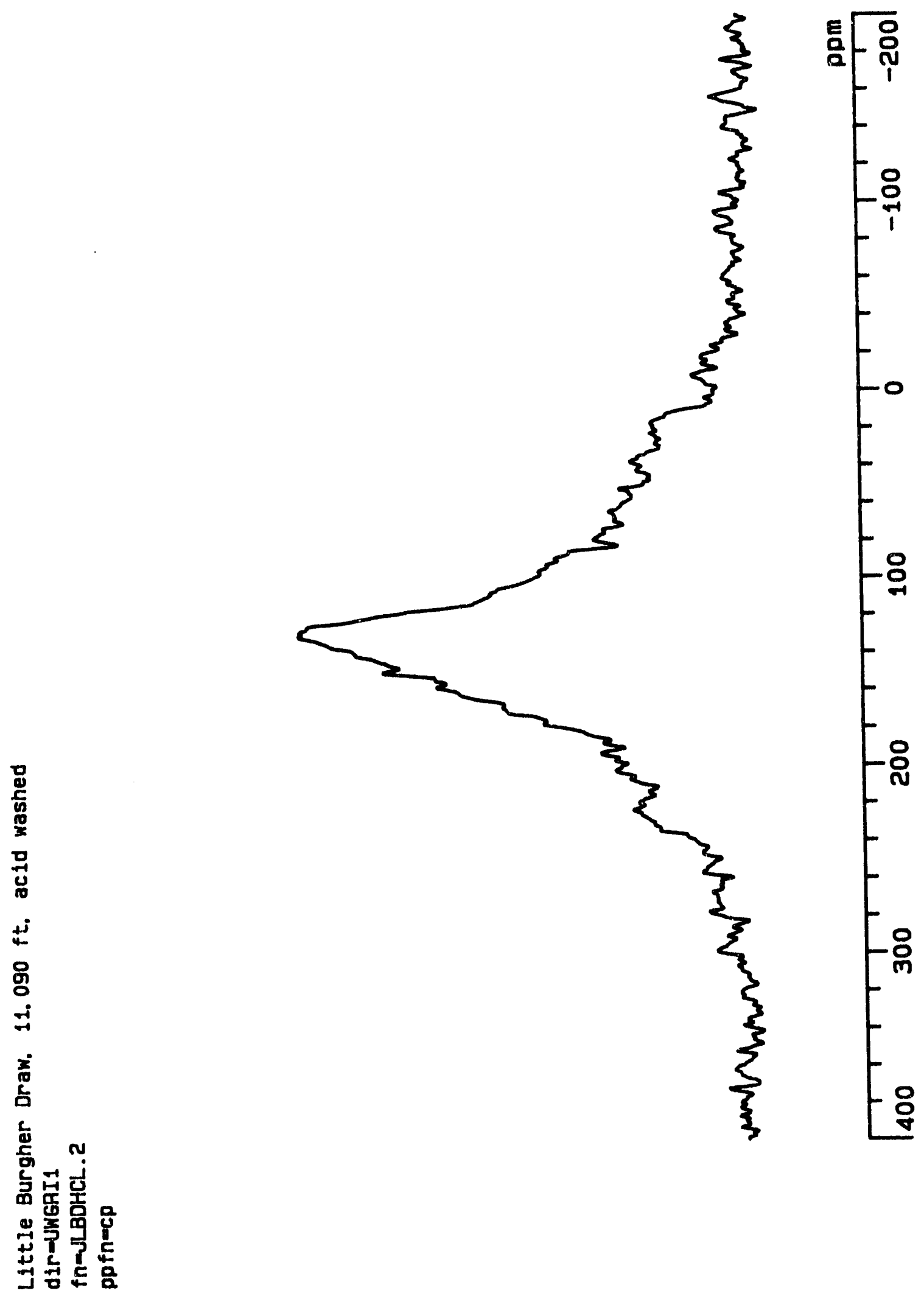

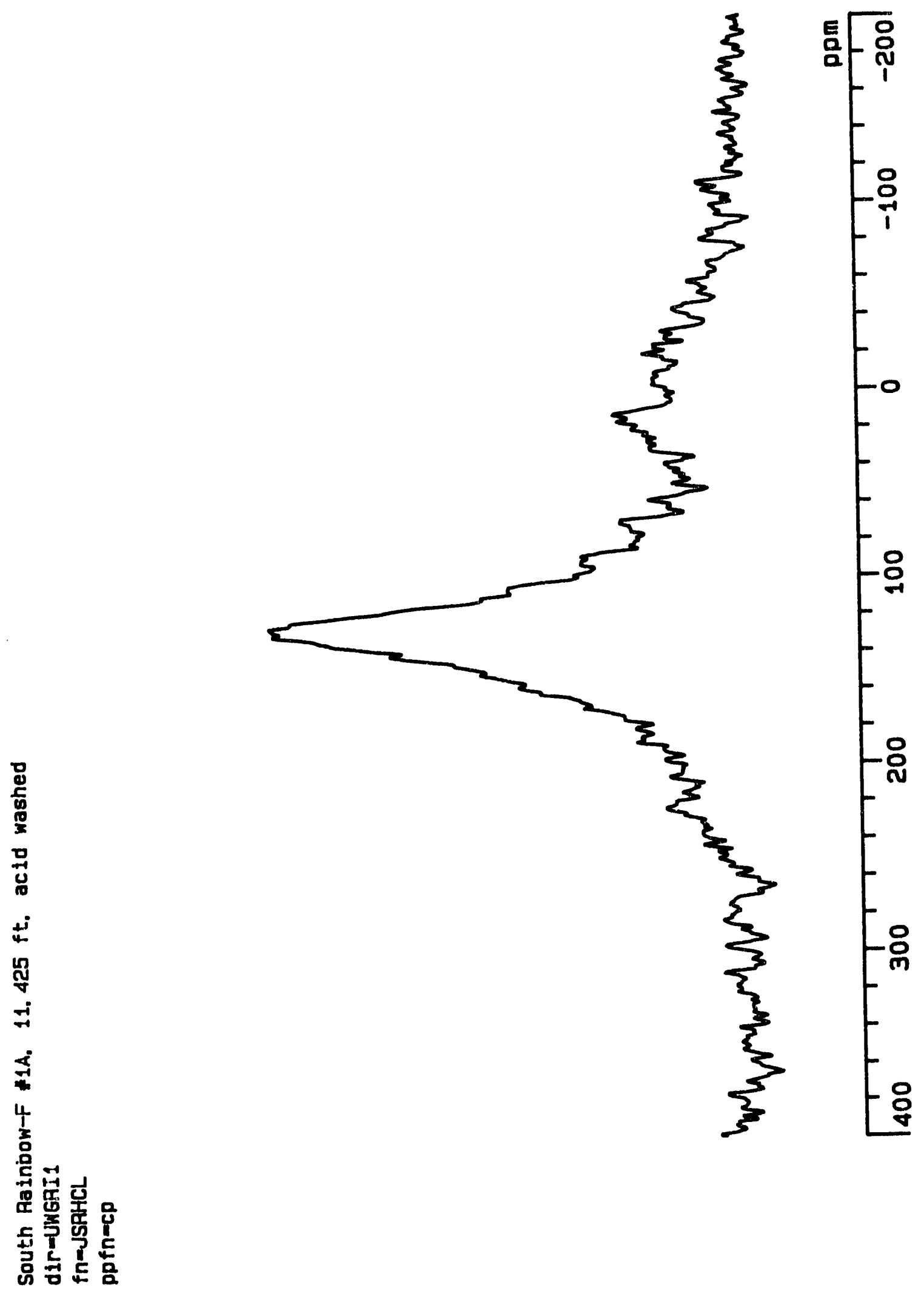


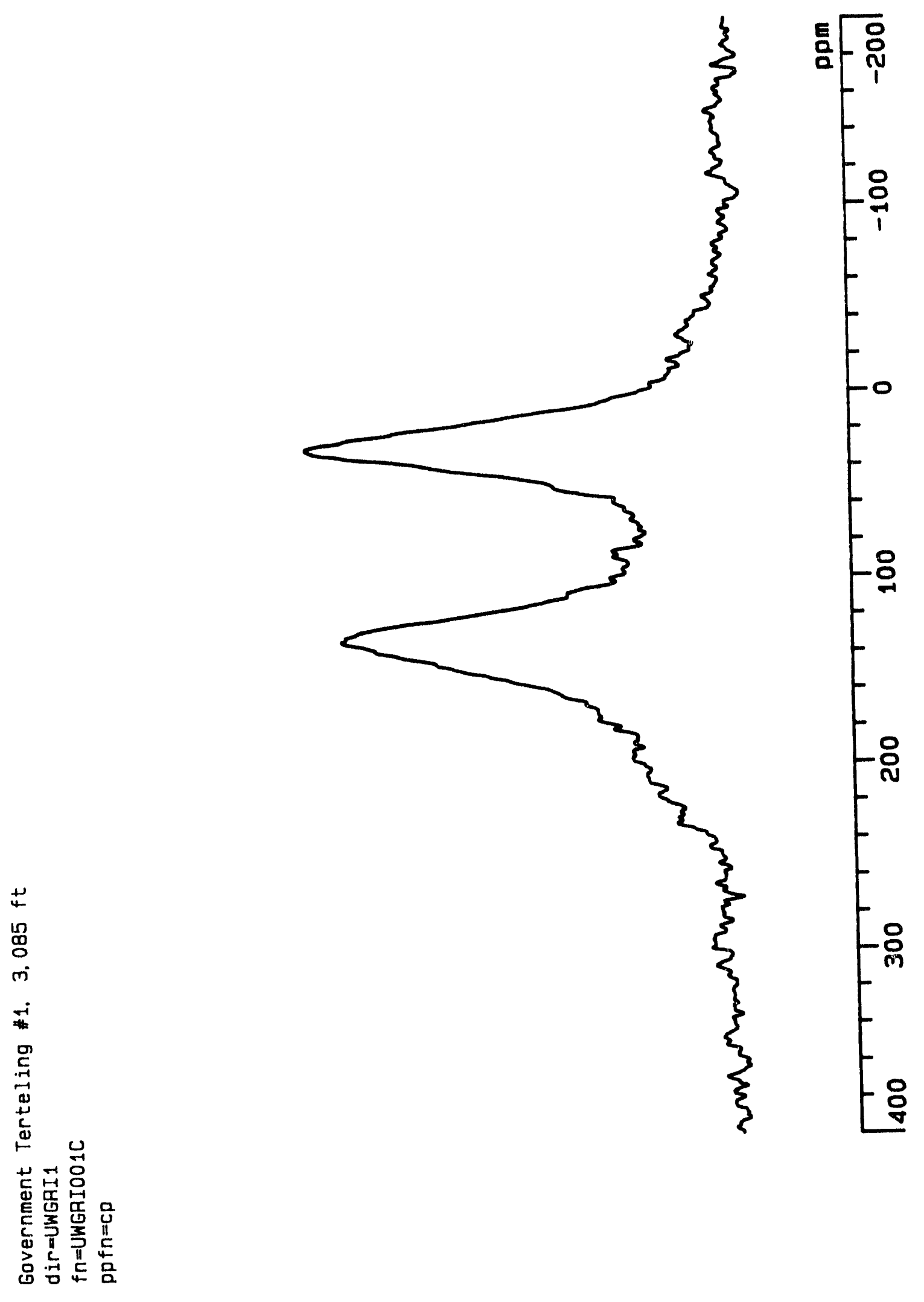




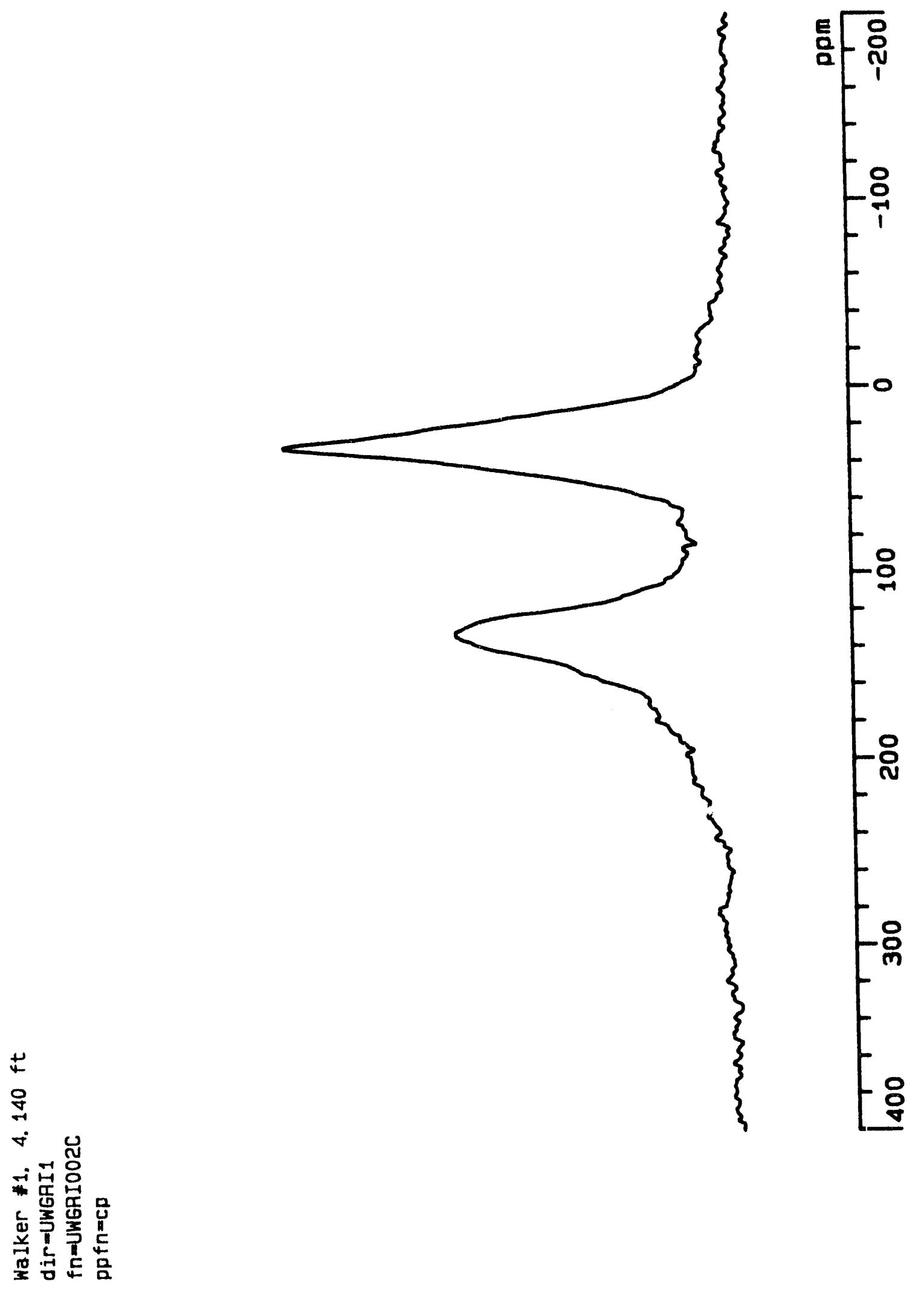




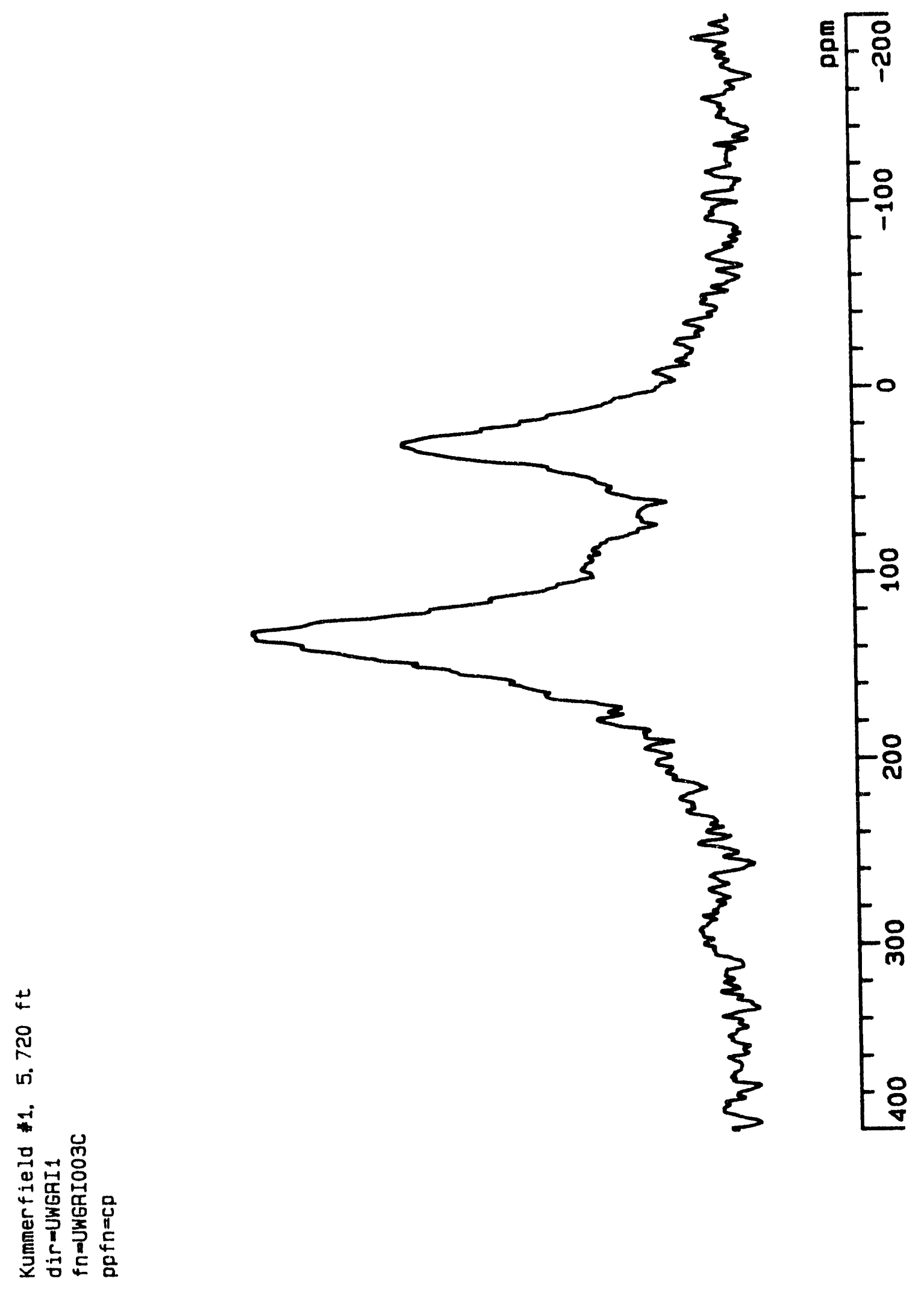




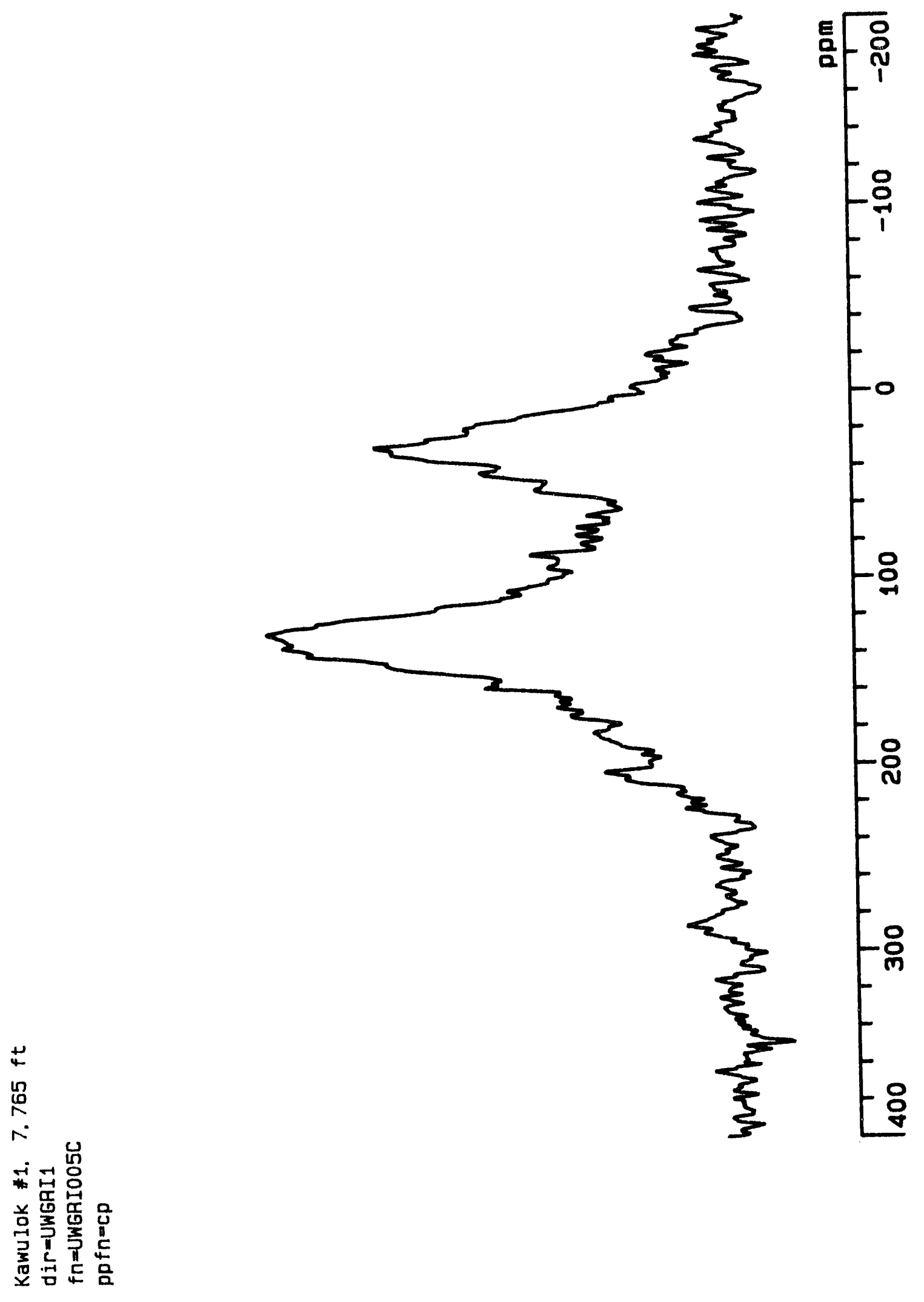




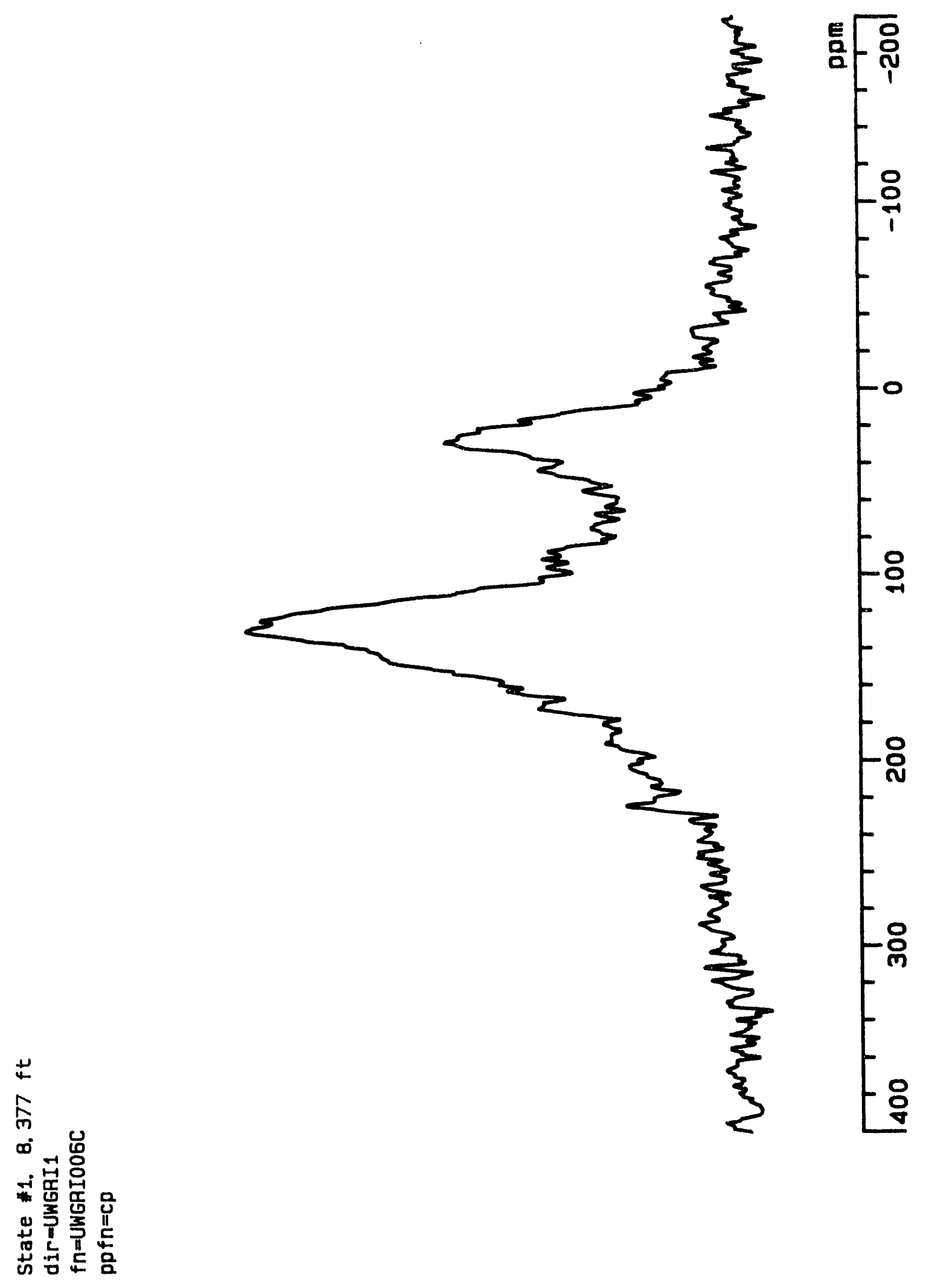




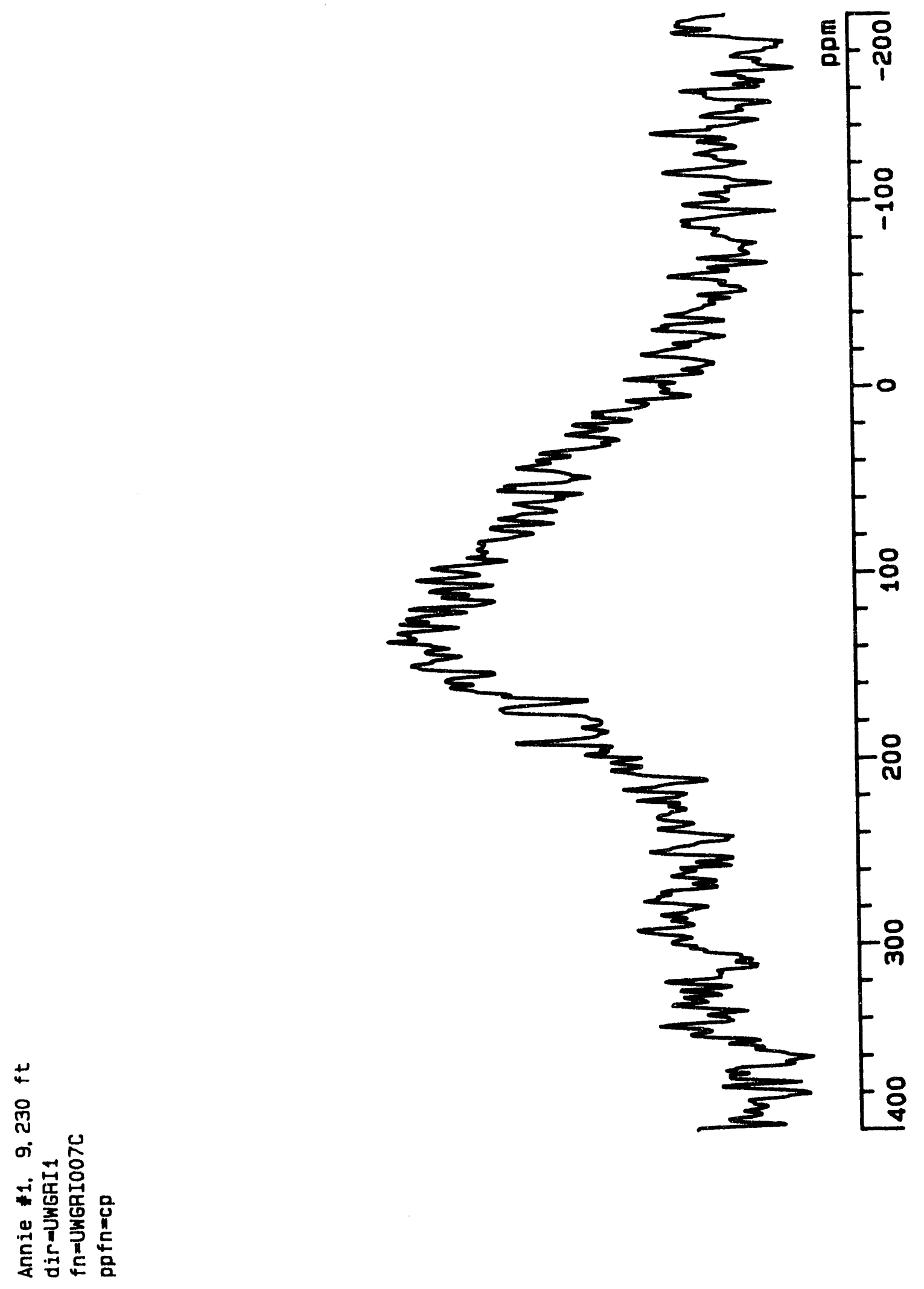




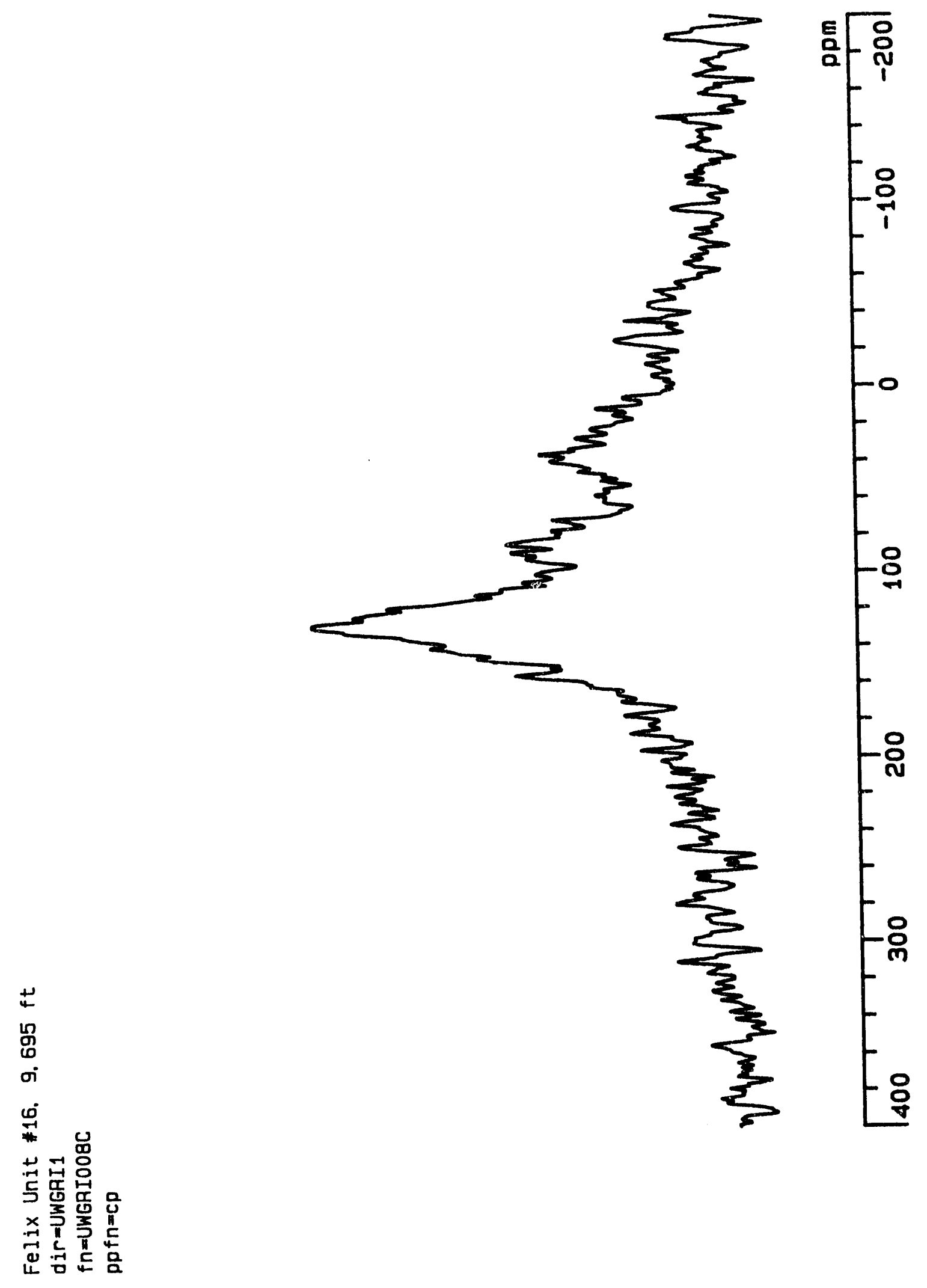




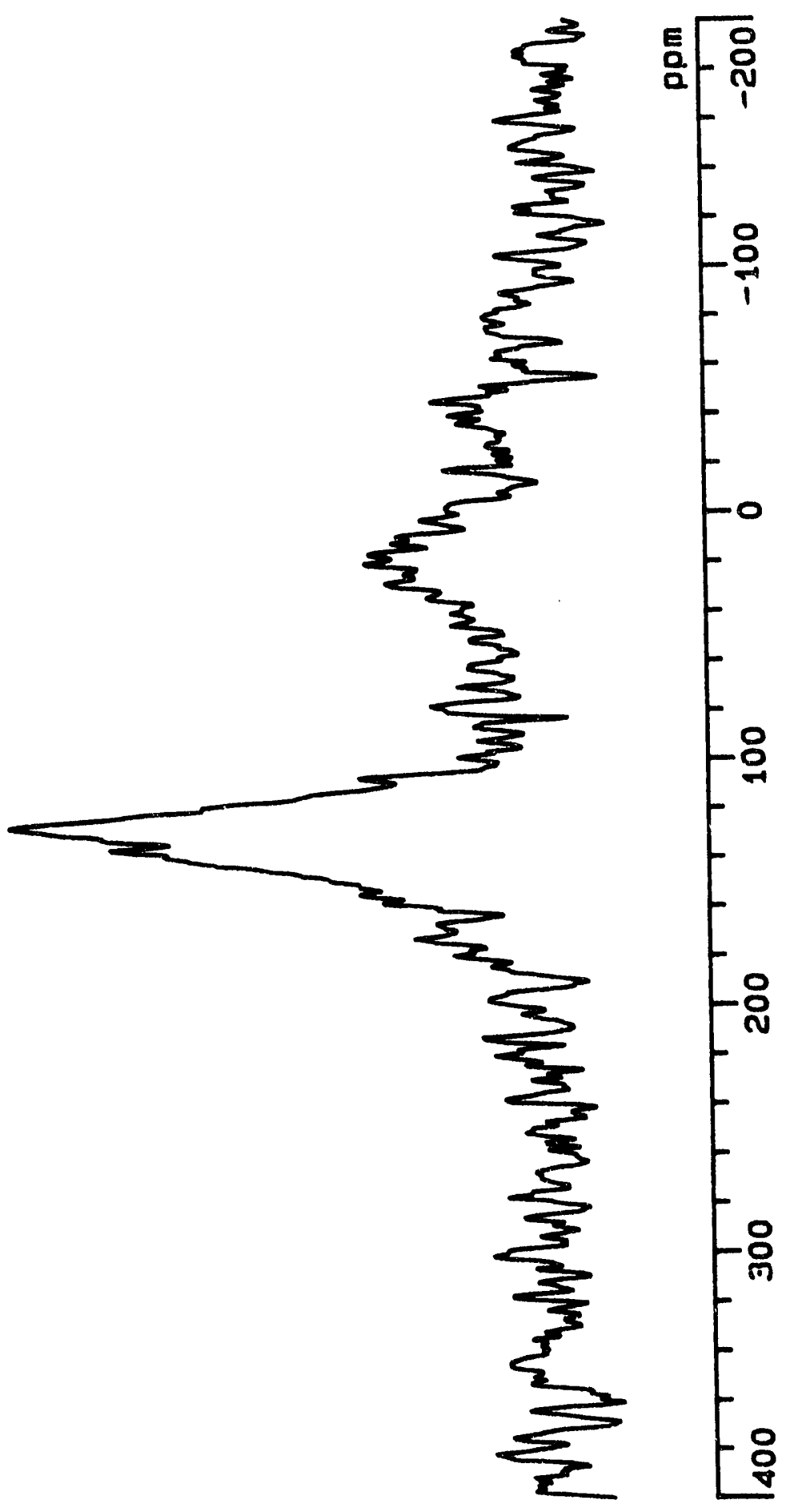

吉 음

今통

面監

일 岳

필

出告象告 

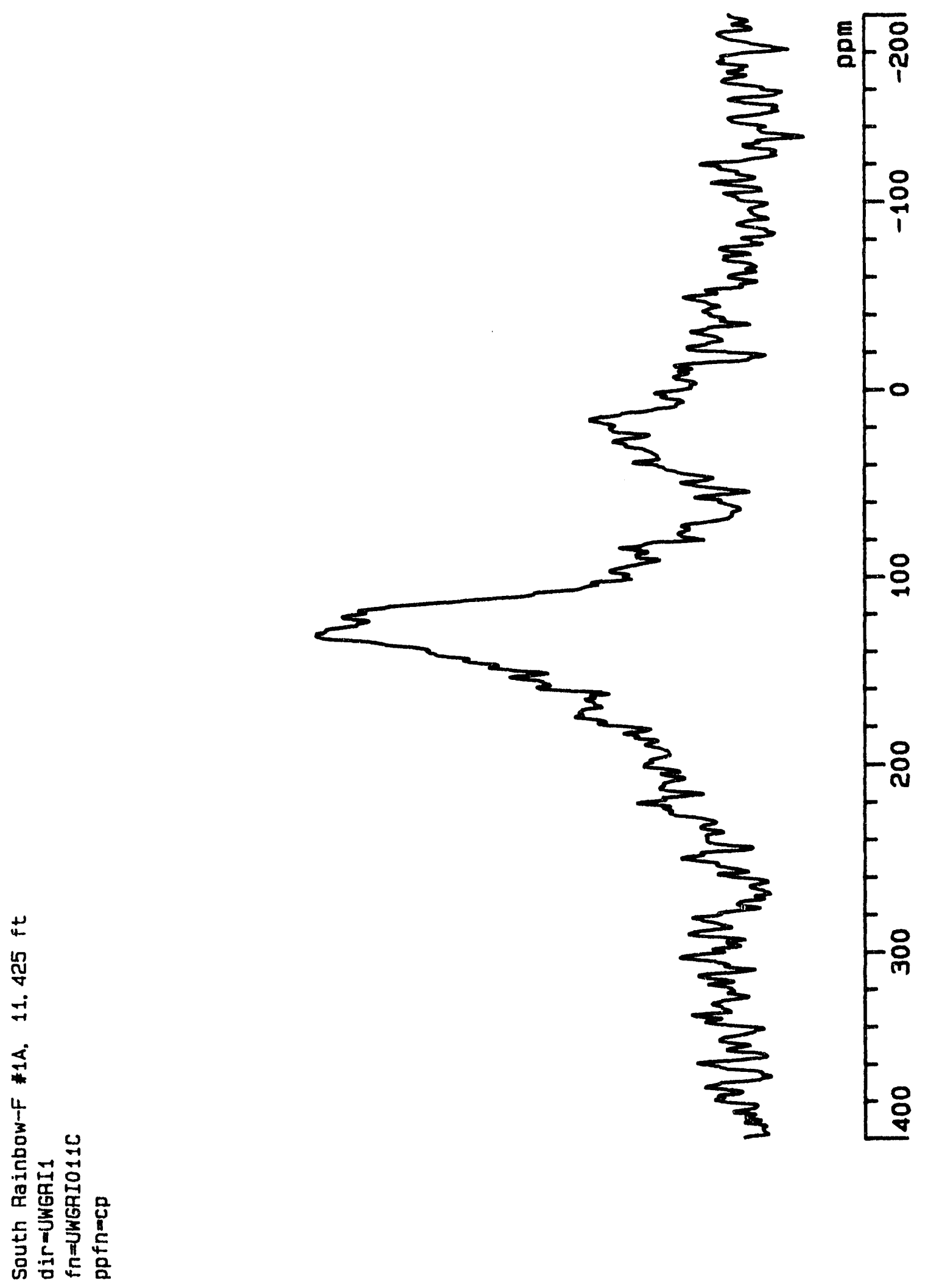


\begin{abstract}
APPENDIX B
Solid-State ${ }^{20}$ Si NMR Spectra of Acid-Washed and Unwashed Mowry Shales
\end{abstract}




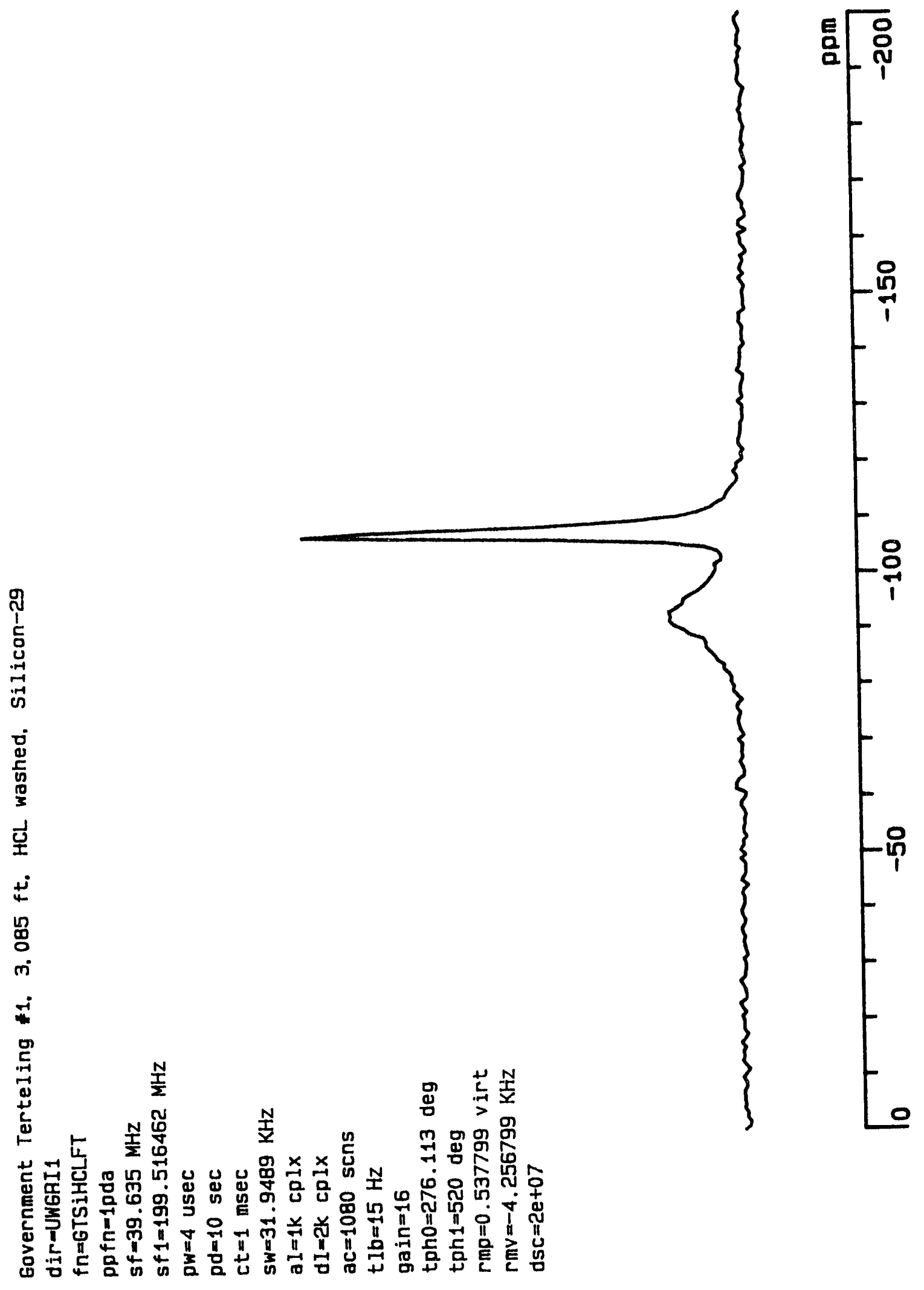




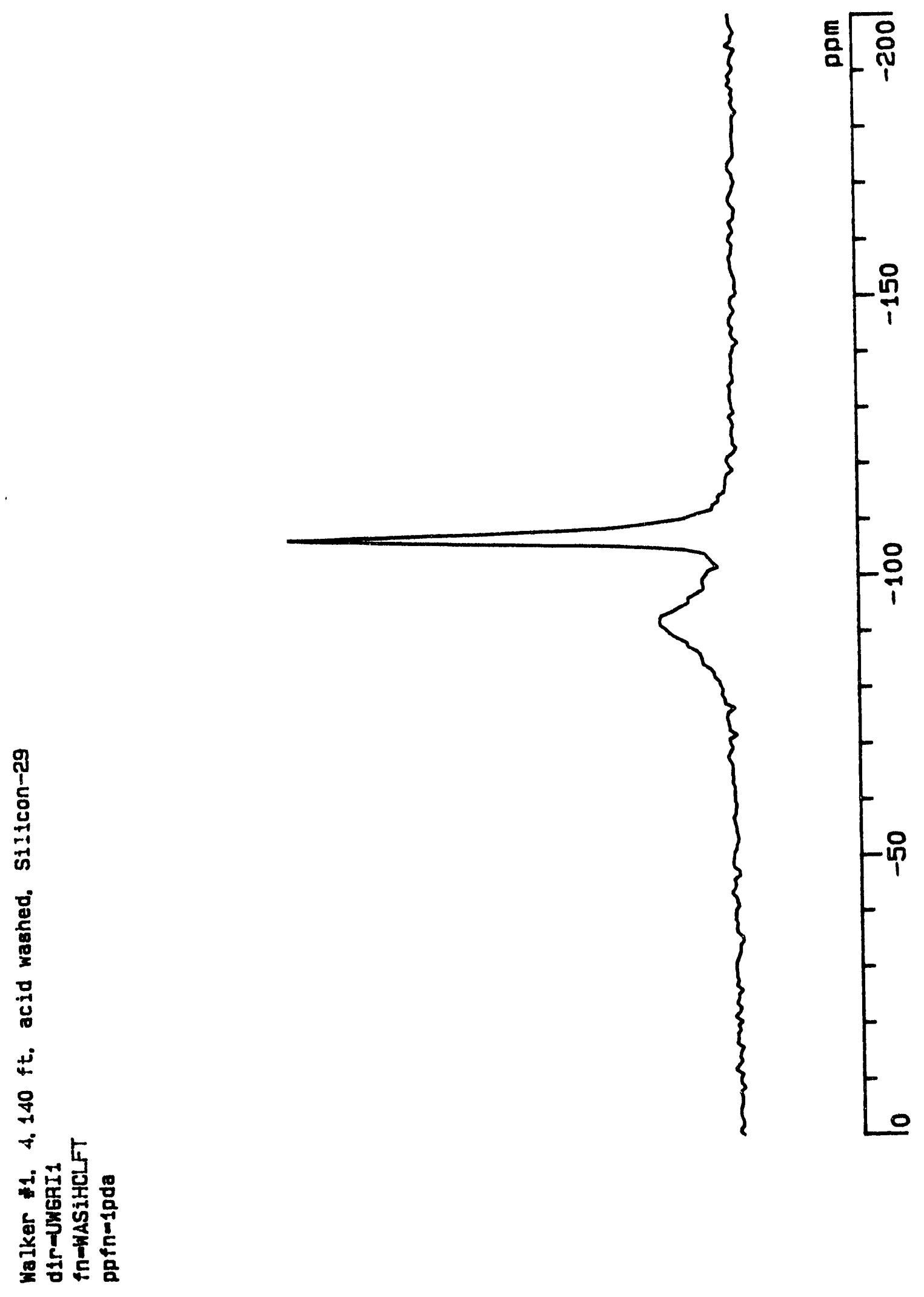




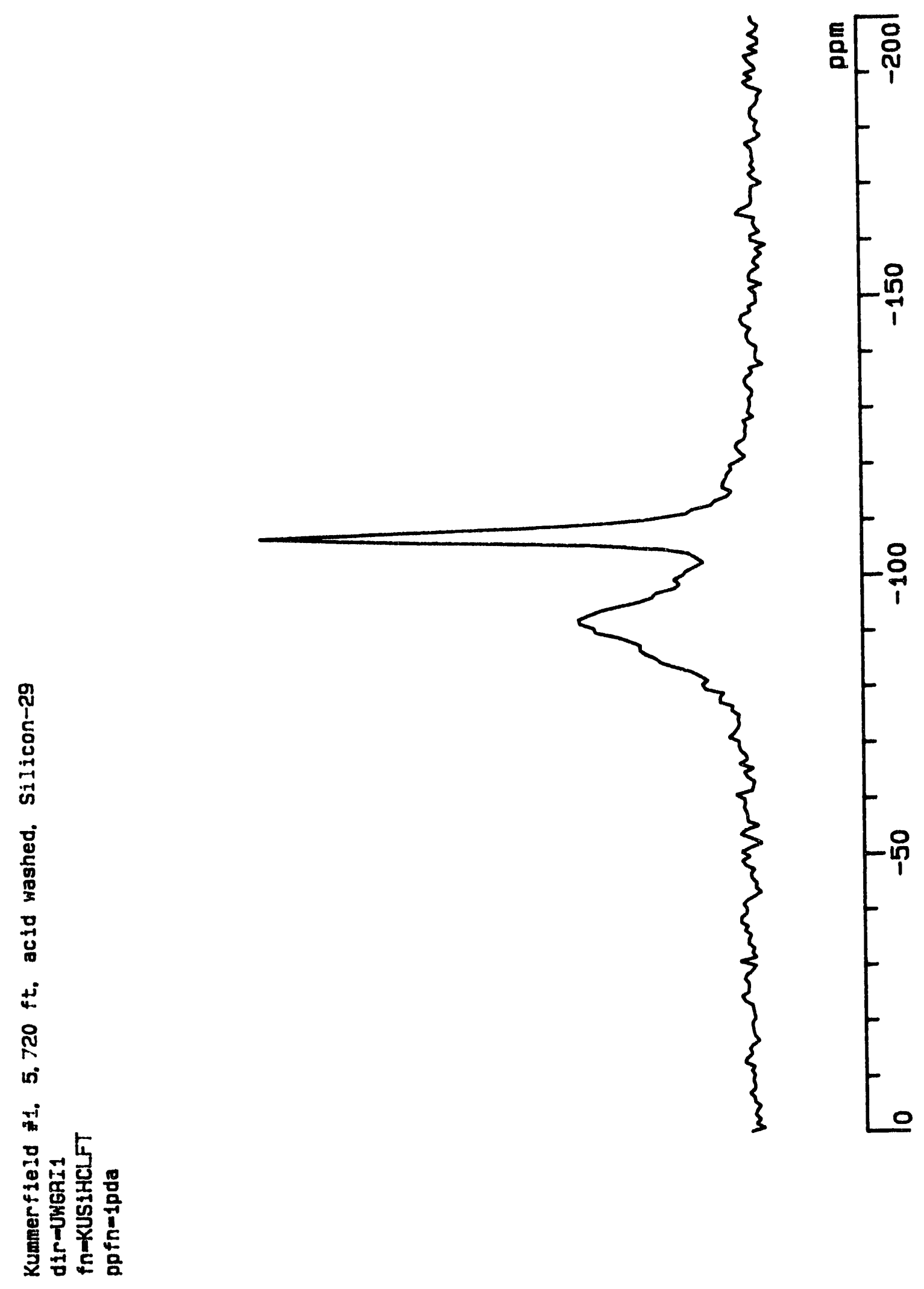



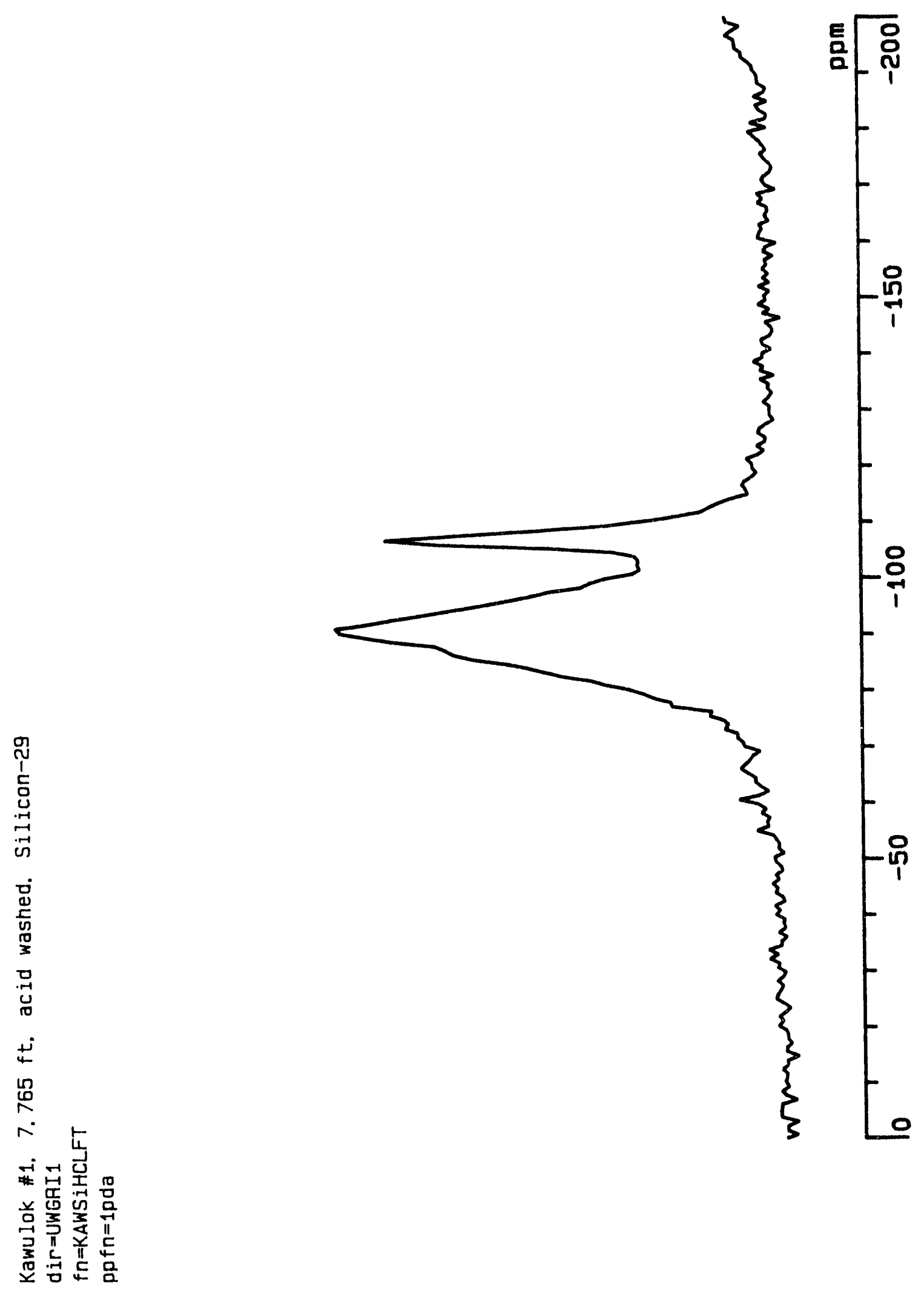

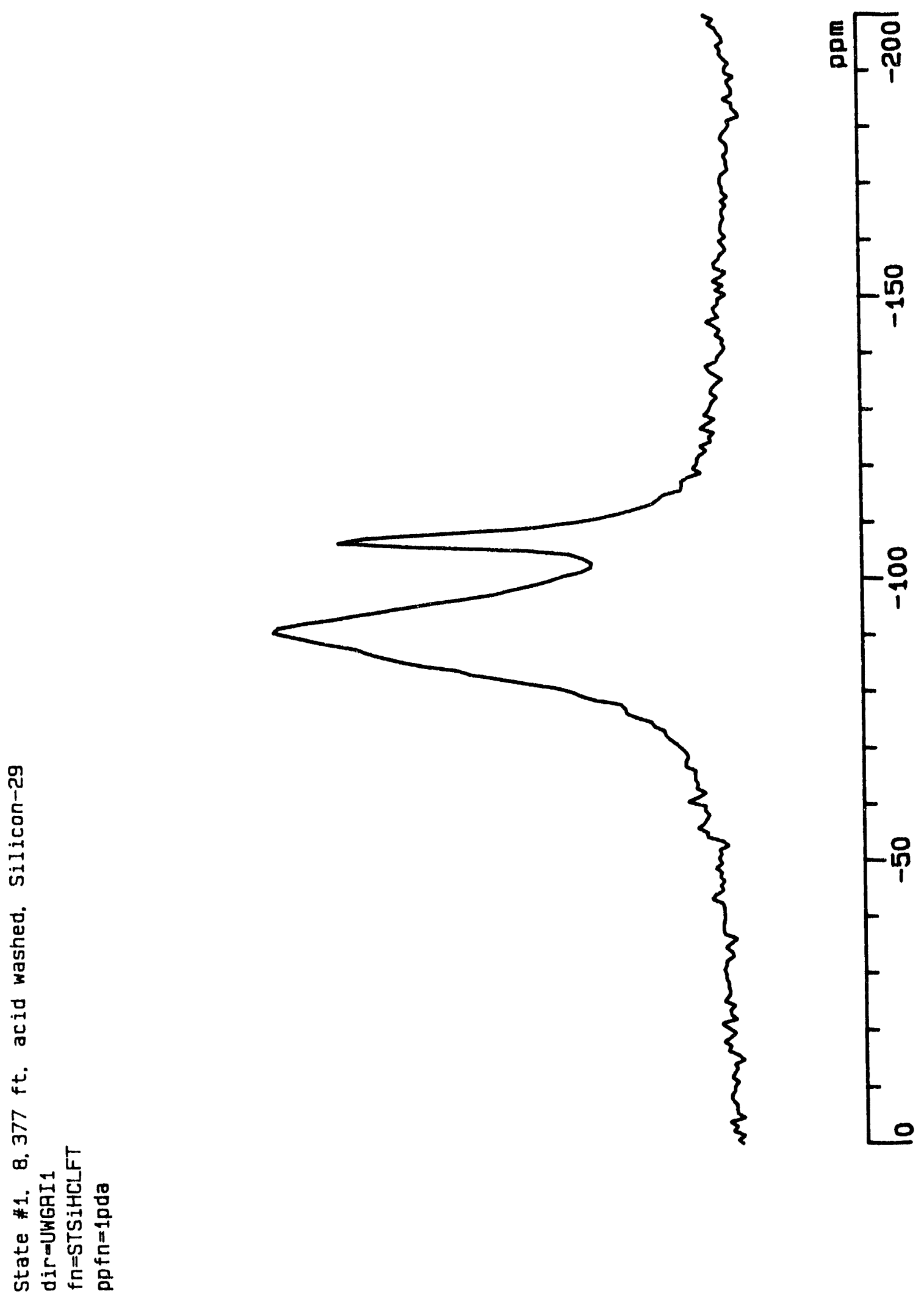


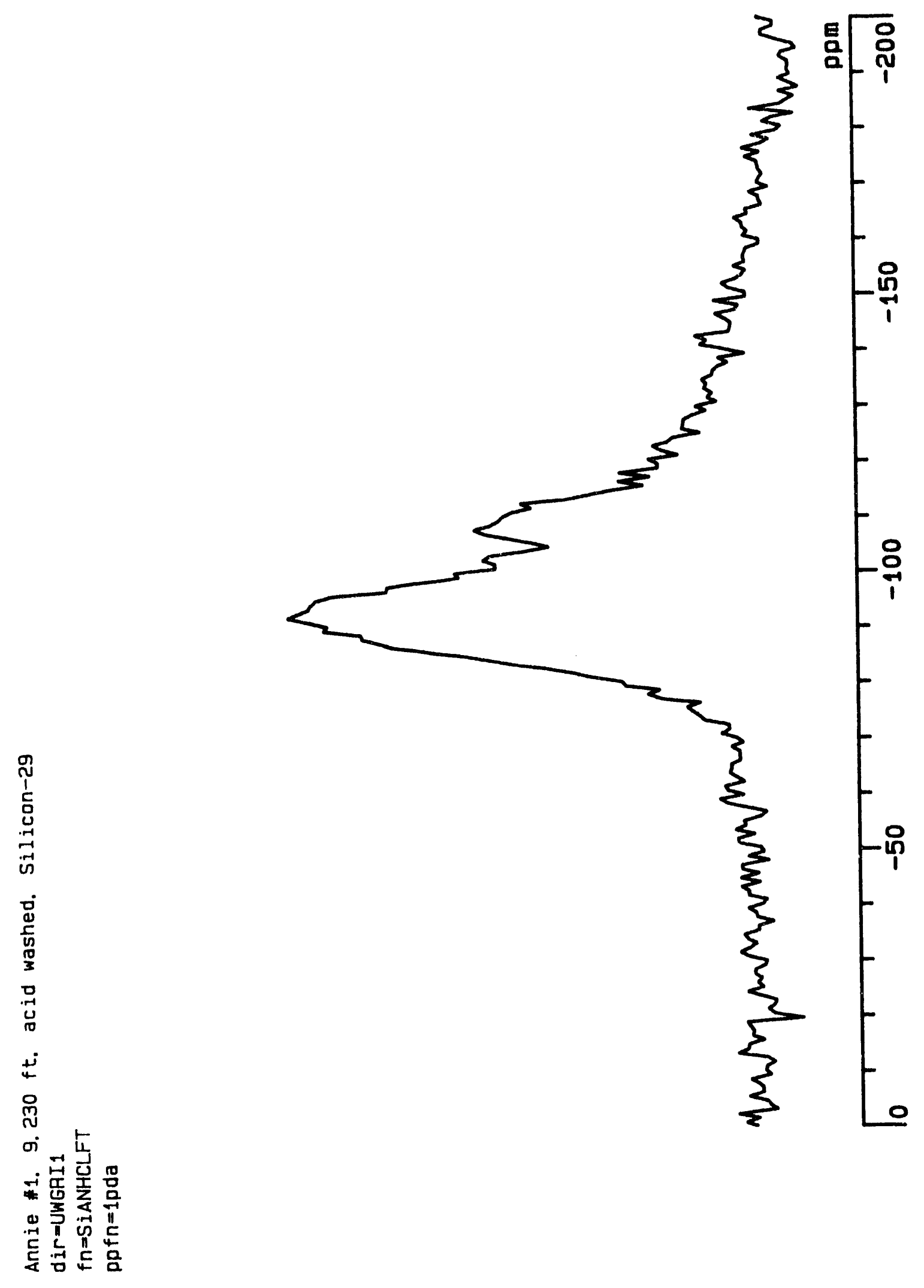



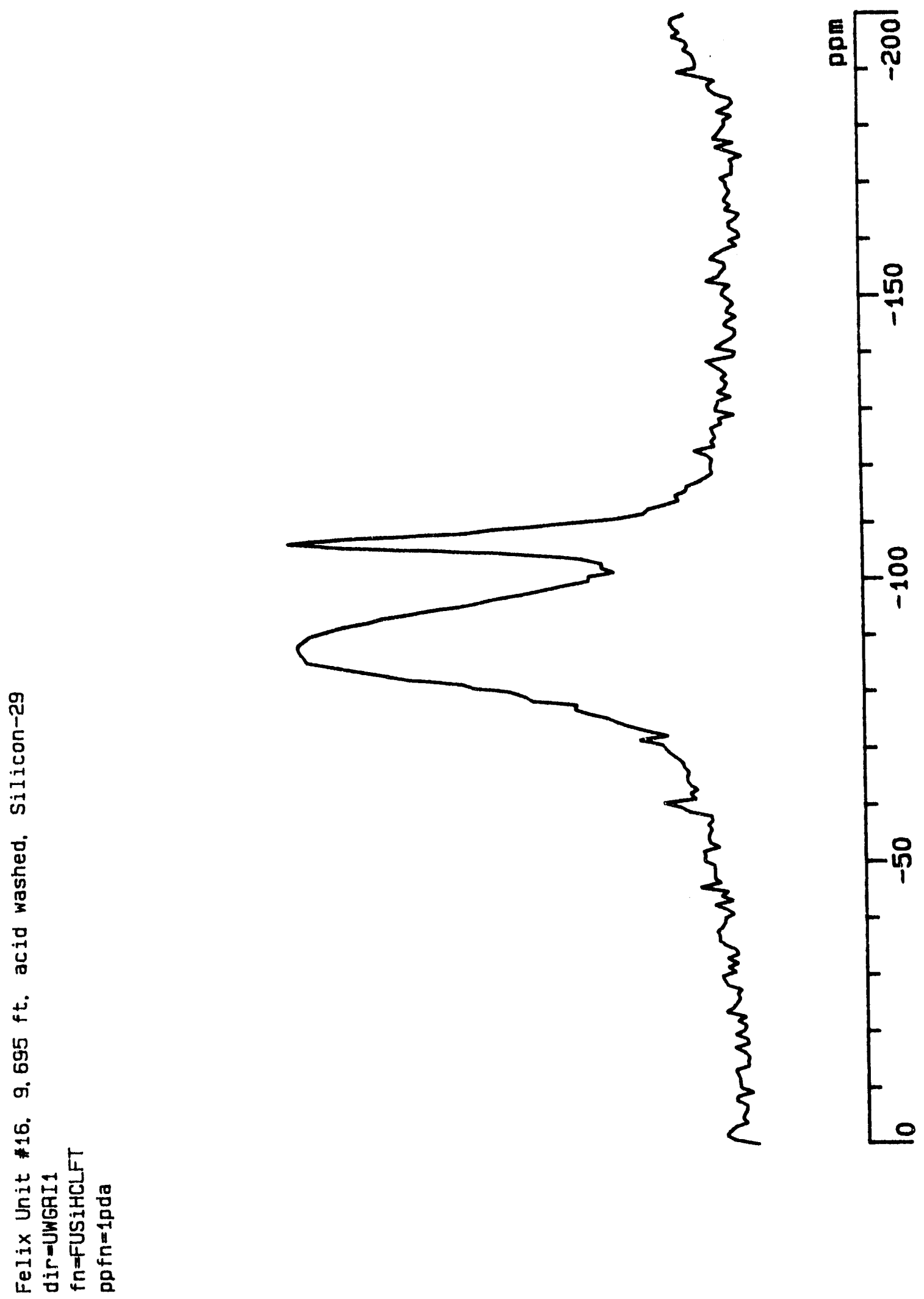


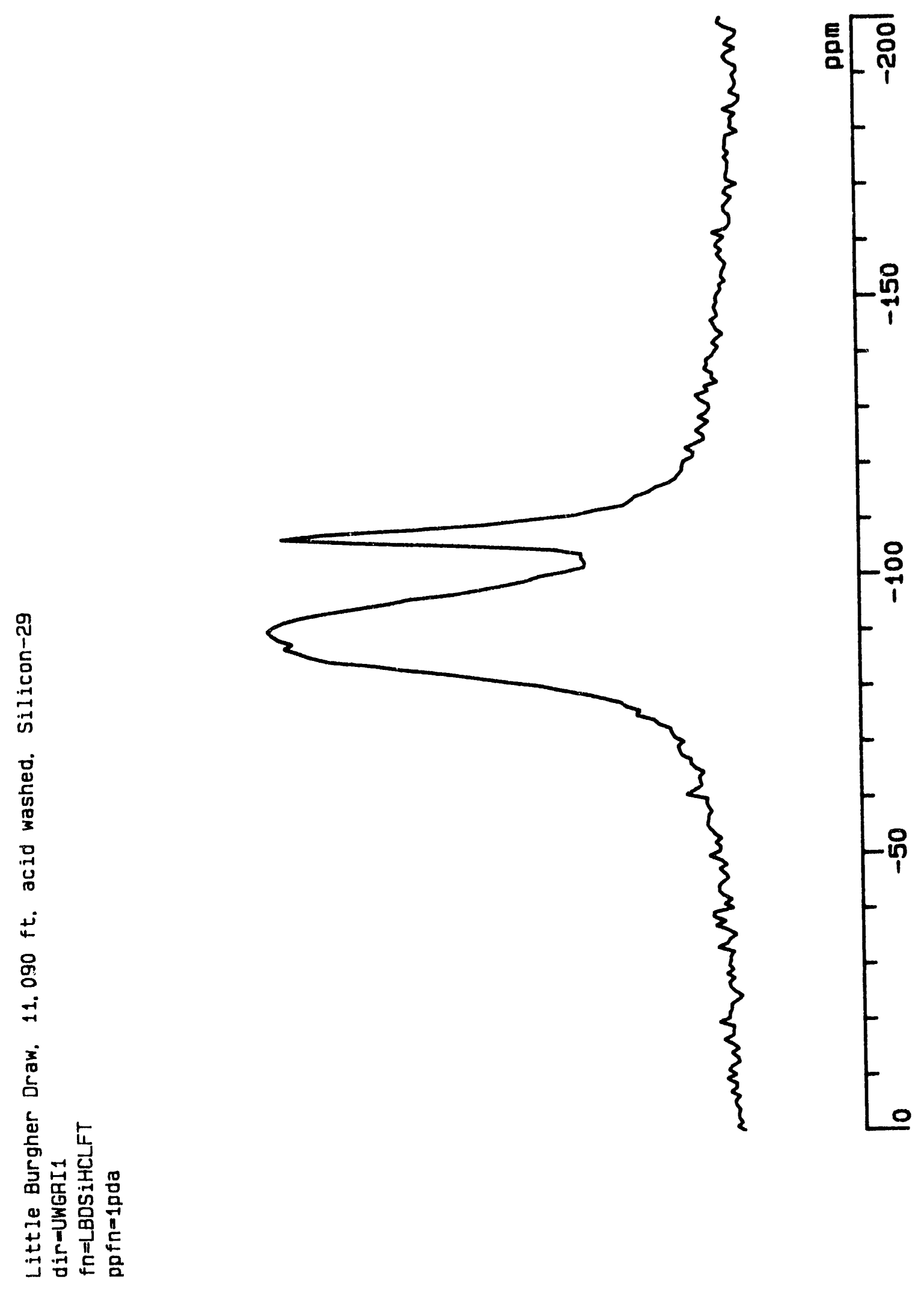



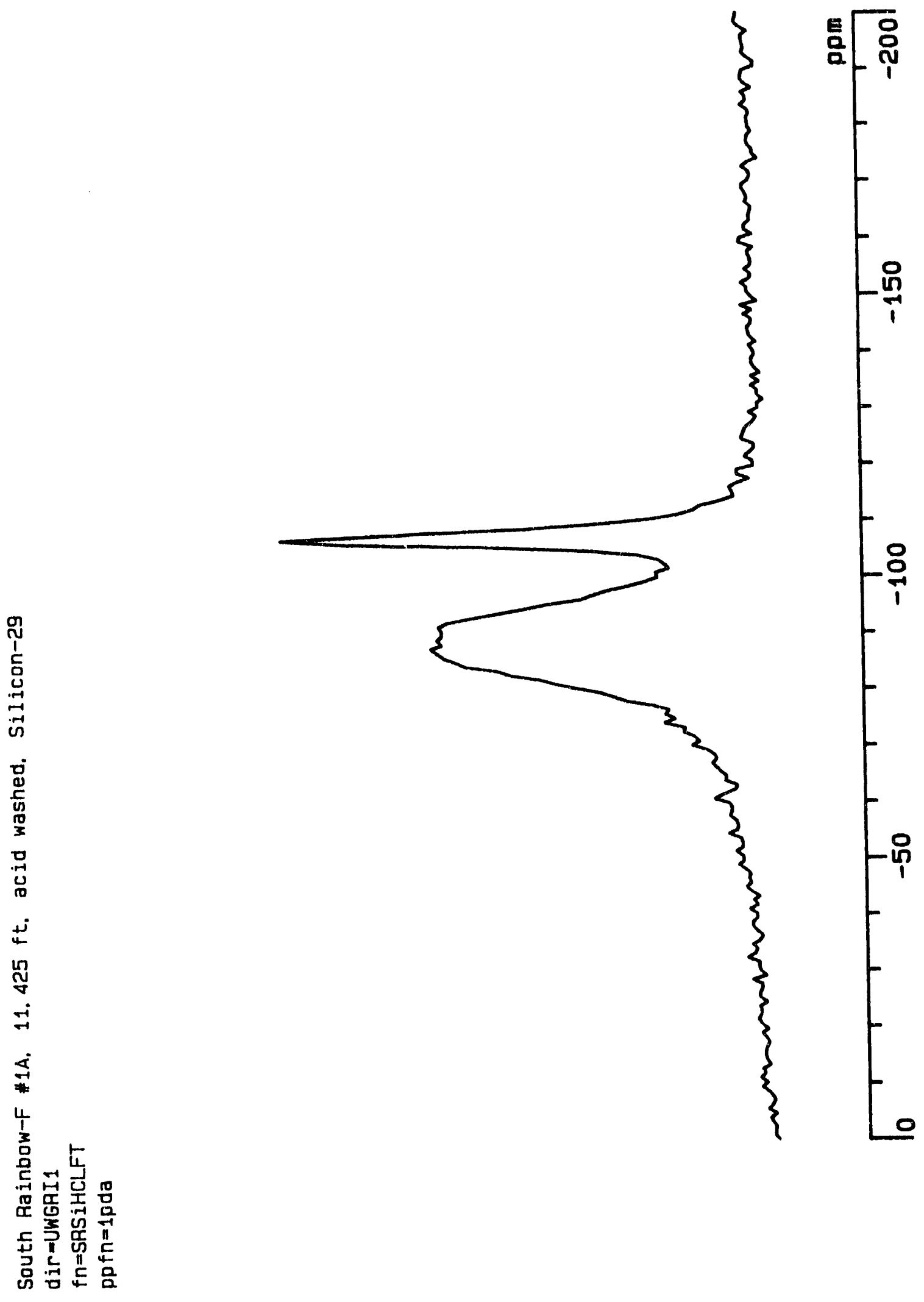


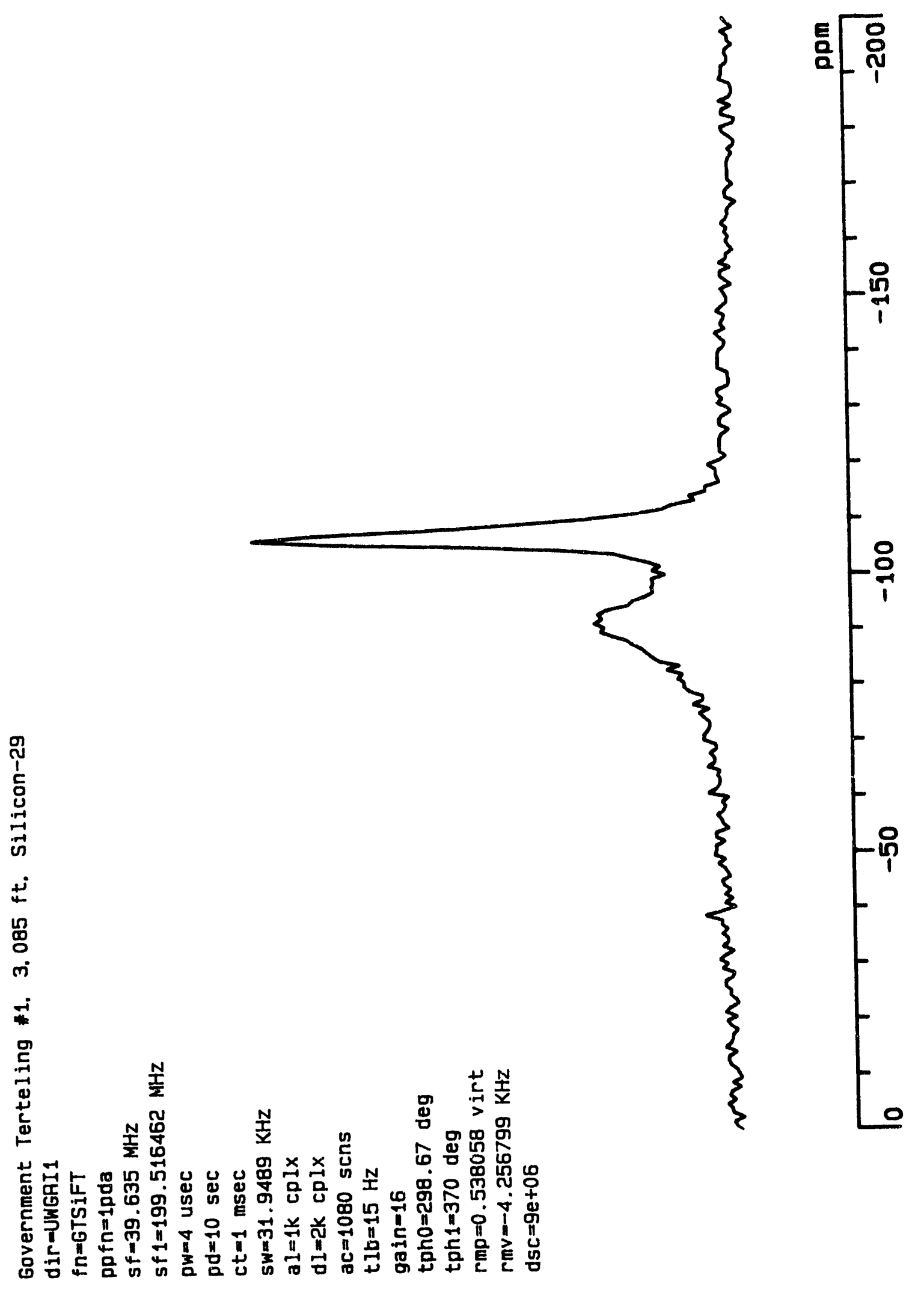




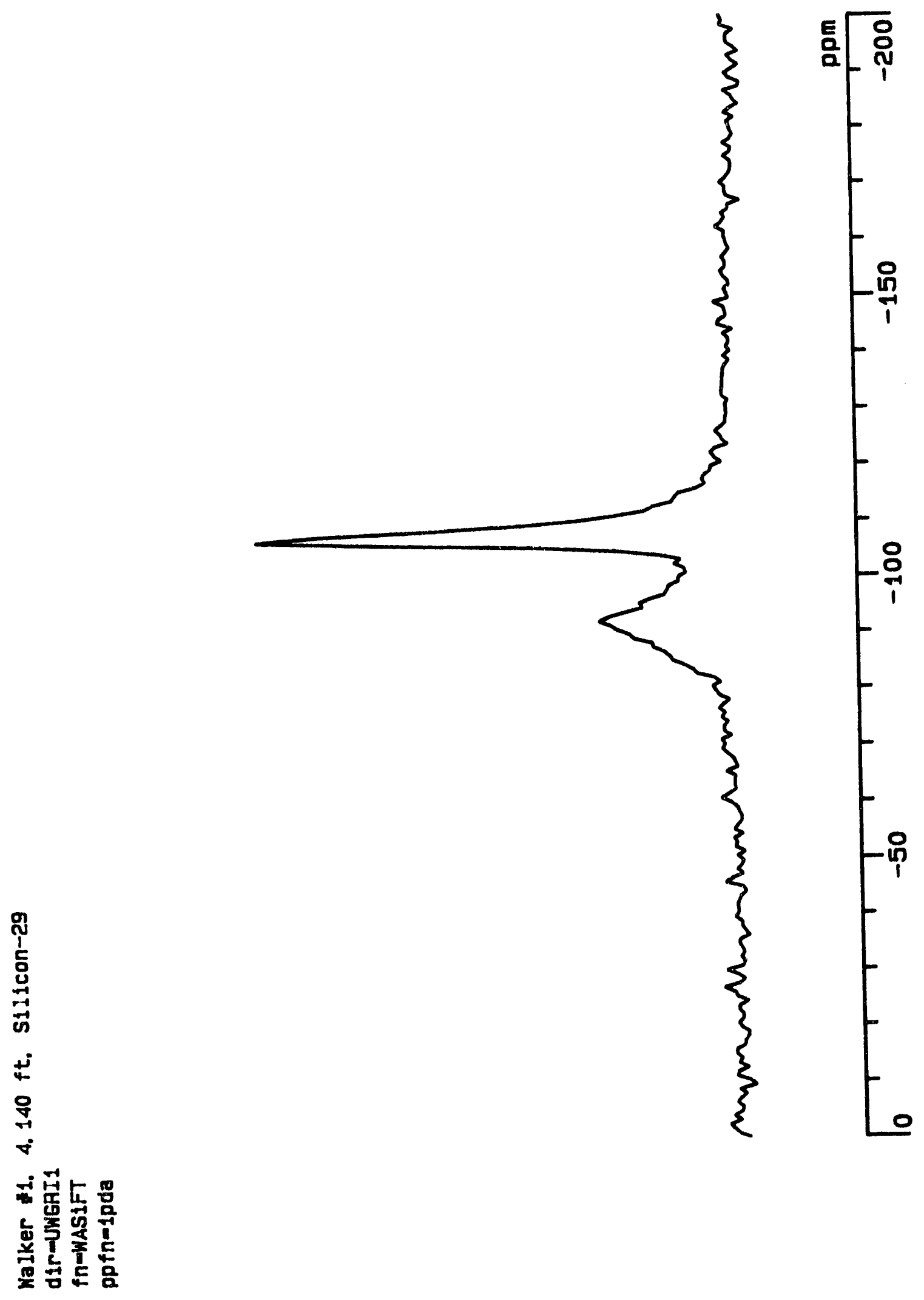



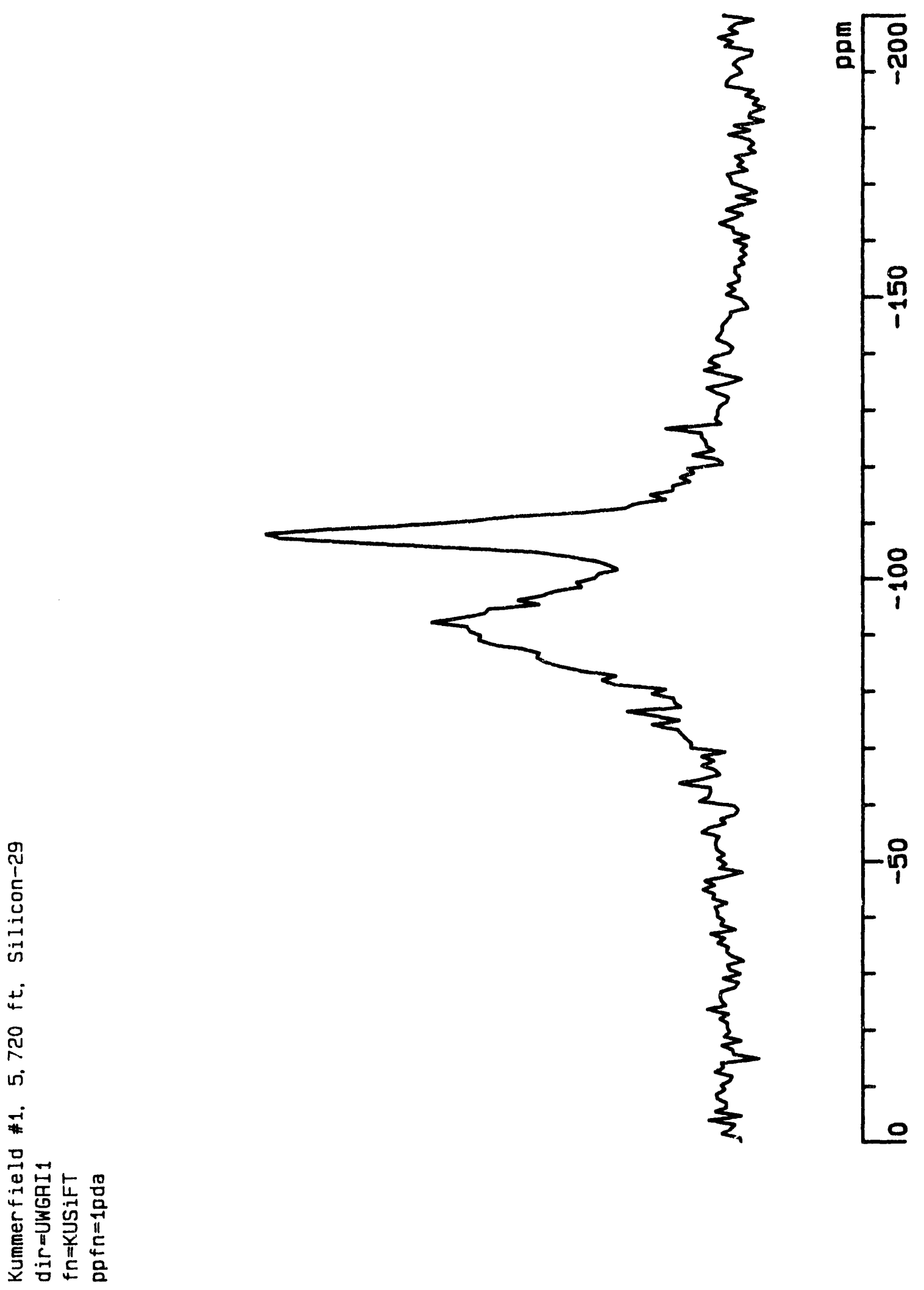

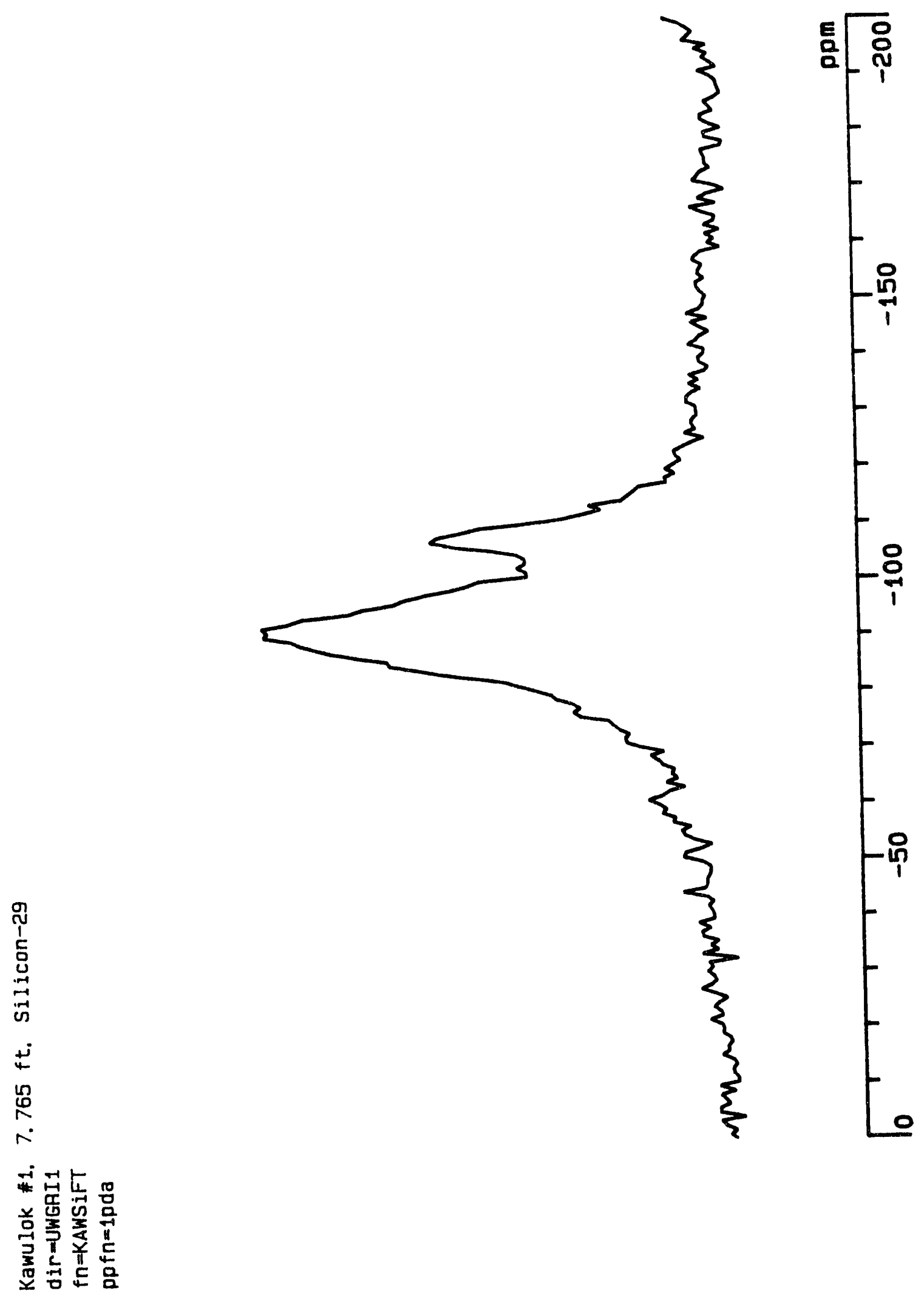

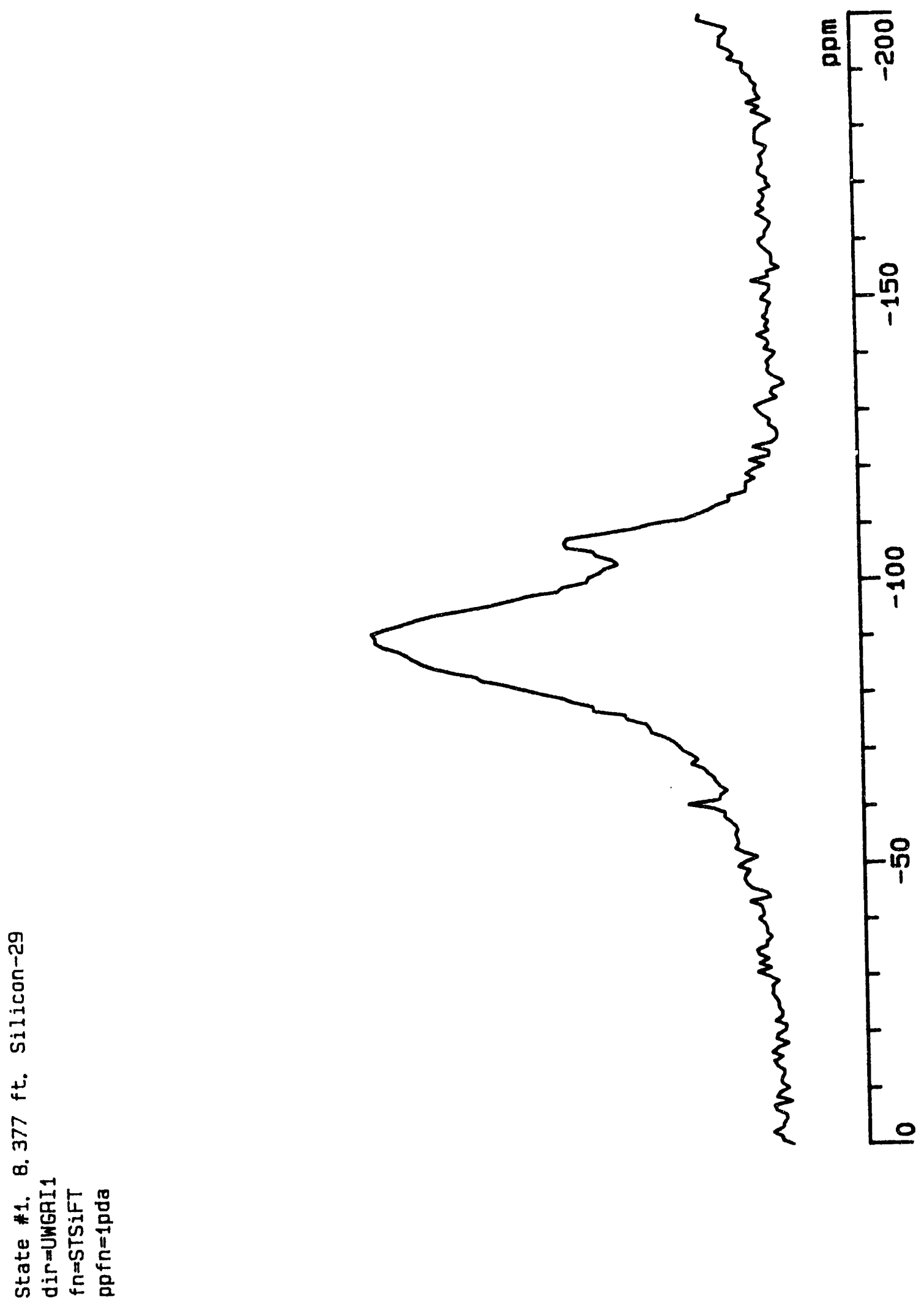

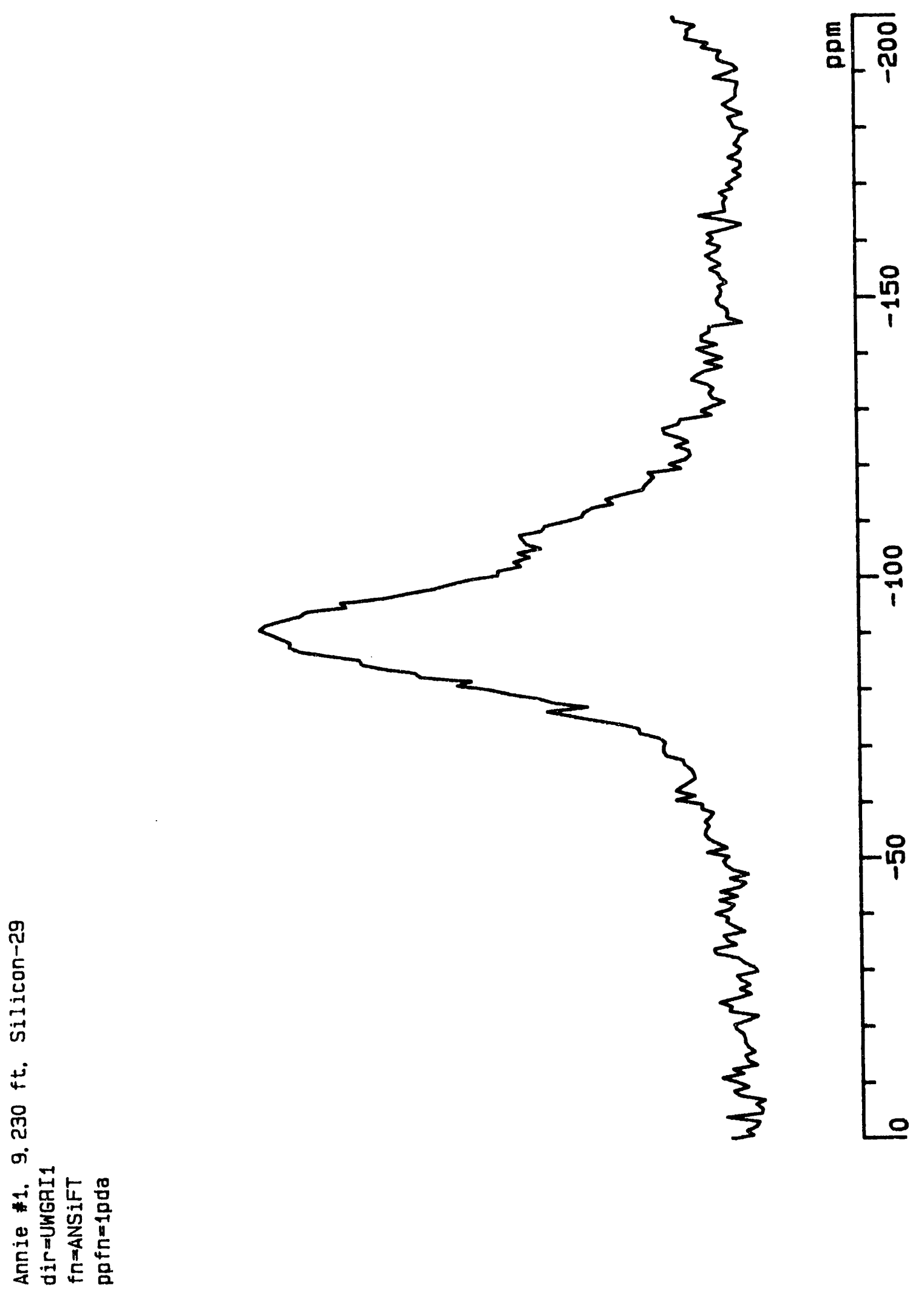

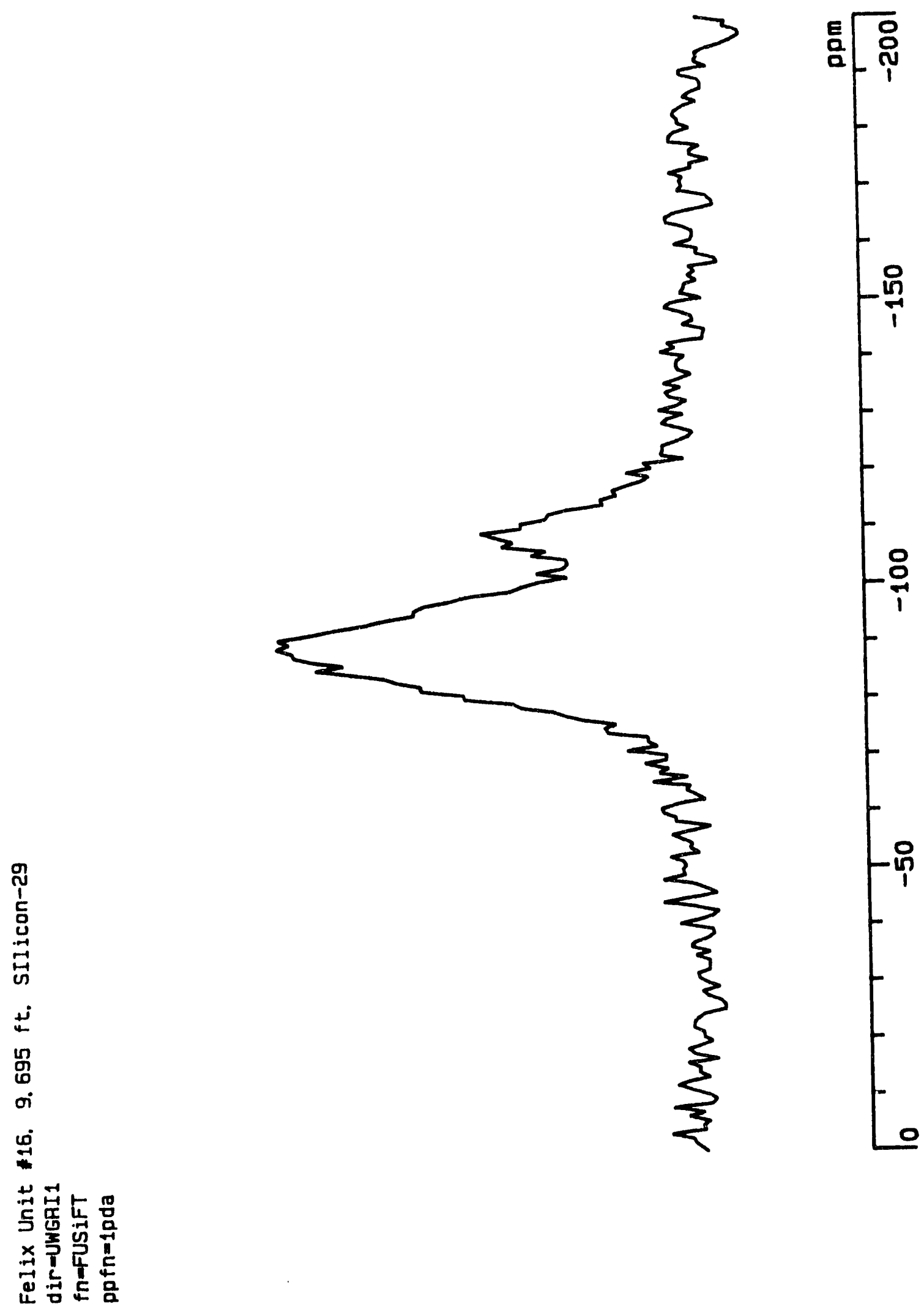


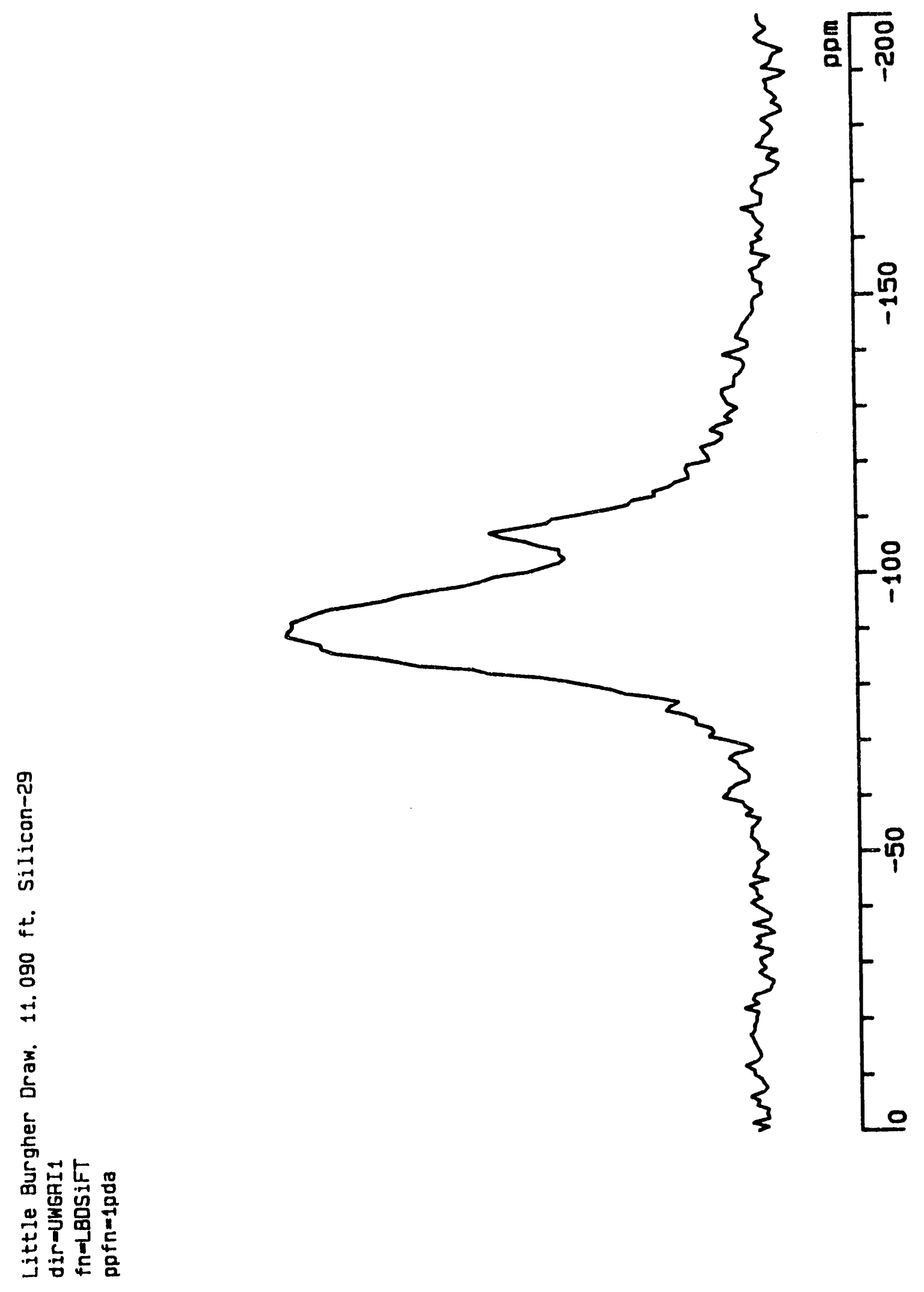




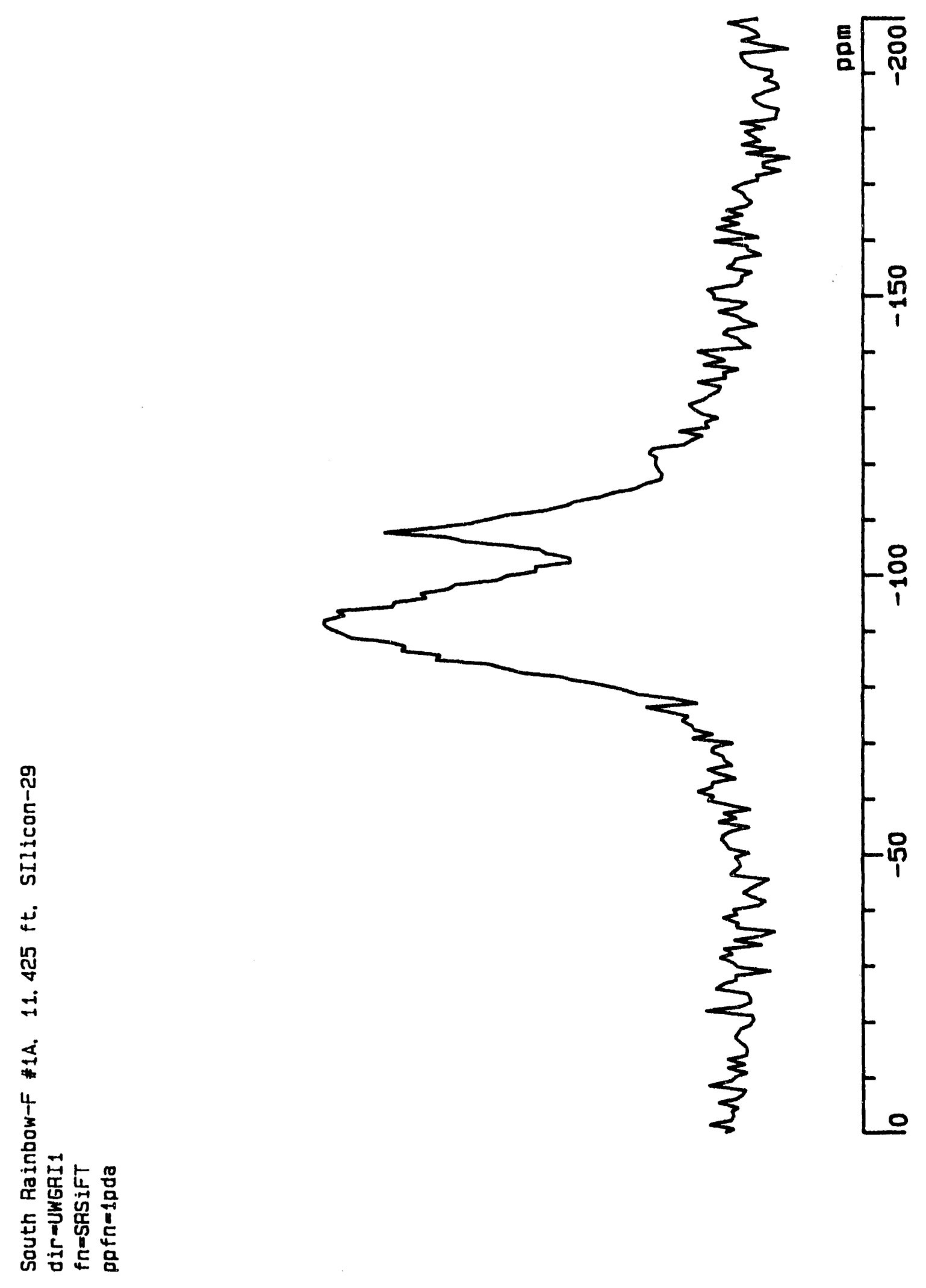



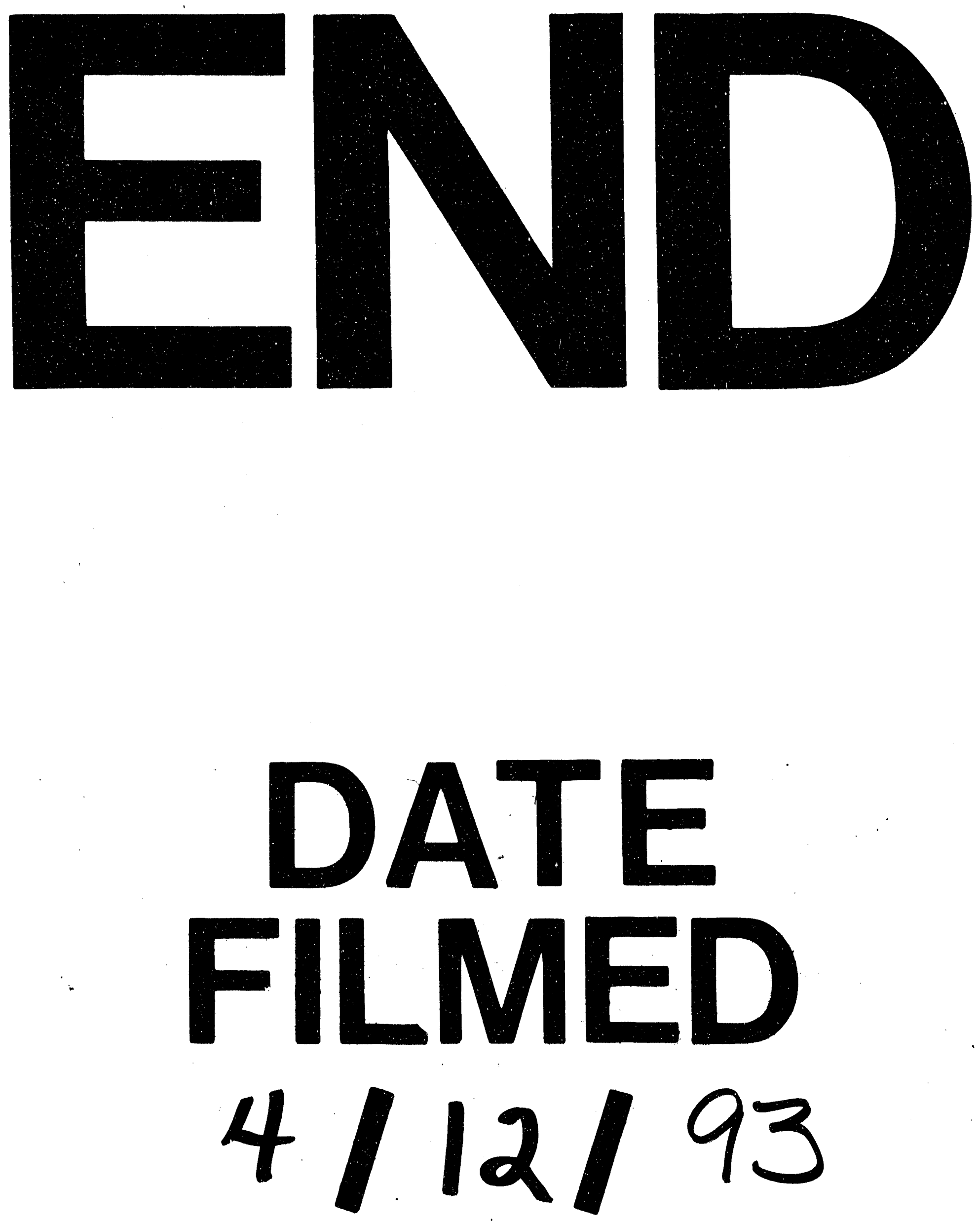
